UNIVERSIDADE DE SÃO PAULO

INSTITUTO DE GEOCIÊNCIAS

\title{
ANÁLISE DO MECANISMO DE ROCK BURST A PARTIR DA TEORIA DA ELASTICIDADE
}

\author{
Bruno Salmoni \\ Orientador: Prof. Dr. Marcos Egydio-Silva \\ DISSERTAÇÃO DE MESTRADO \\ Programa de Pós-Graduação em Geoquímica e Geotectônica
}

SÃO PAULO

2014 

UNIVERSIDADE DE SÃO PAULO

INSTITUTO DE GEOCIÊNCIAS

\title{
ANÁLISE DO MECANISMO DE ROCK BURST A PARTIR DA TEORIA DA ELASTICIDADE
}

\author{
Bruno Salmoni \\ Orientador: Prof. Dr. Marcos Egydio-Silva
}

\section{DISSERTAÇÃO DE MESTRADO}

Programa de Pós-Graduação em Geoquímica e Geotectônica

SÃO PAULO 
Autorizo a reprodução e divulgação total ou parcial deste trabalho, por qualquer meio convencional ou eletrônico, para fins de estudo e pesquisa, desde que citada a fonte.

Ficha catalográfica preparada pelo Serviço de Biblioteca e Documentação do Instituto de Geociências da Universidade de São Paulo

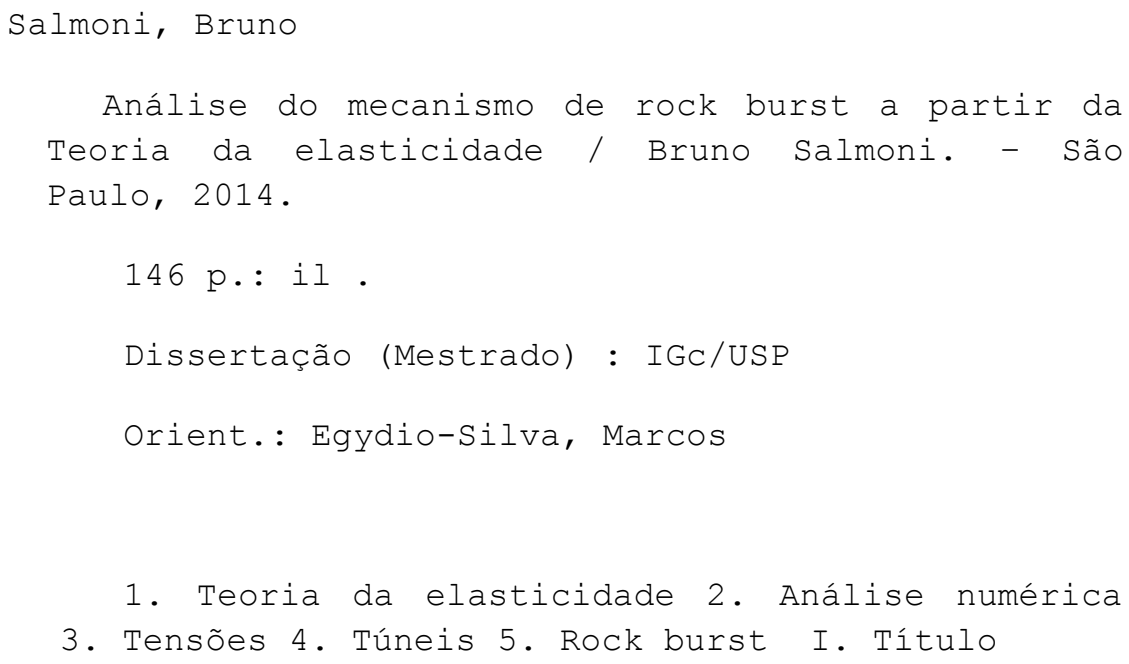


UNIVERSIDADE DE SÃO PAULO

INSTITUTO DE GEOCIÊNCIAS

\title{
ANÁLISE DO MECANISMO DE ROCK BURST A PARTIR DA TEORIA DA ELASTICIDADE
}

\author{
Bruno Salmoni
}

Orientador: Prof. Dr. Marcos Egydio-Silva

DISSERTAÇÃO DE MESTRADO

COMISSÃO JULGADORA

Nome

Assinatura

Presidente:

Examinadores:

SÃO PAULO 



\section{Agradecimentos}

Este trabalho não teria sido desenvolvido sem a imensa ajuda, direta ou indireta, de várias pessoas. Por isso, presto meus agradecimentos:

Aos meus pais Amélia e Guido, e meu irmão Fabio, pela compreensão e suporte nestes últimos dois anos.

À minha namorada e companheira fiel Fernanda Matsumoto pelo apoio e carinho em todos os momentos.

Aos colegas e amigos Camila Viana, Talita Ferreira, Ricardo Pereira, Pedro Henrique Imenez Silva, Lúcio Barcelos, que passaram praticamente dois anos ouvindo lamentos, reclamações e pedidos incessantes de ajuda e ideias.

Ao meu orientador Prof. Dr. Marcos Egydio-Silva pelo apoio e incentivo.

Aos professores Dr. Ginaldo Campanha, Dr. José J. Nader e Dr. Georg Sadowski, com os quais tive discussões bastante frutíferas e que renderam muitas boas e novas ideias, que foram implementadas ao longo do texto.

Um agradecimento especial ao meu ex-chefe e amigo Eng. Werner Bilfinger por ter me dado enorme apoio na decisão de iniciar o mestrado. 


\section{RESUMO}

O mecanismo de rock burst envolve ruptura violenta e instantânea do maciço rochoso ao redor de uma escavação subterrânea, com liberação de grandes quantidades de energia. Neste trabalho, será apresentado uma abordagem baseada na teoria da elasticidade, a partir da qual a importância dos parâmetros elásticos serão avaliados no processo de acúmulo de energia elástica $(W)$.

Foram utilizados métodos analíticos e numéricos e equações que definem $\mathrm{W}$ a partir da matriz de tensões $\boldsymbol{\sigma}$, da matriz de deformação $\boldsymbol{\varepsilon}$, e dos parâmetros elásticos $E$ (módulo de Young, ou módulo de elasticidade) e $v$ (coeficiente de

Poisson). A influência dos parâmetros $E$ e $v$ na quantificação de $\mathrm{W}$ foi testada usando uma gama de valores, baseada em valores médios para as rochas cristalinas apresentados na literatura.

Variações nos valores de $\mathrm{E}$ induzem mudanças consideráveis nos valores de W. Quanto menor $E$, maior W. Baixos valores de $E$ definem maciços rochosos que sofrem maiores deformações sob um determinado regime de tensões, assim resultado em maior trabalho exercido pelo maciço e, consequentemente, mais energia elástica (W). Isto é, para um determinado estado de tensões, maciços mais deformáveis (com baixos valores de $E$ ) têm a capacidade de acumular mais energia elástica que maciços pouco deformáveis. No entanto, considerando também a mecânica de ruptura, maciços menos resistentes rompem sob condições menos extremas de tensões, enquanto maciços mais resistentes necessitam de tensões muito elevadas para sofrerem ruptura. 
Portanto, maciços mais resistentes acumulam mais energia elástica que maciços menos resistentes.

Embora o coeficiente $v$ seja apontado por alguns autores como maior responsável pelo acúmulo de $\mathrm{W}$, este fato não foi observado neste trabalho, e o valor de W não é consideravelmente afetado por variações de $v$, um resultado direto das equações utilizadas. No entanto, uma tendência "anômala" foi observada: fixado o valor de $\mathrm{E}$, valores de $v$ medianos (próximo a 0,25 ) induzem maiores valores de $\mathrm{W}$ no limite da escavação, e conforme se afasta do limite para o sentido do interior do maciço, valores cada vez menores de $v$ passam a induzir os maiores valores de $\mathrm{W}$.

A teoria da elasticidade, por si só, não é capaz de explicar os fenômenos complexos que causam os processos de rock burst. Para uma compreensão completa do problema, é necessário também o estudo de mecânica de fraturas, mecânica de danos no maciço, dissipação de energia ao longo de fraturas, etc.

palavras-chave: teoria da elasticidade, análise numérica, tensões, túneis, rock burst 


\begin{abstract}
The mechanism or rock burst involves sudden and violent fracturing of the rock mass around the opening, with high amounts of energy released. This work demonstrates an approach based on the theory of elasticty and the role of elastic parameters in the process of storing elastic strain energy (W).

Analytical and numerical methods were used. The main equations define $\mathrm{W}$ based on the stress matrix $\boldsymbol{\sigma}$, the strain matrix $\boldsymbol{\varepsilon}$ and the elastic parameters $E$ (Young's modulus) and $v$ (Poisson's ratio). The influence of $\mathrm{E}$ and $v$ was tested using minimum, average and maximum values, based on the values for crystalline hard rocks from the literature.
\end{abstract}

Variations in values of $E$ induce significant changes to the values of $\mathrm{W}$. The lower $E$, the higher W. Low values of $E$ define rock masses which suffer greater displacements under a given stress condition, leading to higher values of W. This leads to the conclusion that, for a given stress state, soft rocks (lower values of $E$ ) have the ability to store more elastic strain energy than stiff rocks. However, if fracture mechanics is also considered, strong rock masses have the ability to endure more stress than weaker rocks before failing, leading to higher amounts of elastic energy stored.

Although Poisson's ratio $(v)$ is considered by some authors as a fundamental piece in energy storage, such conclusion was not observed in this work, and values of $\mathrm{W}$ are not considerably affected by variations of $v$, a direct result of the application of the equations of theory of elasticity. However, an interesting trend was observed: for a given value of $E$, moderate values of $v$ (around 0,25 ) 
induce higher values of $\mathrm{W}$ at the edge of the excavation. In the rock mass interior, lower values of $v$ induce higher values of $\mathrm{W}$.

An analysis purely based on the theory of elasticity is not enough to explain the complex phenomena which occur around an excavation that induce violent failure and rock bursting. For a deeper understanding of the problem, it is also necessary the study of complementary theories, such as fracture mechanics, damage mechanics, energy dissipation during fracturing, and so on.

keywords: theory of elasticity, numerical analysis, stress, tunnels, rock burst 


\section{SUMÁRIO}

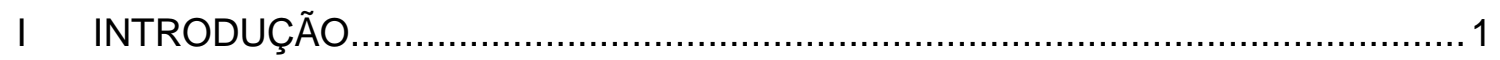

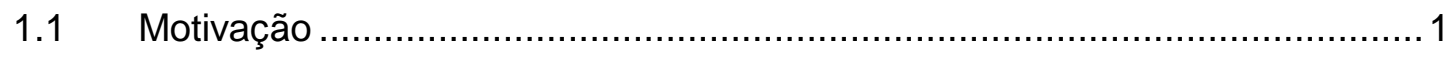

1.2 Rock Burst..................................................................................... 2

II OBJETIVOS DESTE TRABALHO

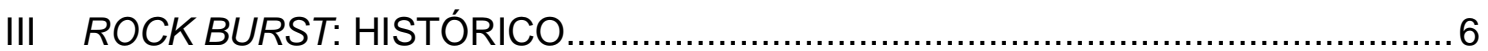

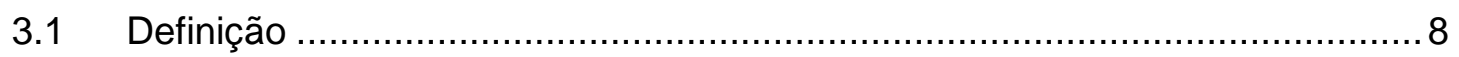

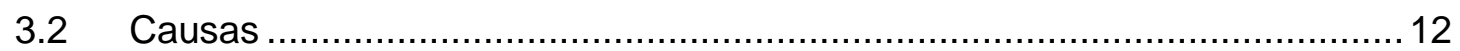

3.2.1 Acúmulo de Tensões ................................................................ 13

3.2.2 Microfraturas............................................................................ 18

3.2.3 Energia elástica de deformação......................................................... 26

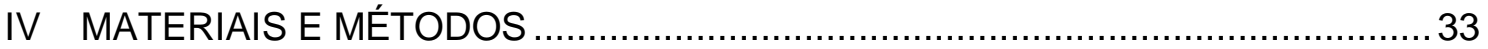

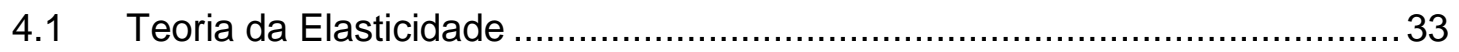

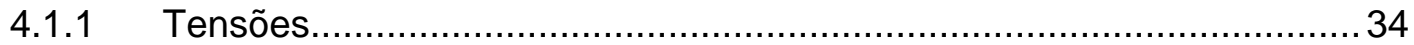

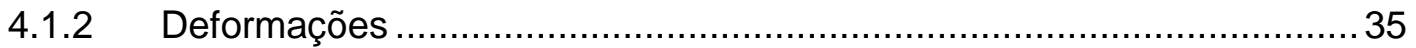

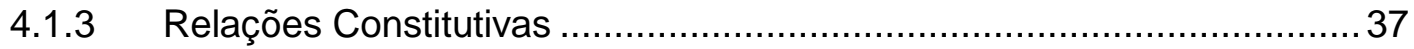

4.1.4 Simplificação para um caso bidimensional ...........................................40

4.1.5 Energia elástica de deformação...................................................... 41

4.2 Tensões ao Redor de Escavações Subterrâneas ........................................ 42

4.2.1. Redistribuição de tensões e deformações: método analítico .................45

4.2.2 Redistribuição das tensões: método numérico ...................................50

4.3 Método dos Elementos Finitos .................................................................... 52

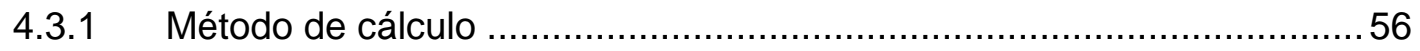

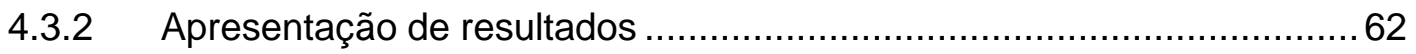

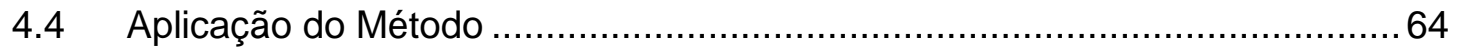

4.4 Determinação de Tensões ao redor de uma Abertura Subterrânea ...............65

4.4.1 Comparação entre os resultados dos métodos ....................................6 67

4.4.2 Determinação de deformações a partir dos valores de tensão ...............69

4.4.3 Determinação da energia elástica....................................................... 71

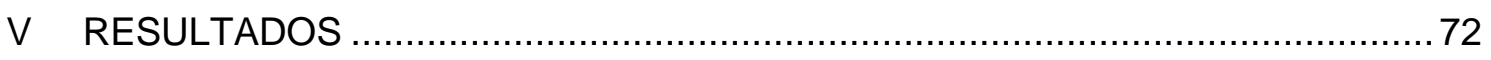

5.1 Energia Elástica Como Função dos Parâmetros Elásticos............................ 72

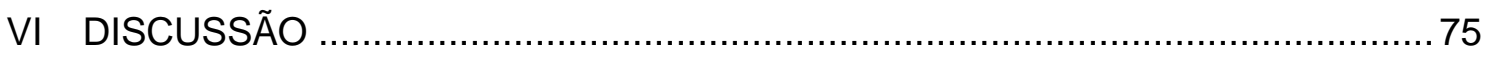

6.1 Energia em Função dos Parâmetros Elásticos .............................................75

6.2 Consequências da Concentração de Tensões............................................. 82 
6.2.1. Em termos de instabilidades nos entornos das escavações .................. 82

6.2.2 Em termos de energia ............................................................. 83

6.3 Maciço Rochoso: Resistência e Redução de Parâmetros.............................. 84

6.3.1 Resistência de rocha intacta e de maciço rochoso ............................... 84

6.3.2 Parâmetros elásticos de maciços rochosos ......................................... 85

6.3.3 Teoria de fraturas e danos no maciço.............................................. 87

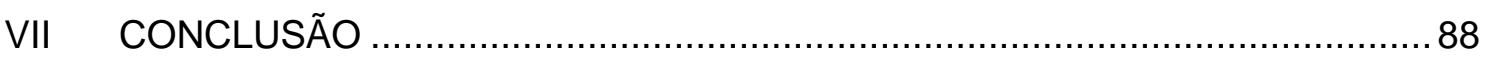

APÊNDICE I TEORIA DA ELASTICIDADE ....................................................... 91

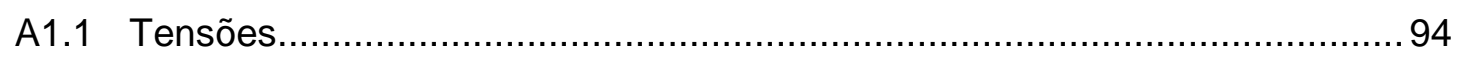

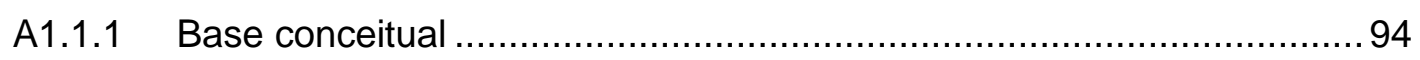

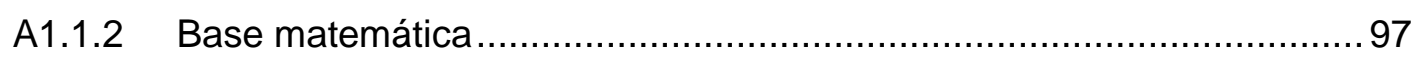

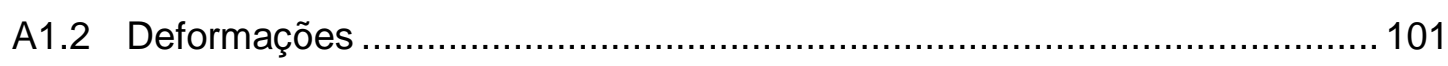

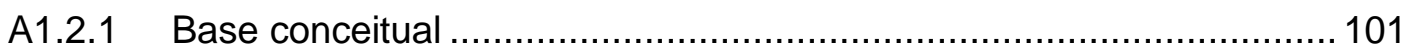

A1.2.2 Base matemática ................................................................ 103

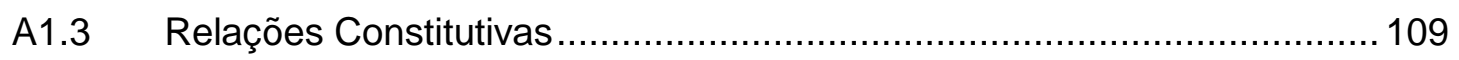

APÊNDICE IIRESISTÊNCIA DAS ROCHAS E CRITÉRIOS DE RUPTURA ..............113

A2.1 Critério de Mohr-Coulomb.................................................................... 114

A2.2 Critério de Griffith........................................................................... 115

A2.3 Critério de Hoek-Brown ...................................................................... 116

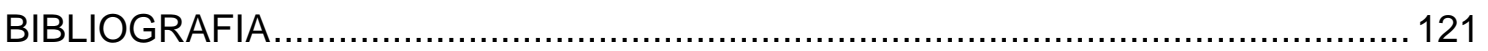




\section{ÍNDICE DE FIGURAS}

Figura 1 - Esquema demonstrativo de strainburst: desplacamentos violentos resultantes de concetrações superficiais de tensões (Ortlepp \& Stacey, 1994)........... 12

Figura 2 - Quadro esquemático relacionando rock burst com tensão tangencial $\sigma_{\tan } \mathrm{e}$ resistência à compressão puntiforme (Russeness, 1974) ….................................... 14

Figura 3 - Indicação esquemática das tensões principais no interior do maciço, nas proximidades de uma encosta natural com declividade acentuada (Broch \& Sørheim, 1984)

Figura 4 - Diagrama esquemático de Mohr-Coulomb, apresentando a envoltória de ruptura e círculos de tensões principais

Figura 5 - Diagrama esquemático da distribuição das tensões tangenciais para o túnel estudado por Broch \& Sørheim (1984).

Figura 6 - Curvas de tensão x deformação com indicação de eventos de microfraturas, coalescência e cisalhamento 19

Figura 7 - Efeito de microfraturas em fotomicrografia de granito (Kranz, 1983)..... 20

Figura 8 - Série de fotomicrografias de cristais que apresentam microfraturas (Lloyd \& Knipe, 1992)

Figura 9 - Esquema do processo de propagação de uma microfratura nos interstícios cristalinos, com diferentes efeitos nos diferentes cristais (Lloyd \& Knipe, 1992) ..........22

Figura 10 - Modelo geométrico do processo de propagação das microfraturas, e a relação desta propagação (desenvolvimento de wing-cracks) com a orientação das tensões principais $\sigma_{1}$ e $\sigma_{2}$ (Mitaim \& Detournay, 2004).

Figura 11 - Gráfico tensão x deformação com indicação de quantidades e diferentes tipos de fraturas geradas (Diederichs, 2007)

Figura 12 - Fluxograma do desenvolvimento de instabilidades provocadas por propagação de microfraturas (baseado em Xie \& Pariseau, 1993) ............................ 26

Figura 13 - Gráfico $\sigma \times \varepsilon$ com indicação das energias de deformação acumulada no processo de compressão, e as energias liberadas durante a descompressão (Wang \& Park, 2001) 30

Figura 14 - Síntese do desenvolvimento de rock burst a partir dos diversos temas abordados nos itens anteriores, e suas relações

Figura 15 - Relação entre tensão $(\sigma)$ e deformação $(\varepsilon)$, para material linear-elástico .38

Figura 16 - Gráfico $\sigma \times \varepsilon$. A área sob o gráfico define a energia elástica do trecho deformado

Figura 17 - Tensões ao redor de uma abertura circular, com tensão regional máxima atuando na vertical (Hoek \& Brown, 1980a)

Figura 18 - Representação esquemática dos parâmetros usados na solução de Kirsch em coordenadas polares (Hoek \& Brown, 1980a)

Figura 19 - Variações de tensão tangencial $\left(\sigma_{\theta}\right)$ resultante com a variação da razão $\mathrm{k}$ das tensões aplicadas 
Figura 20 - Variações da concentração de tensão $\left(\sigma_{\theta} / \sigma_{z}\right)$ com a distância em relação

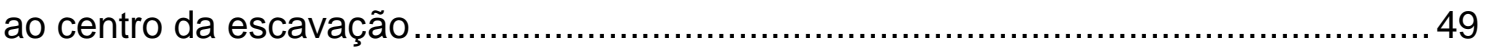

Figura 21 - Representação de um elemento triangular com três nós ..........................54

Figura 22 - Domínio discretizado, com diversos elementos justapostos, conectados

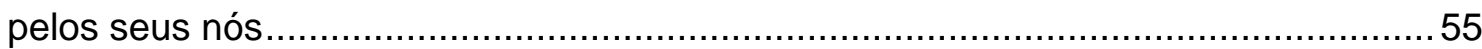

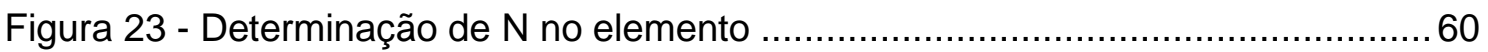

Figura 24 - Representação de isolinhas de magnitudes normalizadas das tensões principais máxima e mínima para uma escavação circular com $\sigma_{\mathrm{h}}=3 \sigma_{\mathrm{v}}$ (Hoek, 2007)

Figura 25 - Diagrama esquemático mostrando trajetórias de tensão e padrões de concentração de tensões principais para um túnel circular em que a relação $\sigma_{\mathrm{v}} / \sigma_{\mathrm{h}}$ é

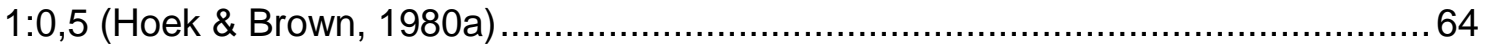

Figura 26 - Malha de elementos utilizada na análise de elementos finitos 67

Figura 27 - Valores de $\sigma_{1}$ ao longo do eixo X segundo os métodos analítico (Kirsch) e numérico (elementos finitos)

Figura 28 - Valores de $\sigma_{2}$ ao longo do eixo $Y$ segundo os métodos analítico (Kirsch) e numérico (elementos finitos)

Figura 29 - Valores das tensões principais após a redistribuição de tensões $\left(\sigma_{1}\right.$ e $\left.\sigma_{2}\right)$

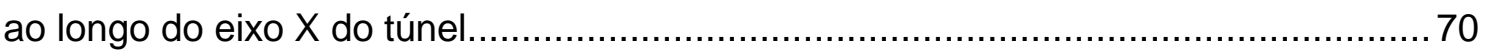

Figura 30 - Resultados das análises pelo método de elementos finitos ...................... 73

Figura 31 - Gráfico da variação dos valores de W com a distância, ao longo do eixo X do túnel

Figura 32 - Comportamento da energia elástica $W$ em relação a valores de $E$, para 0

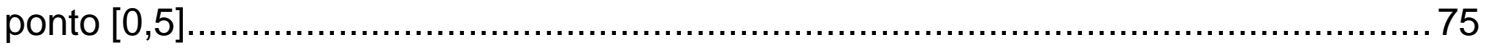

Figura 33 - Relação $W(v)$ para os pontos situados ao longo do eixo $\mathrm{X}$ entre $[5,0 ; 0]$ e $[5,5 ; 0]$ 77

Figura 34 - Relação $W(v)$ para os pontos situados ao longo do eixo $\mathrm{X}$ entre $[5,6 ; 0]$ e $[6,0 ; 0]$ 78

Figura 35 - Para um determinado estados de tensões, materiais mais duros deformam menos que materiais mais macios

Figura 36 - Materiais mais resistentes conseguem suportar maiores tensões antes da ruptura

Figura 37 - Equação de Hoek-Diederichs para estimativas empíricas do modulo elástico para maciços rochosos $\left(E_{r m}\right)$, em função do Geological Strength Index (GSI) e do módulo de elasticidade da rocha intacta $\left(E_{i}\right)$ (Hoek \& Diederichs, 2006) 86 


\section{ÍNDICE DE FOTOGRAFIAS}

Foto 1 - Aspecto de escavação após evento de rock burst (Bräuner, 1994). 8

Foto 2 - Aspecto de escavação após evento de rock burst (Bräuner, 1994). 8

Foto 3 - Aspecto de túneis após eventos de rock burst (Diederichs, 2014). 9

\section{ÍNDICE DE TABELAS}

Tabela 1 - Associação entre os valores de PES e o risco do potencial de ocorrência de rock burst. 31

Tabela 2 - Valores dos parâmetros elásticos usados na análise numérica. 69

\section{NOTAÇÃO}

Vetores são representados sinteticamente com setas sobre o símbolo que os definem: $\vec{v}$.

Tensores de segunda ordem (as matrizes apresentadas neste trabalho) são representados sinteticamente por símbolos em negrito: $\boldsymbol{\sigma}, \boldsymbol{\varepsilon}, \mathbf{D}$, I, etc. 




\section{INTRODUÇÃO}

\subsection{MOTIVAÇÃO}

As escavações subterrâneas sempre tiveram papel muito importante em obras de Engenharia Civil e Engenharia de Minas - incluindo túneis diversos de obras rodoviárias, ferroviárias, metrô, túneis de adução e túneis de desvio para hidrelétricas, gasodutos, oleodutos, e diversas minas de extração de minérios dos mais variados tipos.

As escavações subterrâneas em maciços rochosos lidam com grandes quantidades de variáveis, incluindo incertezas com relação ao tipo de material e suas respostas durante a escavação e em fases posteriores. Não raro, a execução dessas escavações resulta em acidentes, gerando grandes prejuízos materiais e humanos e atrasos no cumprimento de contratos.

Tais acidentes são decorrentes de eventuais incapacidades de previsão das condições reais da natureza do maciço rochoso escavado, como composição litológica, presença e geometria das principais feições estruturais e resposta do maciço frente aos esforços atuantes.

É importante que o conhecimento seja crescente em relação a todos esses parâmetros. No entanto, uma das grandes dificuldades das obras civis é a enorme variabilidade entre diferentes casos. O conhecimento de casos genéricos e amplos é o primeiro passo na determinação de problemas específicos.

O Brasil, como um centro importante na América Latina, vem distribuindo mão de obra e capacitação técnica em obras subterrâneas, em grandes projetos executados em condições especiais como, por exemplo, túneis viários e 
hidrelétricas nos Andes. Espera-se, com este trabalho, aumentar o conhecimento referente ao comportamento dos maciços rochosos nas escavações subterrâneas, contribuindo para a capacitação técnica no planejamento e desenvolvimento das obras civis.

\subsection{ROCK BURST}

Todas as obras subterrâneas estão submetidas a tensões, resultantes do carregamento litostático (i.e. o peso da massa de rocha sobre a escavação) e tensões tectônicas (a magnitude destas tensões horizontais varia, obviamente, com a distância em relação a zonas de contatos de placas tectônicas), que regulam as magnitudes e orientações das "tensões principais" em profundidade (cf. Davis \& Reynolds, 1996).

O mecanismo de rock burst é um problema grave de estabilidade em escavações subterrâneas. Consiste em ruptura violenta e instantânea do maciço rochoso. As consequências podem ser danos severos aos equipamentos e fatalidades aos operários. Estima-se que somente na África do Sul cerca de 20 pessoas morram por ano em consequência de acidentes causados por rock burst (Monroe \& Wicander, 1996)

As definições do problema são muitas, devido à complexidade que cerca os processos que desencadeiam este mecanismo. O termo rock burst é usado para descrever uma ampla gama de ocorrências. O ponto comum é a ocorrência de ejeção violenta de rocha a partir da superfície da escavação. Diversos aspectos da mecânica de rochas podem ser usados para descrever os fenômenos que ocorrem no maciço no desenvolvimento de rock burst. acúmulo de tensões e o desenvolvimento de instabilidades em condições que a tensão exceda a resistência da rocha (pelos critérios de ruptura de Mohr- 
Coulomb, Hoek-Brown), geração e propagação de microfraturas no maciço rochoso e, por fim, o acúmulo e liberação de energia elástica. 


\section{OBJETIVOS DESTE TRABALHO}

Estudos anteriores sobre rock burst focaram em fatores como acúmulo de tensões, ruptura dos maciços rochosos, propagação de microfraturas, e relações de energia elástica dissipada e liberada (cf. item 3.2).

O presente trabalho tem como objetivo entender como materiais com diferentes propriedades elásticas se comportam frente a determinados esforços e deslocamentos em uma abertura subterrânea. De acordo com as equações constitutivas, o módulo de elasticidade $(E)$ e o coeficiente de Poisson $(v)$ são determinantes na relação entre tensão e deformação, e o objetivo será verificar se variações nos valores destes parâmetros têm influência significativa na distribuição da energia potencial elástica concentrada ao redor de uma abertura subterrânea, acompanhando a redistribuição das tensões.

Esta análise compreende a fase de acúmulo de energia em etapas prévias à ruptura do maciço. O objetivo é verificar os pontos ao redor da abertura onde se acumulam maiores quantidades de energia, que potencialmente resultariam em rupturas mais violentas.

A importância dos parâmetros elásticos no comportamento de um maciço rochoso durante a ruptura é descrito em um simples experimento realizado por George H. Davis e apresentado em Davis \& Reynolds (1996): em um ensaio de compressão uniaxial, uma amostra de granito com valores muito baixos de $v$ rompeu de maneira explosiva, com fragmentação da rocha, ao invés de ruptura por cisalhamento em um plano discreto (como seria o esperado). Para os autores, baixos valores de $v$ resultaram em maiores quantidades de energia liberada pela amostra de granito. 
Neste trabalho, não serão realizadas análises em maciços rochosos reais, apenas serão realizados modelos matemáticos para a caracterização geral de aspectos da teoria da elasticidade, que podem ajudar a solucionar alguns problemas de projeto e execução de escavações. 


\section{ROCK BURST: HISTÓRICO}

O fenômeno de rock burst tem um histórico antigo, que remonta às explorações de estanho na Inglaterra no século XVIII, época de grande crescimento na produção de escavações subterrâneas para fins de exploração mineral da Europa. Desde então, o meio da mineração tem convivido com o problema, especialmente as escavações realizadas a maiores profundidades. No entanto, embora o mecanismo de rock burst seja conhecido há tanto tempo, a abordagem da engenharia de minas para todos os problemas em escavações foi por muitos séculos baseada em critérios puramente empíricos, e os processos de instabilidade observados eram tratados de maneira puramente qualitativa (Linkov, 1996).

Foi somente a partir de meados do século XX que os conceitos de mecânica do contínuo e aplicações para mecânica dos materiais começaram a ser desenvolvidos para o âmbito das escavações subterrâneas, incluindo trabalhos experimentais que culminaram em grande evolução no conhecimento da mecânica de rochas.

Muito dos trabalhos pioneiros aplicados ao desenvolvimento do conhecimento em mineração estavam focados nos problemas de rock burst. Foi comum que as soluções teóricas assumissem o maciço rochoso como idealmente elástico e isotrópico, uma aproximação que desconsidera o papel de descontinuidades estruturais para fins de simplificação nos cálculos, mas, mesmo assim, esse tipo de abordagem resultou em avanços no conhecimento das propriedades do comportamento dos maciços rochosos. Os trabalhos mais modernos são fundamentados nestes conceitos de aplicação da teoria da elasticidade (Hoek, 2007). 
O primeiro trabalho que trata de maneira mais completa a relação entre rock burst e aspectos quantitativos da mecânica de rochas e teoria da elasticidade foi apresentado por Cook et al. (1966). Nesse trabalho, os autores analisam dados de diversos casos de rock burst observados em minas sul-africanas e tentam juntar os resultados em um modelo fundamentado em parâmetros matemáticos, garantindo ao fenômeno um aspecto mais quantitativo ao invés de apenas qualitativo.

Com o avanço da tecnologia ao longo do tempo, as escavações subterrâneas para fins de exploração mineral têm tido a capacidade de atingir profundidades ainda maiores, e as empresas mineradoras, cada vez mais globalizadas, têm atuado em uma ampla variedade de localidades ao redor do mundo.

Além disso, no âmbito da engenharia civil novos desafios levam à escavação de túneis viários/ferroviários, túneis de adução, casas de força de hidrelétricas, etc., em profundidades cada vez maiores e percorrendo terrenos cada vez mais complexos em termos de tensões.

O resultado é a ocorrência de rock burst em muitos locais diferentes, o que tem atraído a atenção de pesquisadores de vários países, como África do Sul (Cook, 1965a; Cook et al., 1966), Escandinávia (Broch \& Sørheim, 1984; Grimstad, 1986), Rússia (Linkov, 1996), China (Liu et al., 2011; Li et al., 2012; Zhang et al., 2012), Coréia (Wang \& Park, 2001; Lee et al., 2004), entre outros (Xie \& Pariseau, 1993; Potvin et al., 2000).

Um número crescente de trabalhos tem sido focado neste fenômeno, e muitas diferentes abordagens vêm sendo utilizadas para investigá-lo. Mesmo assim, sua grande complexidade e dificuldade de previsão ainda mantêm o mecanismo de rock burst como um problema a ser resolvido. 


\subsection{DEFINIÇÃO}

Processos de instabilização são comuns em escavações em profundidade, dadas as altas tensões envolvidas ao redor das aberturas e a influência do maquinário e métodos de avanço da escavação no maciço rochoso. Rock bursts estão inseridos nos processos de instabilização que ocorrem nas escavações em profundidade. São considerados grandes riscos às obras subterrâneas por causarem perdas humanas e materiais (Fotos 1 a 3), resultando em grandes prejuízos e atraso em contratos (Hoek \& Brown, 1980a; Palmström, 1995; Potvin et al., 2000).

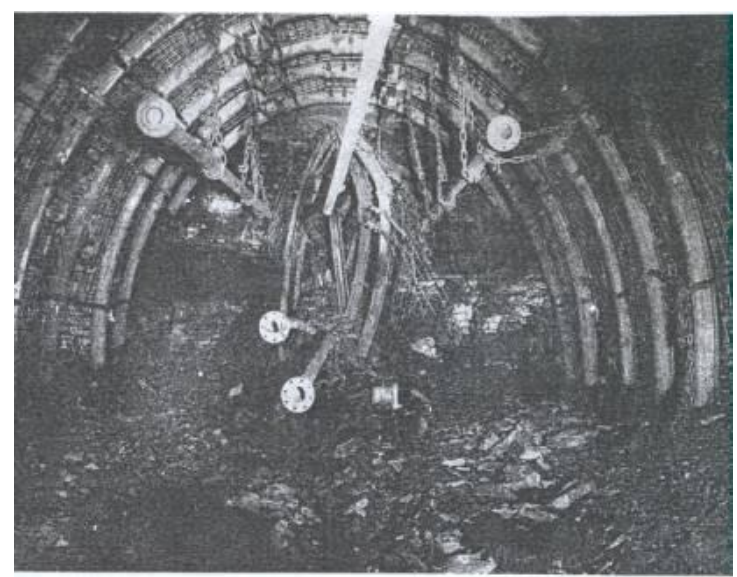

Foto 1 - Aspecto de escavação após evento de rock burst (Bräuner, 1994).

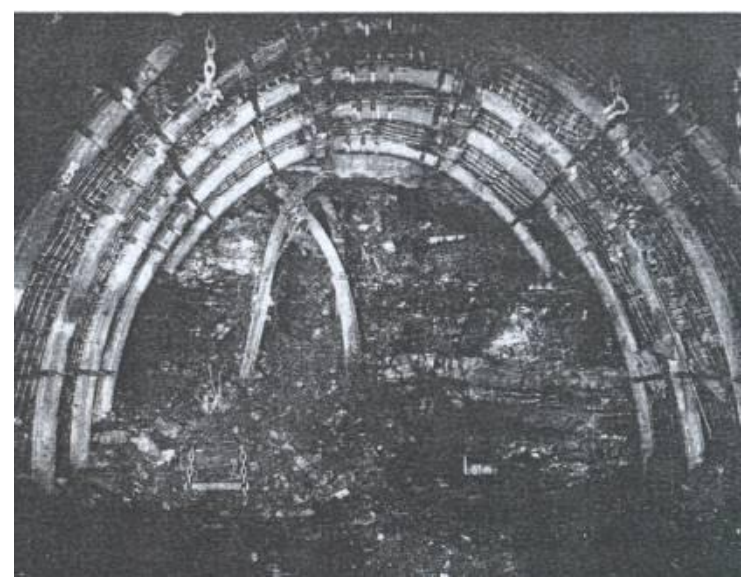

Foto 2 - Aspecto de escavação após evento de rock burst (Bräuner, 1994). 


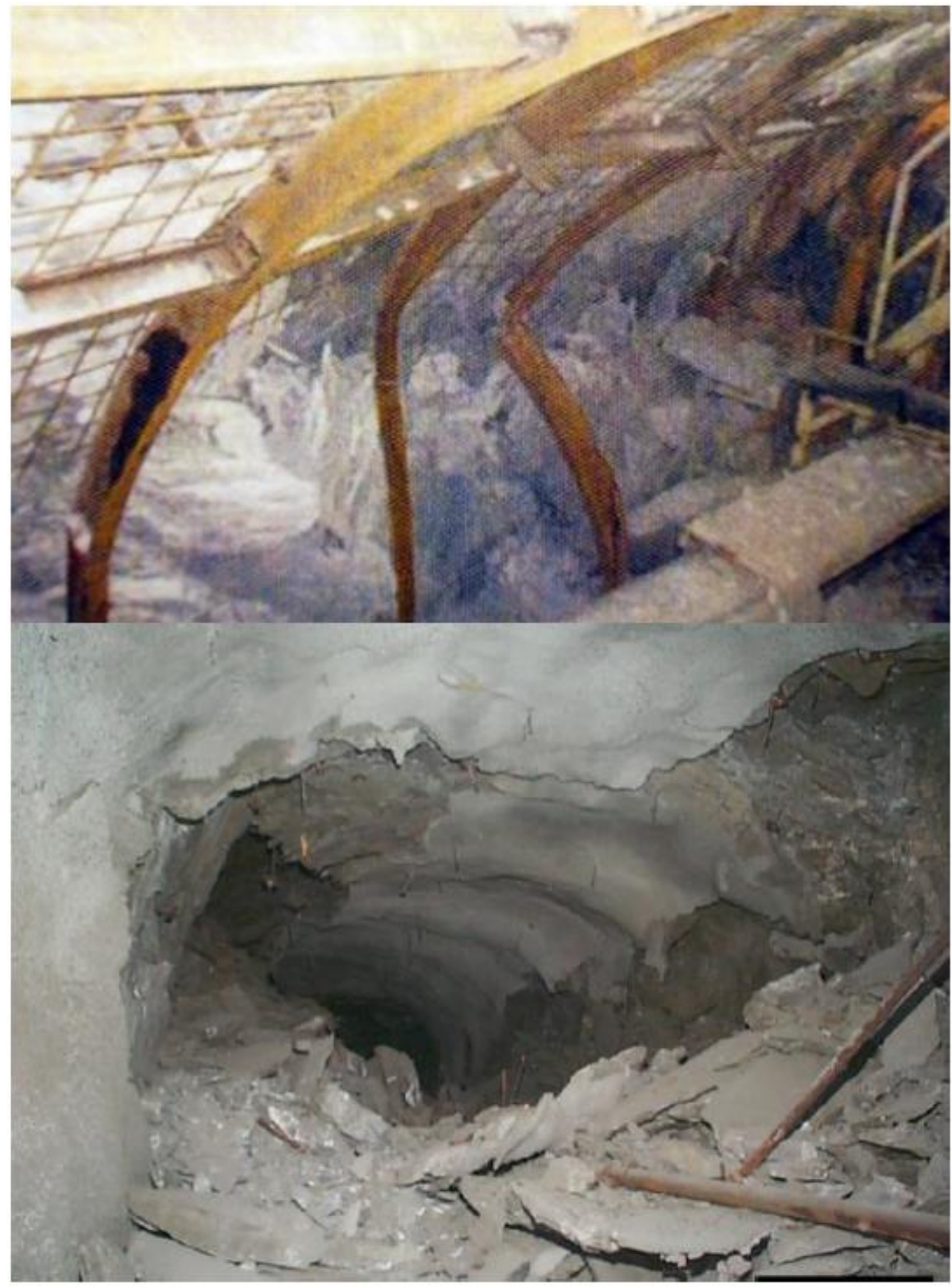

Foto 3 - Aspecto de túneis após eventos de rock burst (Diederichs, 2014).

Whyatt et al. (2002) apresentam a definição formal do U.S. Department of Labor Mine Safety and Health Administration (MSHA cód. 30 CFR 57.3000) como: 
"Um repentino e violento processo de ruptura de rocha submetida a altos regimes de tensão, resultando em liberação instantânea de grandes quantidades de energia acumulada. Rock bursts não incluem estouros resultantes de liberação de gases pressurizados em mineração."

A regulamentação complementar MSHA cód. 30 CFR 57.3461 ressalta os potenciais danos causados às escavações e aos trabalhadores. Nessa regulamentação, um rock burst deve ser reportado às autoridades se:

1. Causar afastamento de funcionários,

2. Danificar sistemas de ventilação,

3. Obstruir passagem, ou

4. Interromper atividade na mina por mais de 1 hora.

Note-se que a definição da MSHA não inclui eventos de ruptura provocados por acúmulos de gases pressurizados no interior do maciço. A emissão de gás é fenômeno restrito a escavações para mineração de materiais como carvão, e explosões de gás em profundidade adquirem uma terminologia própria: outbursts (Litwiniszyn, 1985).

Cook et al. (1966) definem o mecanismo de rock burst como "danos aos trabalhos em escavações subterrâneas causados pelo rompimento do maciço rochoso, associado com liberação violenta de energia, adicional à derivada de queda de blocos por gravidade." A violência do fenômeno é ressaltada por Linkov (1996) e Hoek (2007): rock burst é uma fratura "explosiva" que ocorre geralmente na borda de um veio ou pilar. Rocha sob o efeito de altos valores de tensão se desintegra de maneira repentina, dinâmica e violenta. 
Outra definição ainda engloba o mecanismo de rock burst como "dano causado em um túnel como resultado de evento sísmico, que libera energia suficiente para causar danos à escavação" (Whyatt et al., 1993; Ortlepp \& Stacey, 1994). O dano causado por este evento sísmico pode variar em intensidade, desde pequenos desplacamentos até fraturamento mais generalizado e catastrófico (Potvin et al., 2000).

Palmström (1995) indica a grande variedade de nomenclaturas encontradas para a descrição do fenômeno, especificamente na literatura em inglês: spalling, popping, splitting, slabbing. Ortlepp \& Stacey (1994) e Whyatt et al. (2002) ressaltam ainda a grande variedade de diferentes definições de rock burst na literatura, e que, por este motivo, a compreensão conceitual do mecanismo de rock burst não é uniforme. De fato, o termo rock burst é usado para descrever uma ampla gama de ocorrências, muitas vezes sem atribuir descrição física à natureza dos fenômenos observados. O ponto comum, no entanto, é que praticamente todas as definições envolvem ejeção violenta de rocha a partir da superfície da escavação.

Neste trabalho, o fenômeno de rock burst será considerado como mecanismo descrito por Ortlepp \& Stacey (1994) como strainburst, caracterizado como ruptura rasa na rocha provocada por acúmulo de tensão, resultando na ejeção de fragmentos (figura 1), uma vez que ele é o tipo de rock burst mais importante na construção e operação de túneis civis (Diederichs, 2014). 


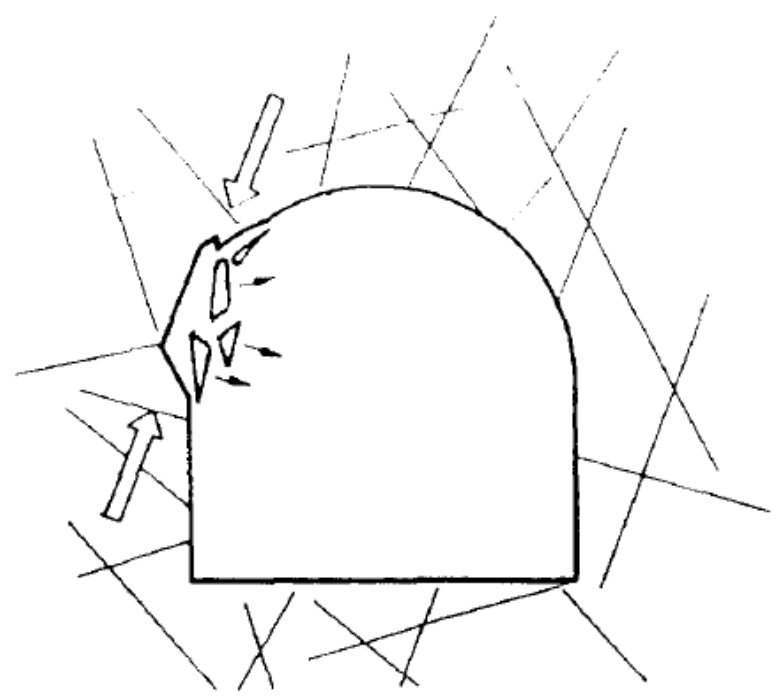

Figura 1 - Esquema demonstrativo de strainburst: desplacamentos violentos resultantes de concetrações superficiais de tensões. (Ortlepp \& Stacey, 1994).

\subsection{CAUSAS}

O fenômeno de rock burst é possivelmente causado por uma série de fatores sobrepostos. Esta complexidade faz com que estes diversos fatores sejam estudados individualmente, para serem colocados num cenário mais amplo, que consiga caracterizar o problema de maneira mais geral.

O mecanismo de rock burst está diretamente associado aos processos de fraturamento de maciços rochosos. O estudo destes processos é realizado por meio de análises do comportamento mecânico das rochas.

As teorias de mecânica de rochas são aplicadas para relacionar as tensões submetidas aos maciços rochosos e a resistência destes materiais, e determinar os padrões de comportamento dos maciços em várias escalas desde microscópicas, nas interações entre os cristais de uma rocha, até grandes dimensões, como as proximidades imediatas de um túnel de vários metros de diâmetro. 
As teorias matemáticas de mecânica de rochas - derivadas das teorias de mecânica do contínuo e teoria da elasticidade - são testadas e aperfeiçoadas através de ensaios em laboratório (ensaios de compressão uniaxial, ensaios triaxiais, etc.), em conjunto com resultados obtidos in situ (determinações de tensões como break-out, e ensaios geofísicos que permitem a estimativa dos parâmetros elásticos do maciço).

Logo, embora haja uma base teórica muito densa para o estudo da mecânica de materiais, uma grande parcela dos parâmetros estudados tem fundamentação empírica e por este motivo estão sujeitos a muitos ajustes e revisões.

Os principais fatores associados à geração do fenômeno de rock burst são descritos sucintamente nos itens deste capítulo. Os conceitos fundamentais de teoria da elasticidade, com ênfase na aplicação em aberturas subterrâneas, serão desenvolvidos no capítulo IV. Um aprofundamento maior é apresentado no Apêndice 1.

\subsubsection{Acúmulo de Tensões}

O senso praticamente comum da literatura aponta para a concentração de tensões como a principal causa da ocorrência do fenômeno de rock burst.

Hoek \& Brown (1980a) e Hoek (2007) caracterizam o mecanismo de rock burst como processo de ruptura violenta que ocorre quando tensões são fortemente concentradas ao redor de escavações subterrâneas, caracteristicamente em rochas muito rígidas e situadas sob altos regimes de tensão.

A execução de escavações subterrâneas induz concentração de tensões como resultado do rearranjo do estado natural de tensões em um maciço rochoso 
quando este é perturbado por uma abertura, que cria vazios em seu interior (Jaeger \& Cook, 1979; Hoek \& Brown, 1980a; Hudson \& Harrison, 1997). Nas regiões em que as tensões se concentram, os valores podem superar a resistência da rocha, rompendo-a (Jaeger, 1971; Cook, 1965a; Hoek et al., 1993; Hoek, 2007. Ver critérios de ruptura, no Apêndice 2).

Nas bordas da escavação, a componente de tensão que atua perpendicularmente às paredes da abertura é nula, devido à remoção do material rochoso. Desta maneira, atuam somente tensões tangenciais à abertura (ver teoria da elasticidade ao redor de escavações subterrâneas, no item 4.2). Para Potvin et al. (2000), a escavação é um fator essencial para a indução de instabilidades, pois cria localmente condições que se aproximam das condições de ensaios de compressão uniaxial, com redução de tensões confinantes, levando à degradação e ruptura da rocha intacta.

A relação entre ocorrência de rock burst em função das tensões tangenciais (Kirsch, 1898) $\left(\sigma_{\theta}\right)$ e da resistência da rocha (resistência puntiforme, I) foi estudada por Russeness (1974) e plotado no gráfico da figura 2.

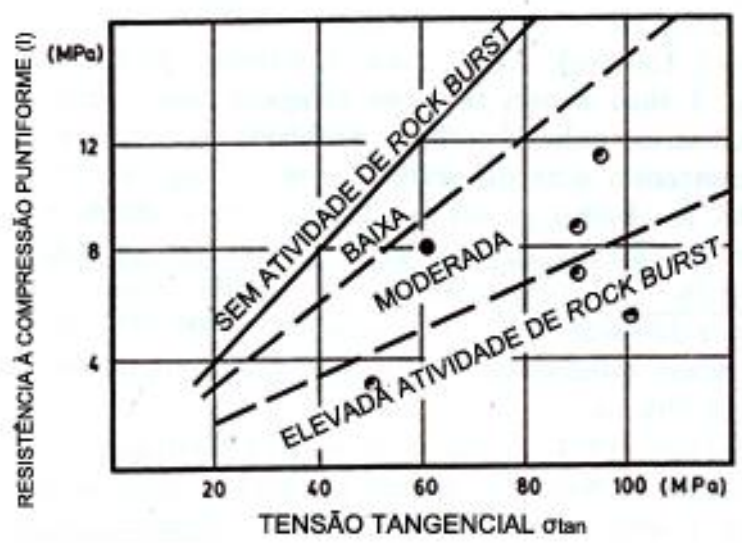

Figura 2 - Quadro esquemático relacionando rock burst com tensão tangencial $\sigma_{\text {tan }}$ e resistência à compressão puntiforme I (Russeness,1974). 
Este gráfico mostra a relação entre a tensão aplicada e a resistência da rocha intacta: quanto maior a razão $\sigma_{\theta} / I$, maior a atividade de rock burst em uma escavação.

Palmström (1995) observa que rock bursts ocorrem geralmente em profundidades superiores a $1000 \mathrm{~m}$, em que as tensões naturais são elevadas devido à elevada carga litostática (gravitacional), mas podem ocorrer a profundidades menores, com ocorrência de elevadas tensões horizontais (possivelmente tectônicas) ou tensões muito anisotrópicas.

Broch \& Sørheim (1984) apresentam estudo de caso de um túnel escavado em fiordes noruegueses. O maciço rochoso do local do empreendimento (gnaisse pré-cambriano) era avaliado como "de muito boa qualidade", e mesmo assim as experiências em construções subterrâneas neste tipo de ambiente indicavam que era esperado que ocorressem rock bursts pela situação de grande anisotropia de tensões, conhecida na região (figura 3).

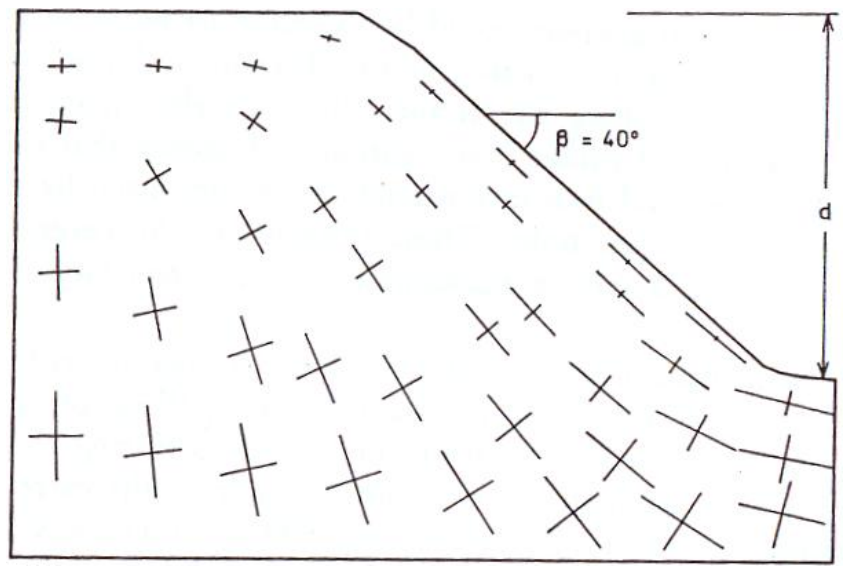

Figura 3 - Indicação esquemática das tensões principais no interior do maciço, nas proximidades de uma encosta natural com declividade acentuada $\left(>40^{\circ}\right)$. Notar que próximo à encosta as tensões são mais anisotrópicas em relação ao interior do maciço (Broch \& Sørheim, 1984) 
De acordo com a figura 3, a anisotropia das tensões nas proximidades da encosta é maior, enquanto no interior do maciço, embora os valores absolutos de tensões sejam maiores, a relação entre as tensões principais é mais isotrópica. No caso do túnel descrito por Broch \& Sørheim (1984), a ocorrência de rock bursts teve relação direta com estes diferentes estados de tensão: foi observado um maior número de rock bursts nas proximidades das encostas nas quais o estado de tensões é mais anisotrópico - do que nas regiões mais interiores do maciço - nas quais o estado de tensões é mais isotrópico.

As observações apresentadas acima são compatíveis com as previsões dos critérios de ruptura (Apêndice 2). Estados de tensão fortemente anisotrópicos se aproximam mais da envoltória de ruptura.

Segundo o critério de Mohr-Coulomb, estados mais anisotrópicos resultam em círculos de Mohr maiores, em relação a estados de tensão mais isotrópicos, mesmo no caso em que as tensões principais do regime mais isotrópico sejam muito altas. Como resultado, em situações de maior anisotropia aumenta a possibilidade de se superar o limite da envoltória de ruptura (figura 4). Esta análise corrobora as observações de Broch \& Sørheim (1984) em seu túnel escavado nas encostas dos fiordes. 


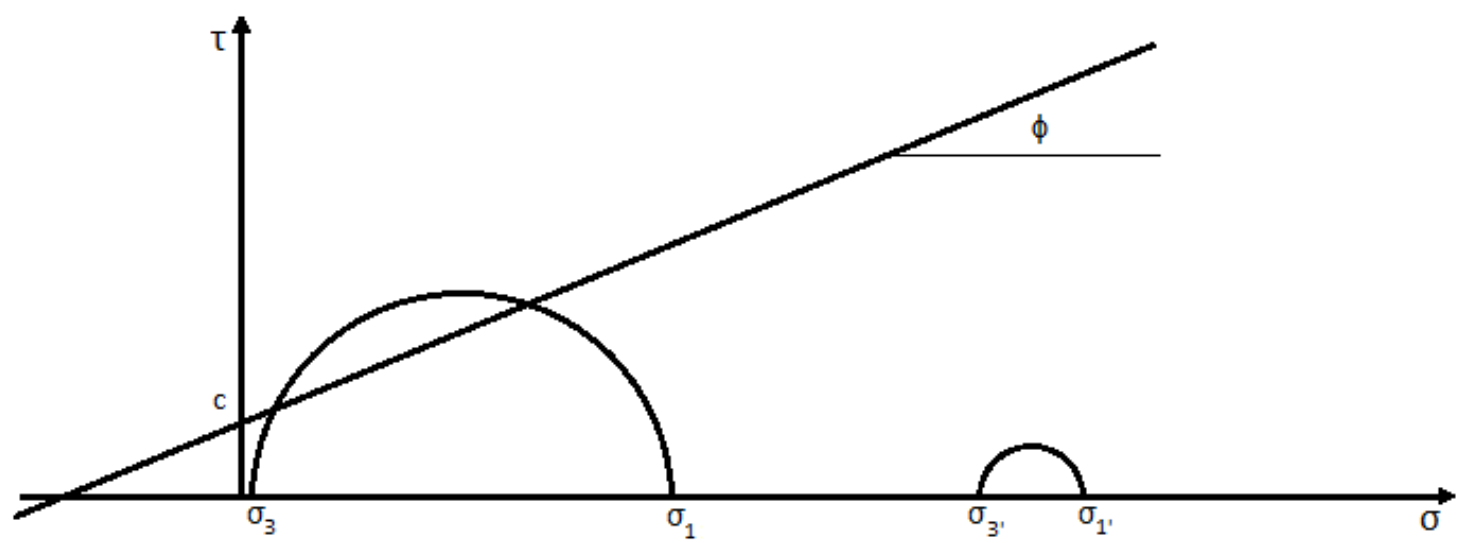

Figura 4 - Diagrama esquemático de Mohr-Coulomb, apresentando a envoltória de ruptura e círculos de tensões principais. Altos valores de tensão desviatória $\left(\sigma_{3}-\sigma_{1}\right)$ são mais problemáticos para ruptura do maciço que altos valores absolutos de tensão. No caso da figura, um estado de tensões definido por tensões mais elevadas e mais isotrópicas $\left(\sigma_{1}, \sigma_{3 \prime}\right)$ é mais estável que um estado de tensões definido por tensões menos elevadas, porém muito anisotrópicas $\left(\sigma_{1}, \sigma_{3}\right)$.

Esta análise, no entanto, deve levar em consideração a anisotropia de tensões resultante após a escavação. As relações entre as tensões principais $\sigma_{1}$ e $\sigma_{3}$ atuantes no maciço rochoso determinam os valores das tensões resultantes ao redor da abertura (ver teoria da elasticidade ao redor de escavações subterrâneas, no item 4.2), definidas aqui como $\sigma_{\theta}$ e $\sigma_{r}$.

O determinante para a ruptura do maciço seria, então, a anisotropia entre estas novas tensões. Nas fronteiras da escavação, como só ocorre $\sigma_{\theta}$, resulta 0 estado mais anisotrópico possível e, portanto, mais crítico do campo de tensões local.

As magnitudes de tensões tangenciais, resultantes da redistribuição das tensões após a abertura da escavação, foi estimada para o túnel de Broch \& 
Sørheim (1984) por meio de análise fotoelástica, conforme apresentado na figura 5.

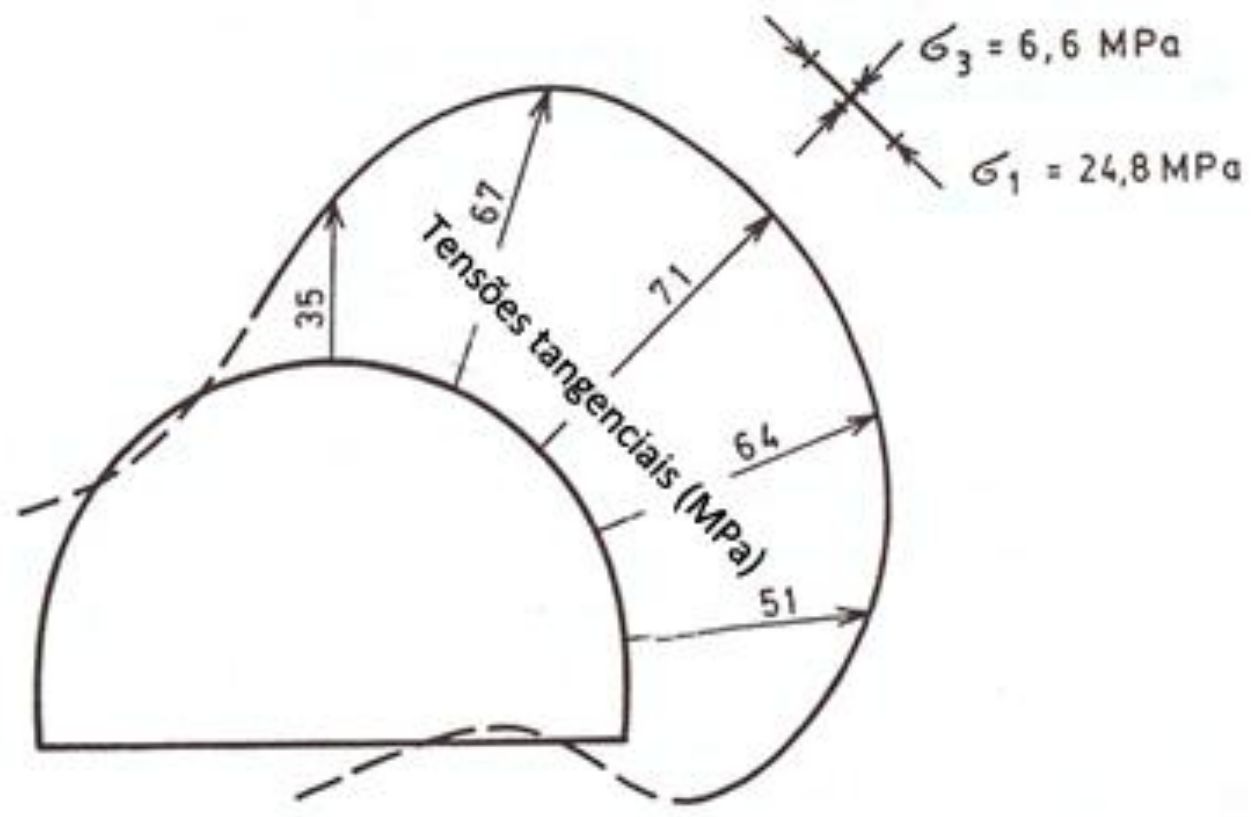

Figura 5 - Diagrama esquemático da distribuição das tensões tangenciais para o túnel estudado por Broch \& Sørheim (1984).

\subsubsection{Microfraturas}

A ruptura da rocha, que tem início na criação e propagação de microfraturas ${ }^{1}$, é um assunto muito complexo, descrito em Cook (1965b), Scholz, (1968a), Scholz (1968b), Xie \& Pariseau (1993), Mitaim \& Detournay (2004), Diederichs, (2007).

O mecanismo de ruptura em rochas foi estudado a partir da década de 1960 em experimentos de laboratório por meio de ensaios de compressão uniaxial e triaxial. Os resultados são modelos empíricos nos quais o comportamento do material é detalhado em várias etapas de carregamento e descarregamento ${ }^{2} \mathrm{e}$

\footnotetext{
${ }^{1}$ Em inglês, estas feições são denominadas microcracks.

${ }^{2}$ Em inglês, usa-se os termos loading e unloading.
} 
registrados em gráficos do tipo tensão x deformação (Cook, 1965b; Scholz, 1968a; Scholz, 1968b).

Os resultados mostram que, na prática, as rochas cristalinas não apresentam comportamento perfeitamente elástico-linear. As curvas resultantes dos ensaios de compressão mostram trechos de comportamento curvilíneo, com a concavidade para cima no início dos experimentos (devido ao fechamento de micro-fraturas e de outros defeitos no arranjo cristalino) e com a concavidade para baixo a partir de valores de tensão superior a $60 \%$ da resistência da rocha (devido ao surgimento de novas micro-fraturas, que dão à rocha caráter semiplástico). Esta situação pode ser observada na figura 6.

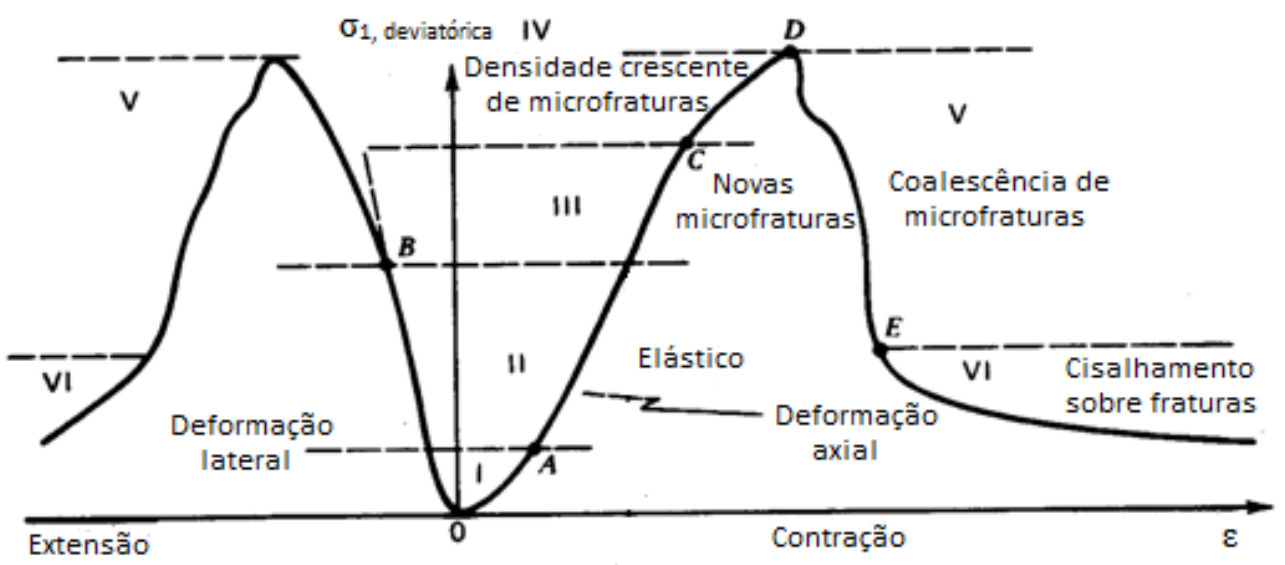

Figura 6 - Curvas de tensão x deformação com indicação de eventos de microfraturas, coalescência e cisalhamento. As curvas de tensão x deformação não são perfeitamente lineares, especialmente a partir dos pontos B (para extensão) e C (para compressão), refletindo caráter semiplástico dos materiais naturais.

O processo físico do desenvolvimento de microfraturas é abordado já nos experimentos de autores como Cook (1965a) e Scholz (1968b). Estudos 
posteriores foram responsáveis pelo aprofundamento do conhecimento no assunto. Não será objetivo deste trabalho descrever em detalhes as características do processo de microfraturamento e coalescência. Será realizada apenas uma caracterização ampla, e o leitor que se interessar no aprofundamento do tema pode encontrar informações mais completas na literatura referenciada ao longo do capítulo.

O efeito de tensões e a origem de microfraturas a partir de vários diferentes processos nos interstícios cristalinos (figuras 7 e 8) e sua propagação em micro-escala (figura 9) são abordados em Kranz (1983) e Lloyd \& Knipe (1992).

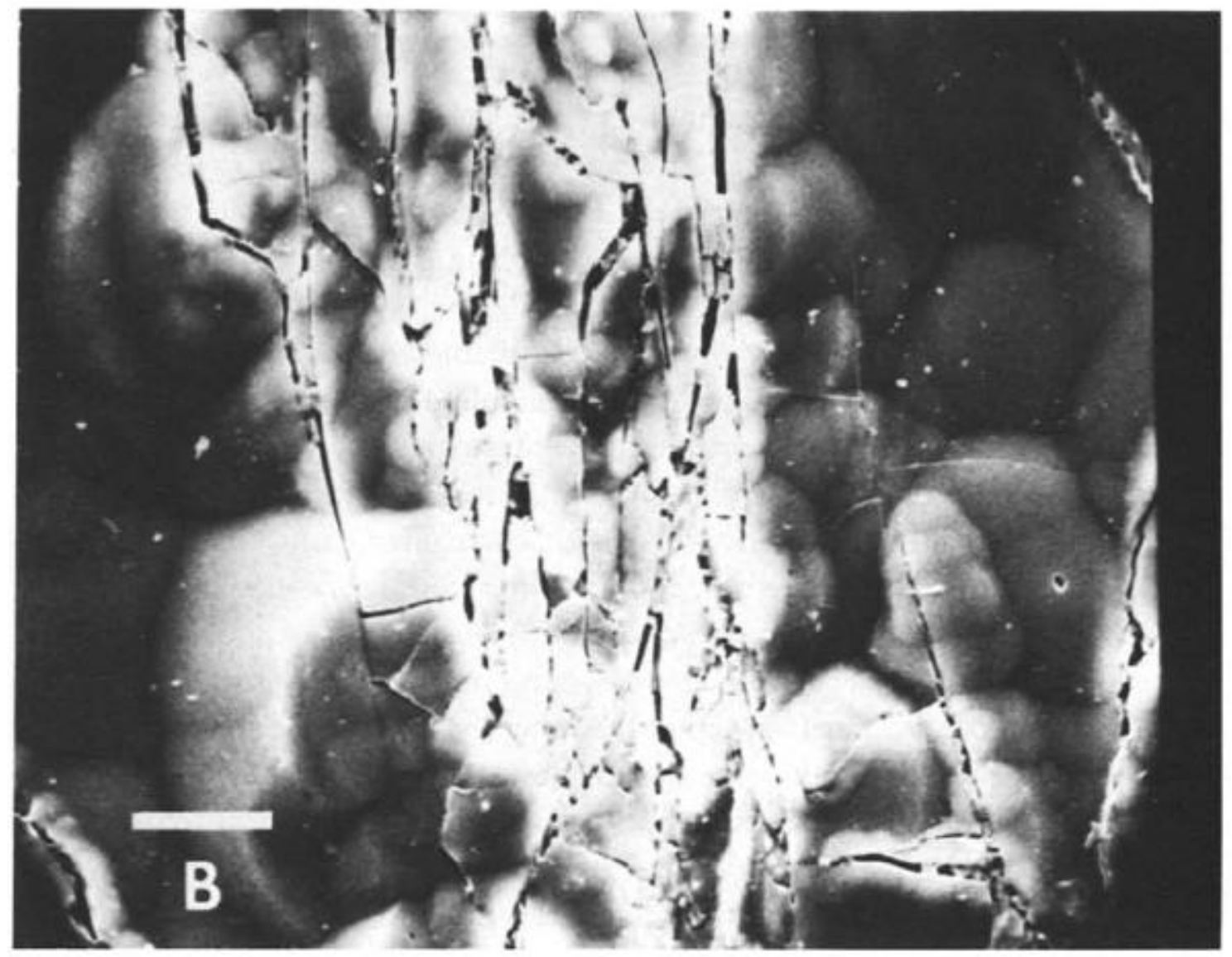

Figura 7 - Efeito de microfraturas em fotomicrografia de granito. A escala "B" mede $25 \mu \mathrm{m}$ (Kranz, 1983). 

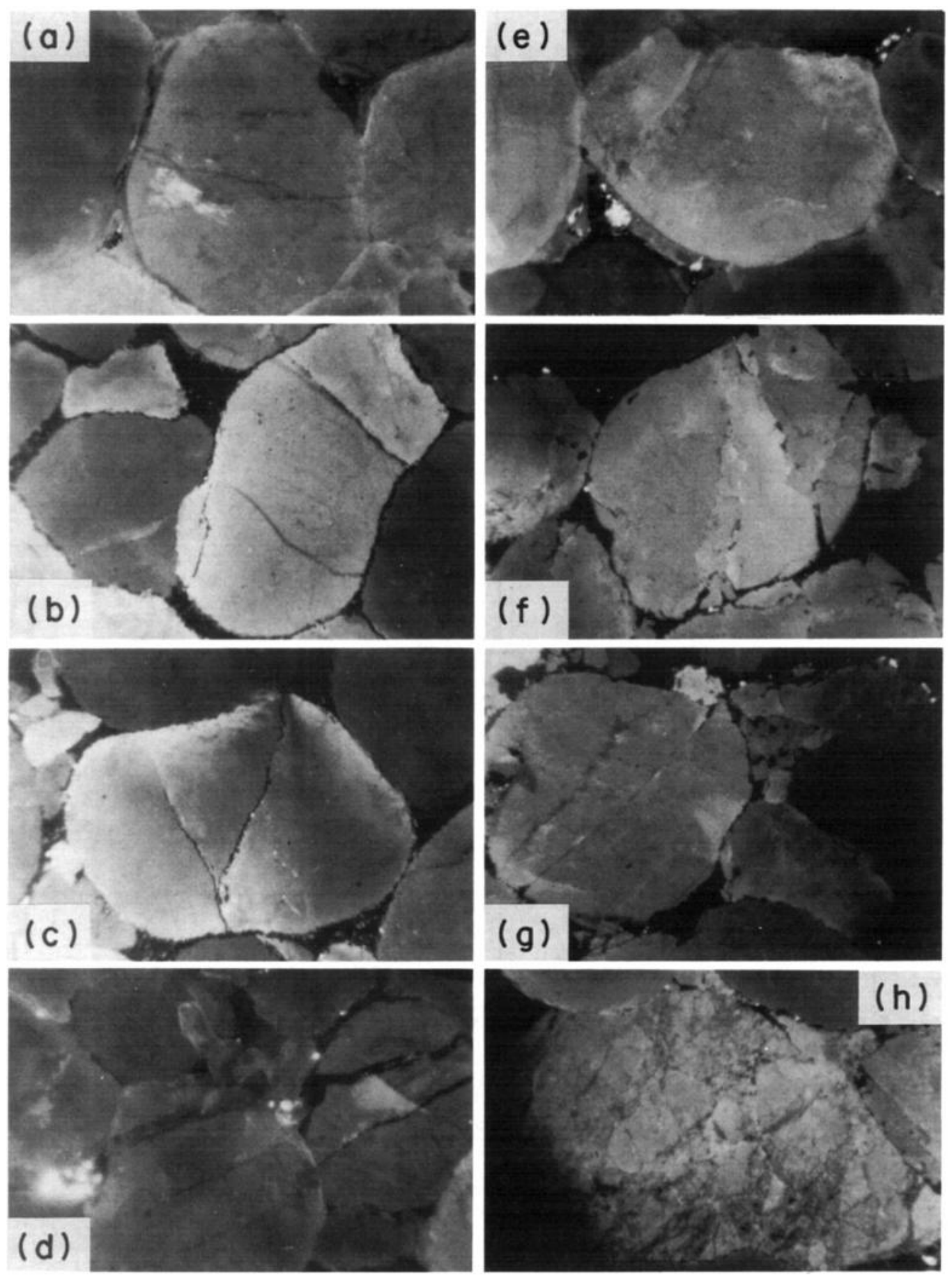

Figura 8 - Série de fotomicrografias de cristais que apresentam microfraturas.

(Lloyd \& Knipe, 1992). 


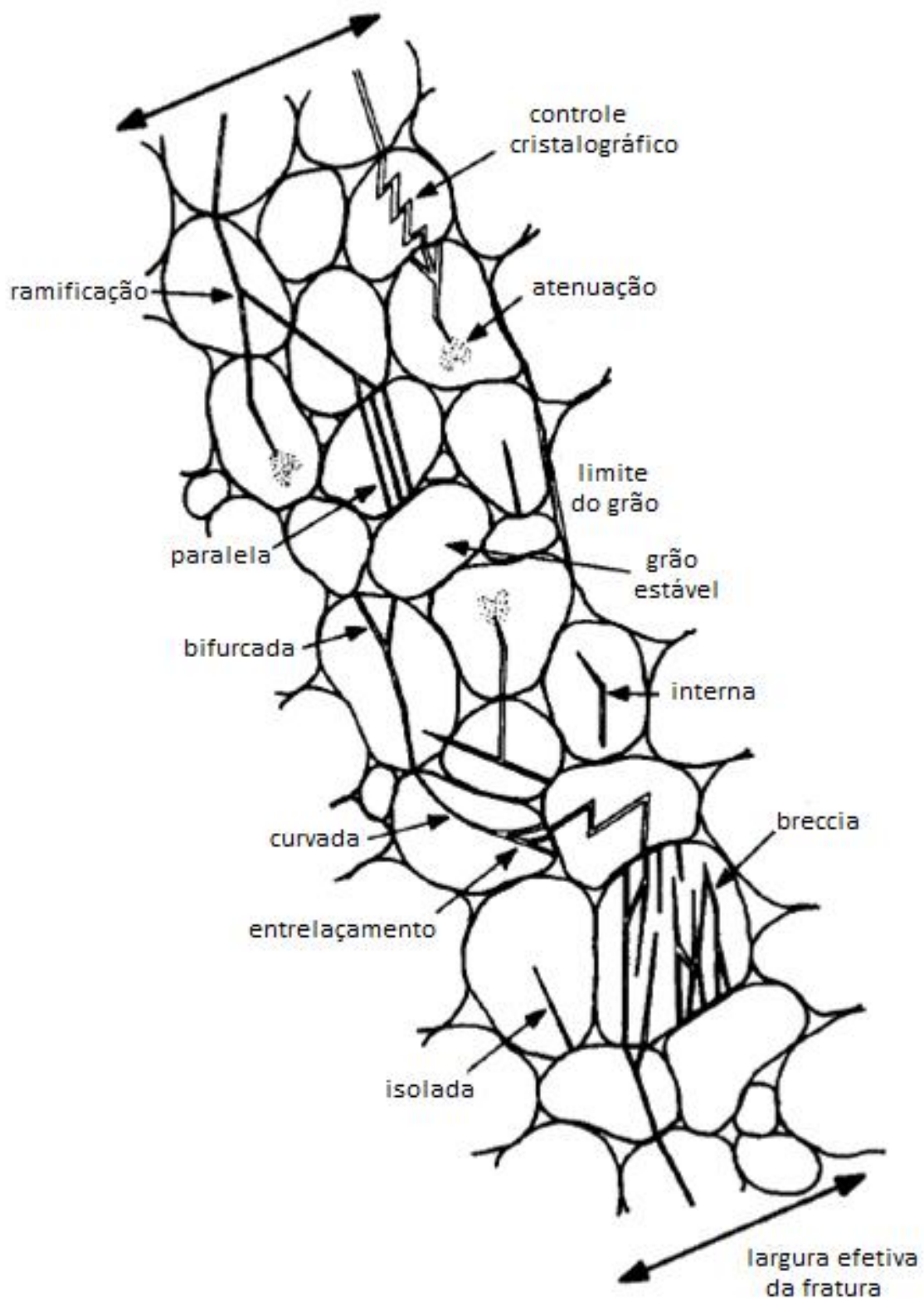

Figura 9 - Esquema do processo de propagação de uma microfratura nos interstícios cristalinos, com diferentes efeitos nos diferentes cristais (Lloyd \& Knipe, 1992).

Mitaim \& Detournay (2004) mostram o processo de propagação das microfraturas e a relação desta propagação (desenvolvimento de wing-cracks) com a orientação das tensões principais $\sigma_{1}$ e $\sigma_{2}$ (figura 10). 

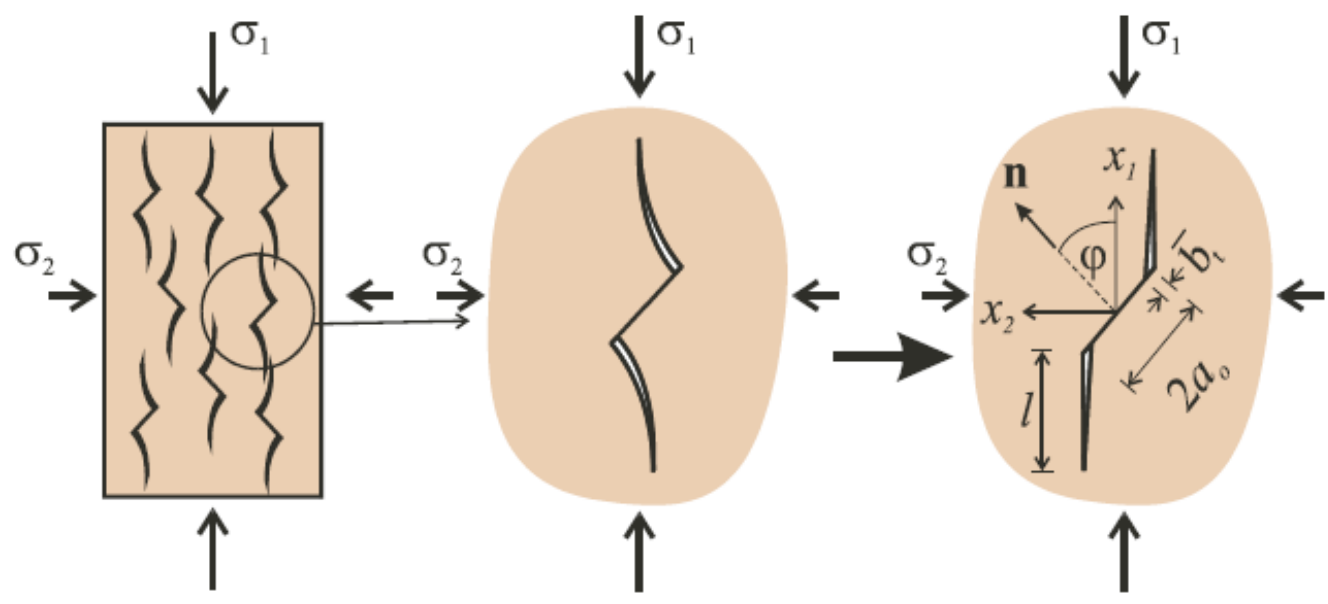

Figura 10 - Modelo geométrico do processo de propagação das microfraturas, e a relação desta propagação (desenvolvimento de wing-cracks) com a orientação das tensões principais $\sigma_{1}$ e $\sigma_{2}$ (Mitaim \& Detournay, 2004).

Diederichs (2007) apresenta um estudo de mecânica de instabilidades em escavações subterrâneas com grande foco na origem e propagação de fraturas de tração, em oposição às fraturas por cisalhamento. Para o autor, os mecanismos de spalling e strain burst estariam associados às fraturas de tração, e o estudo destas fraturas acaba sendo incompatível com os critérios de ruptura adotados pelos modelos convencionais, especialmente o de MohrCoulomb, que descreve o comportamento dos materiais em relação a fraturas por cisalhamento. Atrito e coesão teriam papel pouco significativo no desenvolvimento de fraturas por tração. Como consequência, ensaios realizados pelo autor mostram que a incidência de fraturas por tração pode ser muito maior que a incidência de fraturas por cisalhamento (figura 11). 


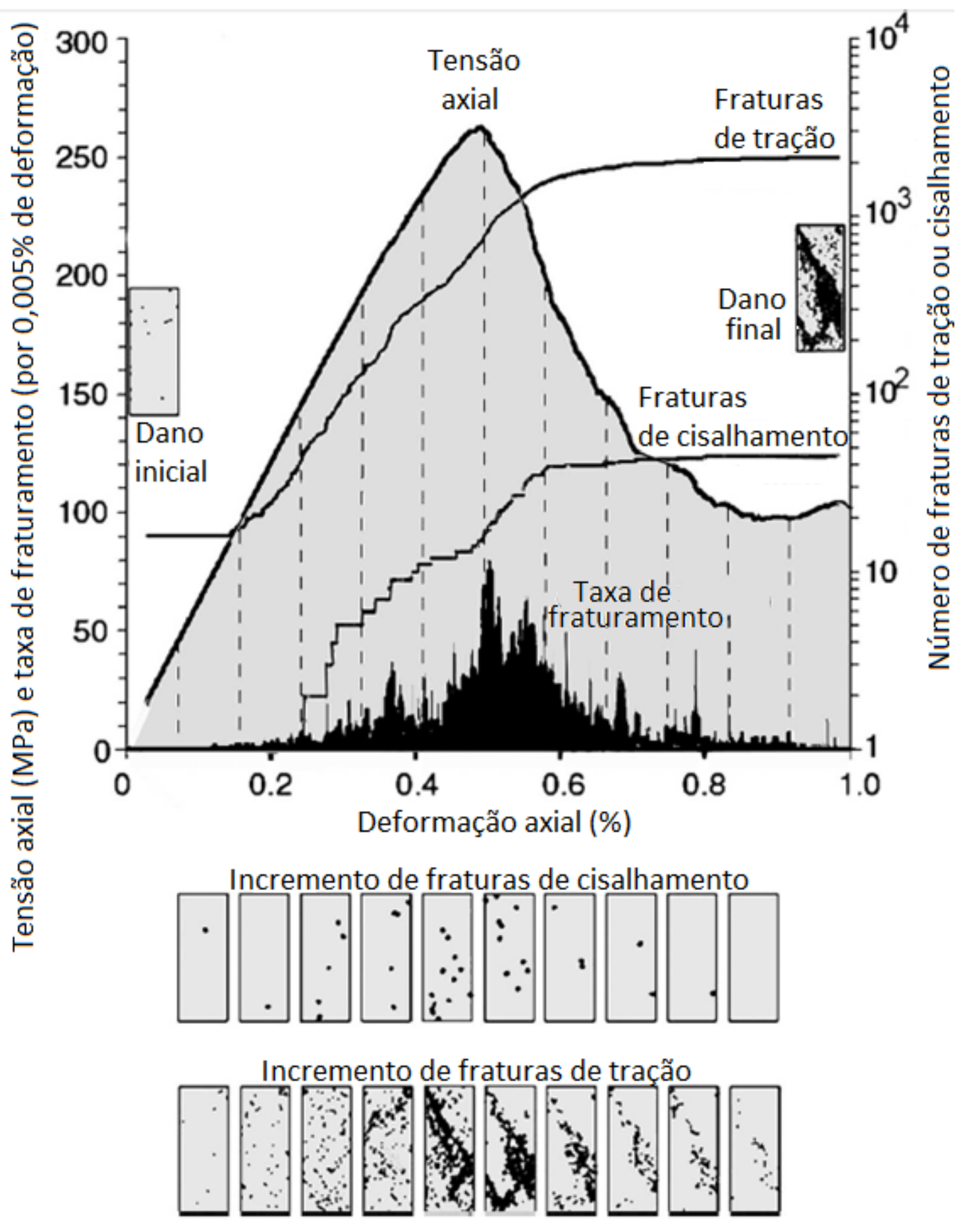

Figura 11 - Gráfico tensão x deformação com indicação de quantidades e diferentes tipos de fraturas geradas. Notar que a quantidade de fraturas de tração (tensile cracks) é maior que a quantidade de fraturas de cisalhamento (shear cracks). (Diederichs, 2007). 
Um resumo do processo de origem e propagação das microfraturas até a eventual ruptura do maciço rochoso é apresentado em Xie \& Pariseau (1993):

Para esses autores, o processo físico de um rock burst pode ser descrito da seguinte maneira (figura 12): primeiro, microfraturamento (microcracking) se desenvolve localmente no maciço rochoso onde estados de tensão trativos podem ocorrer devido à presença de defeitos naturais da rocha, mesmo em regimes puramente compressivos. $O$ fraturamento se propaga com 0 crescimento/concentração das tensões - especialmente nas extremidades das microfraturas -, e estas fraturas formadas em pequena escala começam a se agrupar em determinadas regiões do maciço rochoso (coalescência), criando zonas frágeis. Este processo de coalescência é um evento de atividade sísmica em pequena escala, e pode ser identificado devido ao aumento significativo de emissões acústicas no maciço rochoso. Tensões adicionais induzidas pelo processo de escavação, em conjunto com a presença de estruturas e feições geológicas (como falhas, diques, juntas, etc.), podem fazer com que a zona de coalescência dê origem a uma ruptura violenta, isto é, rock burst. 


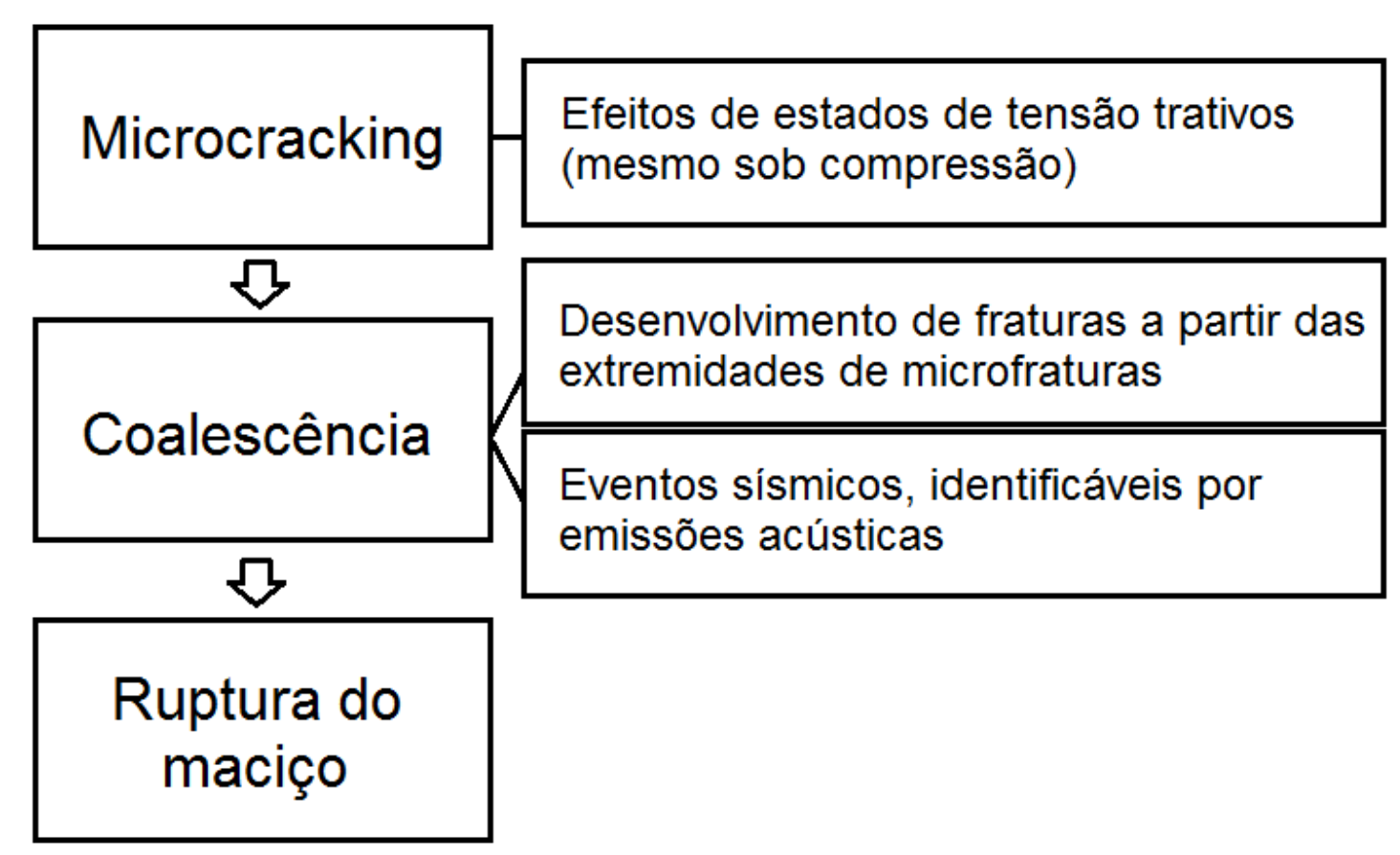

Figura 12 - Fluxograma do desenvolvimento de instabilidades provocadas por propagação de microfraturas (baseado em Xie \& Pariseau, 1993).

\subsubsection{Energia elástica de deformação}

O papel da energia elástica foi descrito de maneira geral por Cook et al. (1966), mas estudos quantitativos deste tema só foram efetuados a partir do final do século XX. Para Xie et al. (2009), ensaios de laboratório mostram que a ruptura em rocha não pode ser completamente descrita apenas por meio de tensões e deformações: situações com regimes similares de tensão e deformação podem acarretar cenários com diferentes quantidades de liberação de energia. Além disso, quanto maior a quantidade de energia absorvida pela rocha durante a deformação, mais fragmentos serão produzidos pelo maciço após a ruptura (Davis \& Reynolds, 1996). Consequentemente, os processos de deformação e fraturamento podem ser complementados por análise de balanço de energia.

A energia relacionada à deformação é denominada energia elástica de deformação (elastic strain energy), definida como o trabalho realizado pelo 
maciço rochoso durante a deformação. A liberação repentina e instantânea da energia elástica acumulada no maciço rochoso na forma de energia cinética causa fraturamento violento do maciço rochoso, isto é, processos de ruptura violenta como rock burst são relacionados com a energia elástica acumulada no maciço (Cook et al., 1966; Müller, 1991; Khanlari \& Ghaderi-Meybodi, 2011, Diederichs, 2014)

No processo de redistribuição das tensões, o maciço que forma os limites da escavação terá que suportar maiores quantidades de esforços devido à remoção do suporte original exercido pela rocha anteriormente situada no interior do túnel. Com o incremento das tensões, o maciço é deslocado para o sentido do interior do túnel, vazio. Esta mudança em relação ao estado original resulta em trabalho realizado no maciço rochoso, resultando em energia elástica de deformação. Quanto maior a resistência da rocha, maior a energia acumulada. Rock bursts ocorrem devido à liberação violenta e abrupta desta energia, acumulada no maciço rochoso (Lee et al., 2004).

Maciços rochosos mais íntegros e mais rígidos são mais favoráveis ao acúmulo de energia e sua dissipação de maneira violenta (Broch \& Sørheim, 1984). Maciços fraturados ou menos rígidos possuem a propriedade de acomodarem a deformação por meio das fraturas ou por meio de deformação plástica a semi-plástica (Lee et al., 2004). A liberação de energia, em maciços de pior qualidade, ocorre durante os processos de geração e propagação de fraturas.

A taxa de liberação de energia e sua dissipação de maneira não violenta - por meio de deformação plástica - é conceito apresentado por Cook et al. (1966) e por Linkov (1996) como a razão de liberação de energia (Energy Release Rate $-\mathrm{ERR})$. 
As seguintes considerações são feitas por Cook et al. (1966):

Se os maciços rochosos fossem puramente elásticos, qualquer mudança volumétrica na escavação seria acompanhada de liberação de energia cinética na forma de ondas sísmicas. Na prática, parte da energia é absorvida no processo de fraturamento da rocha ao redor da escavação e parte é liberada violentamente na forma de energia cinética (ondas sísmicas) durante rock bursts e outras fraturas violentas, causando danos severos nas escavações.

Aspectos importantes apresentados pelos autores são a profundidade da escavação e a dimensão das aberturas. Em pequenas aberturas, a energia dissipada pelo processo de fraturamento $\left(\mathrm{W}_{\mathrm{F}}\right)$ é maior que a energia elástica liberada $\left(W_{R}\right)$, criando uma situação estável, sem caráter explosivo. A quantidade de energia $W_{R}$ liberada por unidade de volume extraído pela escavação/mineração aumenta rapidamente com o aumento da dimensão da escavação, enquanto a energia dissipada $W_{F}$ é praticamente constante. Esta relação entre aumento de energia liberada e manutenção da energia dissipada faz com que o aumento das dimensões haja maior potencial de rock burst.

Existe uma dimensão crítica para a abertura subterrânea, que é tanto menor quanto maior a profundidade. Nela, $\mathrm{W}_{\mathrm{F}}=\mathrm{W}_{\mathrm{R}}$.

Wang \& Park (2001) analisam efeitos da energia elástica de deformação em casos reais, usando o princípio da ERR. Ensaios de compressão uniaxial e triaxial de amostras de rocha de uma mina de ouro chinesa situada a $570 \mathrm{~m}$ de profundidade, com sensores para medir as deformações axiais e laterais, mostram que: 
- No processo de compressão, as amostras se deformam elasticamente e plasticamente, e acumulam energia potencial elástica.

- Ao remover a compressão antes do pico de resistência da rocha (até aproximadamente $70 \%$ da resistência à compressão uniaxial - UCS), a deformação elástica é totalmente reversível, mas a plástica é permanente.

- O rock burst é provocado pela liberação repentina da energia elástica quando a rocha sofre ruptura.

A figura 13 mostra um gráfico $\sigma \times \varepsilon$ em que são indicadas as regiões associadas às diferentes energias acumuladas e liberadas no processo de compressão e descompressão da rocha ensaiada. 


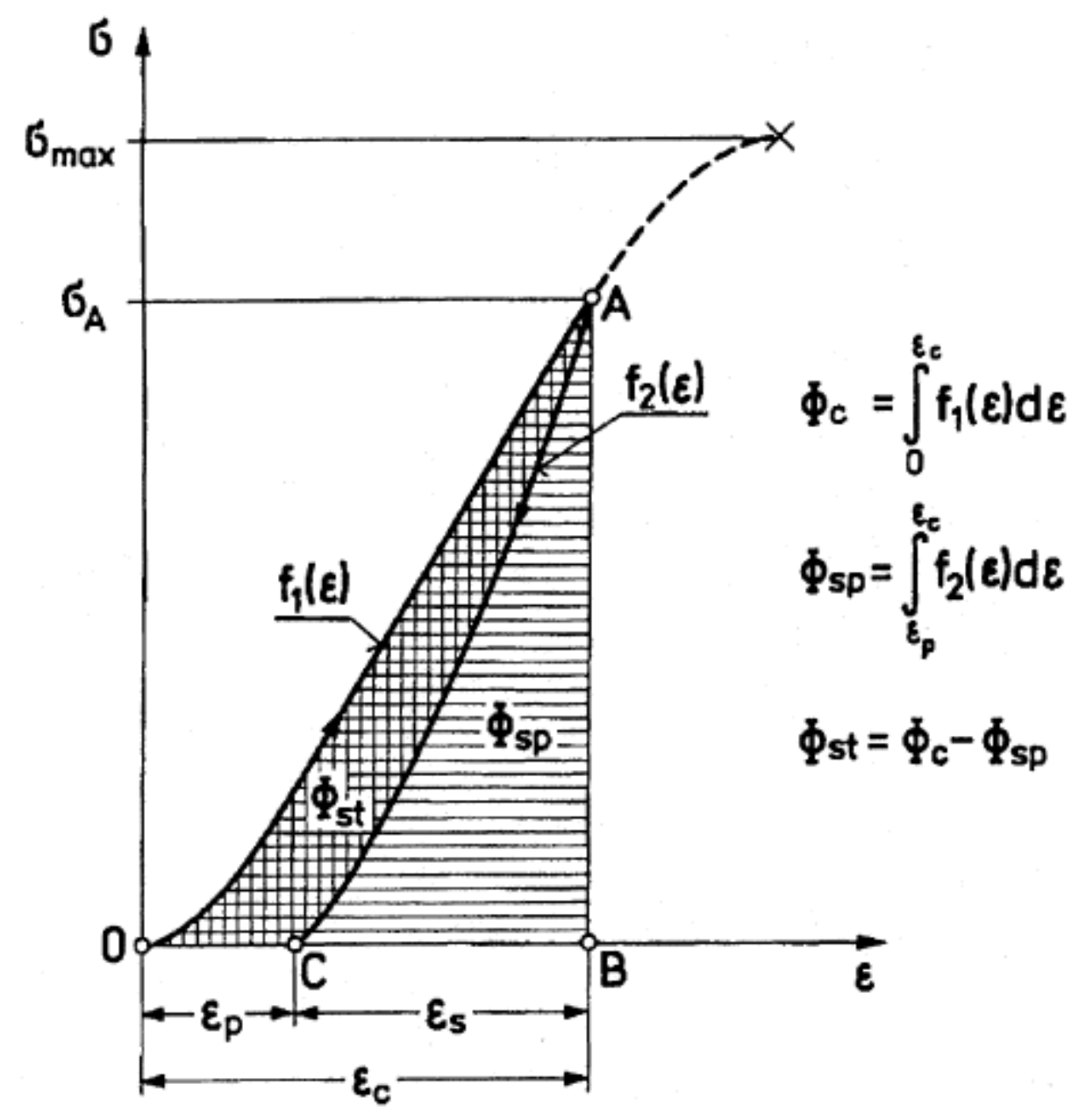

Figura 13 - Gráfico $\sigma \times \varepsilon$ com indicação das energias de deformação acumulada no processo de compressão $\left(\phi_{c}\right)$, e as energias liberadas durante a descompressão $\left(\phi_{s t^{-}}\right.$energia dissipada na deformação plástica; $\phi_{s p^{-}}$energia elástica liberada). Quanto menor o valor da energia dissipada $\phi_{s t}$ maior o valor da energia $\phi_{s p}$ liberada (Wang \& Park, 2001).

Para os autores, quanto maior a relação $\frac{\phi_{\mathrm{sp}}}{\phi_{\mathrm{st}}}$, mais violenta a ruptura, devido ao excesso de energia disponível no sistema após o processo de ruptura. A ocorrência de rock burst depende não apenas da capacidade do maciço de concentrar ou liberar energia elástica durante a ruptura, mas também das condições gerais do maciço rochoso e sua capacidade de concentrar tensões e energia. 
Kwasinewski (1994) relaciona parâmetros de resistência e parâmetros elásticos do maciço rochoso, e define a energia potencial de deformação elástica (PES equação 1):

$$
P E S=\frac{\sigma_{c}^{2}}{2 E_{e}}
$$

Onde $\sigma_{\mathrm{c}}$ é a resistência à compressão uniaxial da rocha intacta (UCS), e $E_{e}$ é o módulo elástico tangencial durante a descompressão. A unidade de PES é $\mathrm{kJ} / \mathrm{m}^{3}$, isto é, energia por unidade de volume.

A tabela 1 apresenta valores de PES e a interpretação para correlação com o risco de rock burst.

Tabela 1 - Associação entre os valores de PES e o risco do potencial de ocorrência de rock burst (extraído de Kwasinewski, 1994)

\begin{tabular}{cc}
\hline PES $\left(\mathrm{kJ} / \mathrm{m}^{3}\right)$ & Risco \\
\hline PES $\leq 50$ & Muito baixo \\
$50 \leq \mathrm{PES} \leq 100$ & Baixo \\
$100 \leq \mathrm{PES} \leq 150$ & Moderado \\
$150 \leq \mathrm{PES} \leq 200$ & Alto \\
PES $>200$ & Muito alto
\end{tabular}

Outros autores, como Potvin et al. (2000) e Zhu et al. (2010), reconhecem a taxa de liberação de energia como fundamental para o desenvolvimento de rock bursts e processos correlatos (figura 14). 


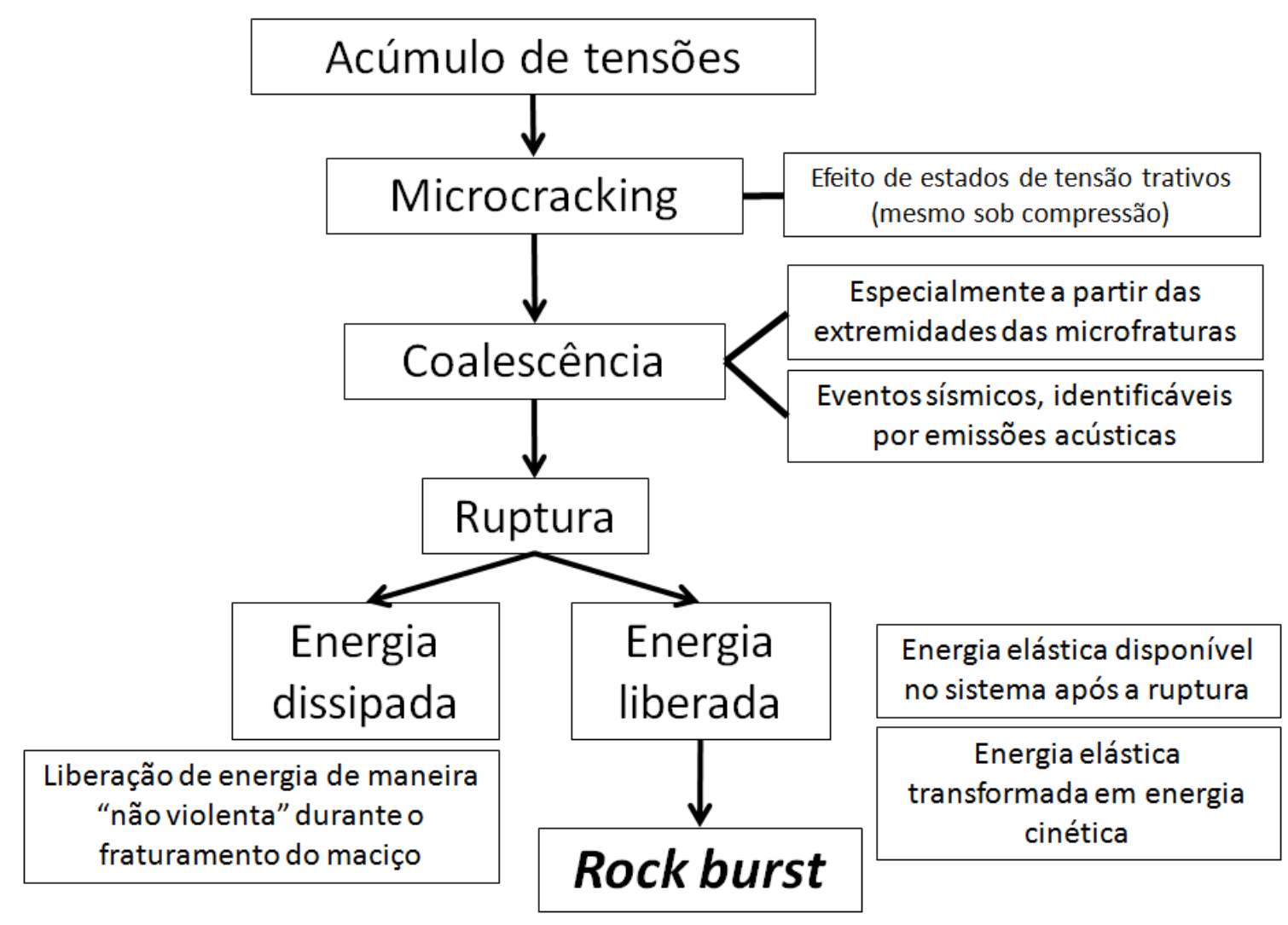

Figura 14 - Síntese do desenvolvimento de rock burst a partir dos diversos temas abordados nos itens anteriores, e suas relações: o problema tem início na concentração de tensões, seguido pelo aparecimento de microfraturas. Estas se propagam, e a rocha rompe. Caso a energia seja dissipada em processos de deformação plástica, ela é perdida na forma de calor. Caso a energia seja totalmente liberada durante o processo de ruptura, a energia elástica é transformada em energia cinética, levando ao fenômeno de rock burst.

Embora muitos estudos a respeito do papel da energia elástica, seus meios de acumulação e liberação/dissipação, os parâmetros que controlam o acúmulo e liberação de energia ainda não foram totalmente compreendidos, e a resistência à compressão uniaxial ainda é o parâmetro mais utilizado (Diederichs, 2014). 


\section{MATERIAIS E MÉTODOS}

\subsection{TEORIA DA ELASTICIDADE}

Grande parte dos problemas de engenharia pode ser formulada através dos princípios gerais da Mecânica do Contínuo (Timoshenko \& Goodier, 1970; Gurtin, 1981). Este ramo da mecânica trata a matéria como sendo um meio contínuo, sem vazios interiores, desconsiderando sua estrutura molecular. 0 conceito de "continuum" permite a definição do ponto geométrico (de volume igual a zero), por um limite tal como na definição de derivadas no cálculo infinitesimal (Ribeiro, 2004). Assim, na Mecânica do Contínuo os princípios da física são escritos sob a forma de equações diferenciais. Os efeitos da constituição interna molecular dos materiais são levados em conta de forma através das equações constitutivas do material.

No presente estudo, as análises e considerações gerais sobre o comportamento dos materiais partirão da premissa que os maciços rochosos se comportam como materiais idealmente elástico-lineares, isto é, apresentam deformação proporcional ao esforço aplicado sobre eles, e esta deformação é totalmente reversível após a remoção dos esforços.

Como foi apresentado no item 3.2.2, os maciços rochosos apresentam irregularidades naturais e anisotropias, e não são perfeitamente elásticos, havendo comportamento semiplástico durante a geração e propagação de microfraturas. No entanto, a aproximação para materiais perfeitamente elásticos permite uma grande simplificação nos cálculos, sem desviar consideravelmente do comportamento real, especialmente para o caso de 
rochas sãs e maciços rochosos de muito boa qualidade, hipótese assumida neste trabalho.

Tais aproximações têm se mostrado bastante satisfatórias, e resultam em considerável ganho de tempo na confecção de modelos aplicados em projetos de engenharia (Davis \& Selvadurai, 1996).

Serão introduzidos, de maneira resumida, os principais conceitos da teoria da elasticidade utilizados neste trabalho. Uma base teórica mais completa pode ser encontrada no Apêndice 1.

\subsubsection{Tensões}

O conceito de "tensão" é similar ao conceito de "pressão", pois ambas lidam com forças de superfície atuando sobre uma unidade de área. A relação é simples, definida pela equação 2:

$$
\vec{\sigma}=\frac{\vec{F}}{A}
$$

Em que $\vec{\sigma}$ é o vetor tensão, resultado da razão da atuação do vetor força $\vec{F}$ sobre uma área $A$.

Os sólidos reais dificilmente estão sujeitos à atuação de uma única componente de força. Um ponto inserido no interior de um maciço rochoso está sujeito à aplicação de forças em todas as direções, que, combinadas, definem

o estado de tensões. O estado de tensões pode ser representado pela matriz de tensões (equação 3).

$$
\boldsymbol{\sigma}=\left[\begin{array}{ccc}
\sigma_{x} & \tau_{x y} & \tau_{x z} \\
& \sigma_{y} & \tau_{y z} \\
& & \sigma_{z}
\end{array}\right]
$$


em que $\sigma_{i}$ são as componentes de tensão normal, e $\tau_{i j}$ são as componentes de tensão cisalhante. A matriz $\boldsymbol{\sigma}$ é simétrica, pelo princípio do equilíbrio de forças.

O conjunto de estados de tensão no espaço define o campo de tensões. Se os estados de tensão forem iguais em todos os pontos do espaço, então o campo de tensões é homogêneo, e pode ser definido por uma matriz de tensões com elementos constantes (equação 4). Se, por outro lado, os estados de tensão forem variáveis no espaço, então o campo de tensões é heterogêneo, e pode ser definido por uma matriz de tensões com elementos variáveis (equação 5).

$$
\begin{aligned}
& \boldsymbol{\sigma}=\left[\begin{array}{lll}
a & b & c \\
& d & e \\
& & f
\end{array}\right] \\
& \boldsymbol{\sigma}=\left[\begin{array}{ccc}
a y^{2} & b x^{2} & c \\
& d x & -2 b x z \\
& & e
\end{array}\right]
\end{aligned}
$$

\subsubsection{Deformações}

O conceito de deformação pode ser entendido como a variação na configuração dos pontos de um corpo no espaço. Sendo assim, um corpo é deformado de seu estado inicial se ocorre variação na relação entre a configuração original e final de qualquer um dos pontos que o compõem.

Tomemos um ponto no espaço, cuja posição é descrita por coordenadas cartesianas $P=P(X, Y, Z)$, no estado inicial, ou indeformado. Com a deformação, este ponto sofre um deslocamento $\vec{u}$, e suas coordenadas passam então a ser $p=p(x, y, z)$, no estado final, ou deformado.

O deslocamento do ponto é descrito como: 


$$
\vec{u}=\left[\begin{array}{l}
u_{x} \\
u_{y} \\
u_{z}
\end{array}\right]=\left[\begin{array}{l}
p_{x}-P_{X} \\
p_{y}-P_{Y} \\
p_{z}-P_{Z}
\end{array}\right]
$$

Num corpo de dimensões e formas complexas, os deslocamentos não são necessariamente iguais em todos os pontos que o compõem. Para descrever o deslocamento nesses casos, usa-se a taxa de variação dos deslocamentos com relação aos eixos cartesianos, definindo-se, assim, a matriz de gradiente de deslocamentos:

$$
\boldsymbol{\nabla} \overrightarrow{\mathbf{u}}=\left[\begin{array}{lll}
\frac{\partial u_{x}}{\partial x} & \frac{\partial u_{x}}{\partial y} & \frac{\partial u_{x}}{\partial z} \\
\frac{\partial u_{y}}{\partial x} & \frac{\partial u_{y}}{\partial y} & \frac{\partial u_{y}}{\partial z} \\
\frac{\partial u_{z}}{\partial x} & \frac{\partial u_{z}}{\partial y} & \frac{\partial u_{z}}{\partial z}
\end{array}\right]
$$

A deformação pode ser descrita como a relação entre as coordenadas do ponto no estado deformado em relação às coordenadas deste mesmo ponto no estado indeformado:

$$
x=f(X)
$$

A deformação pode ser descrita também de outras várias maneiras. Means (1976) faz uma análise mais criteriosa e completa das possíveis relações entre os estados indeformado e deformado e a relação com o deslocamento. Algumas delas são apresentadas no Apêndice 1 .

No estudo apresentado neste trabalho, será utilizado o conceito das deformações infinitesimais, isto é, deformações cujas quantidades absolutas são muito pequenas diante da dimensão do corpo analisado. Para o caso das deformações infinitesimais, as deformações estão relacionadas com os deslocamentos da seguinte forma: 


$$
\boldsymbol{\varepsilon}=\frac{1}{2}\left(\nabla \overrightarrow{\boldsymbol{u}}+\nabla \overrightarrow{\boldsymbol{u}}^{t}\right)
$$

Resultando na matriz de deformações infinitesimais $\varepsilon$ (Means, 1976):

$$
\boldsymbol{\varepsilon}=\left[\begin{array}{ccc}
\frac{\partial u_{x}}{\partial x} & \frac{1}{2}\left(\frac{\partial u_{x}}{\partial y}+\frac{\partial u_{y}}{\partial x}\right) & \frac{1}{2}\left(\frac{\partial u_{x}}{\partial z}+\frac{\partial u_{z}}{\partial x}\right) \\
\frac{1}{2}\left(\frac{\partial u_{y}}{\partial x}+\frac{\partial u_{x}}{\partial y}\right) & \frac{\partial u_{y}}{\partial y} & \frac{1}{2}\left(\frac{\partial u_{y}}{\partial z}+\frac{\partial u_{z}}{\partial y}\right) \\
\frac{1}{2}\left(\frac{\partial u_{z}}{\partial x}+\frac{\partial u_{x}}{\partial z}\right) & \frac{1}{2}\left(\frac{\partial u_{z}}{\partial y}+\frac{\partial u_{y}}{\partial z}\right) & \frac{\partial u_{z}}{\partial z}
\end{array}\right]
$$

Cujos componentes podem ser simplificados, uma vez que (Jaeger, 1971):

$$
\begin{aligned}
& \varepsilon_{i}=\frac{\partial u_{i}}{\partial i} \\
& \gamma_{i j}=\gamma_{j i}=\left(\frac{\partial u_{i}}{\partial j}+\frac{\partial u_{j}}{\partial i}\right)
\end{aligned}
$$

Desta maneira, a matriz $\varepsilon$ apresentada na equação 10 pode ser reescrita da seguinte maneira:

$$
\boldsymbol{\varepsilon}=\left[\begin{array}{ccc}
\varepsilon_{x} & \frac{1}{2} \gamma_{x y} & \frac{1}{2} \gamma_{x z} \\
\frac{1}{2} \gamma_{x y} & \varepsilon_{y} & \frac{1}{2} \gamma_{y z} \\
\frac{1}{2} \gamma_{x z} & \frac{1}{2} \gamma_{y z} & \varepsilon_{z}
\end{array}\right]
$$

Esta matriz descreve o estado de deformação de um ponto no espaço, no estado deformado.

\subsubsection{Relações Constitutivas}

Tensões e deformações estão relacionadas. Isto é intuitivo: se um corpo é submetido a um esforço, se não houver forças que compensem este esforço aplicado haverá deslocamento de alguma de suas partes. Do mesmo modo, para que um corpo se deforme é necessário que atuem sobre ele forças que tirem suas partes do estado de repouso. 
Num corpo idealmente elástico, a deformação é proporcional à tensão aplicada e a relação $\sigma=f(\varepsilon)$ descreve uma reta (figura 15). O parâmetro $E$ (módulo de elasticidade, módulo de deformação ou módulo de Young) define a declividade desta reta, e representa facilidade de um corpo ser deformado, conforme uma tensão aplicada sobre ele.

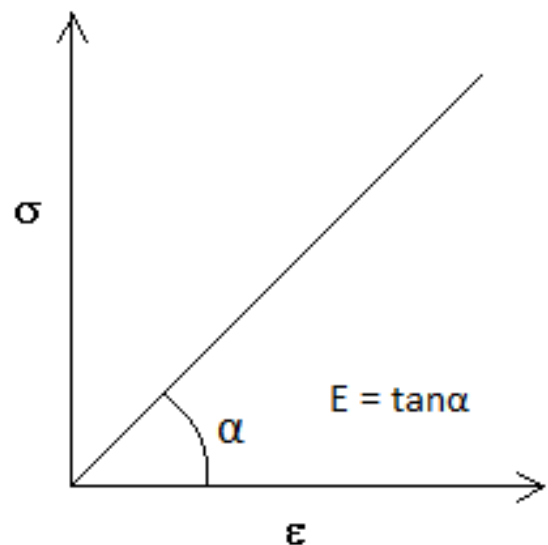

Figura 15 - Relação entre tensão $(\sigma)$ e deformação $(\varepsilon)$, para material linearelástico.

Esta relação define a Lei de Hooke:

$$
\sigma=E \varepsilon
$$

Outro parâmetro característico dos sólidos é o coeficiente de Poisson, representado pela letra grega $v(\mathrm{nu})$. Este coeficiente relaciona a deformação lateral de um corpo quando este se deforma longitudinalmente.

$$
v=\frac{\varepsilon_{\text {lat }}}{\varepsilon_{\text {long }}}
$$

A relação $\varepsilon=f(\sigma)$ pode ser escrita na forma matricial, em que a tensão e deformação são expressos pelos respectivos vetores $\vec{\sigma}$ e $\vec{\varepsilon}$ :

$$
\vec{\varepsilon}=\boldsymbol{D} \vec{\sigma}
$$


Esta é Lei geral de Hooke para sólidos elasticos isotrópicos (Timoshenko \& Goodier, 1970; Ramsay \& Lisle, 2000; Pollard \& Fletcher, 2005; Sadd, 2004), em que $\mathbf{D}$ é a matriz constitutiva na qual estão presentes os parâmetros $E$ e $v$ :

$$
\boldsymbol{D}=\left[\begin{array}{cccccc}
\frac{1}{E} & -\frac{v}{E} & -\frac{v}{E} & 0 & 0 & 0 \\
-\frac{v}{E} & \frac{1}{E} & -\frac{v}{E} & 0 & 0 & 0 \\
-\frac{v}{E} & -\frac{v}{E} & \frac{1}{E} & 0 & 0 & 0 \\
0 & 0 & 0 & \frac{2(1+v)}{E} & 0 & 0 \\
0 & 0 & 0 & 0 & \frac{2(1+v)}{E} & 0 \\
0 & 0 & 0 & 0 & 0 & \frac{2(1+v)}{E}
\end{array}\right]
$$

As relações entre tensão e deformação segundo a Lei geral de Hooke estão apresentadas no Apêndice 1 .

Neste trabalho iremos usar uma derivação das relações estudadas por Gurtin (1981) e Sadd (2005), que apresentam lei geral de Hooke utilizando outros parâmetros elásticos:, o módulo de Lamé $(\lambda)$ e módulo de cisalhamento $(\mu)$. Estes dois parâmetros são definidos por relações entre $E$ e $v$.

$$
\begin{aligned}
& \lambda=\frac{E v}{(1+v)(1-2 v)} \\
& \mu=\frac{E}{2(1+v)}
\end{aligned}
$$

O resultado é uma Lei de Hooke que utiliza relações matriciais, nas quais são inseridas as matrizes de tensão e deformação, apresentadas nos itens $1.1 \mathrm{e}$ 1.2 (equações 3 e 13).

$$
\boldsymbol{\varepsilon}=\frac{1}{2 \mu}\left(\boldsymbol{\sigma}-\frac{\lambda}{3 \mu+3 \lambda}(\operatorname{tr} \boldsymbol{\sigma}) \boldsymbol{I}\right)
$$




\subsubsection{Simplificação para um caso bidimensional}

Embora todas as situações reais sejam tridimensionais, com a presença de três eixos principais de tensão $\left(\sigma_{1}, \sigma_{2}, \sigma_{3}\right)$ e três eixos principais de deformação $\left(\varepsilon_{1}, \varepsilon_{2}, \varepsilon_{3}\right)$, no caso de estudos para uma escavação contínua, cuja seção é constante em praticamente sua totalidade, é possível criar uma simplificação para um modelo bidimensional.

No entanto, a passagem de um modelo tridimensional para bidimensional não é realizado apenas zerando ou ignorando os termos matriciais com índice 3 (Jaeger et al., 2007).

O modelo bidimensional é um caso "especial" de relação tensão-deformação, e pode apresentar, de maneira geral, dois tipos (Hoek \& Brown, 1980a; Ramsay \& Lisle, 2000; Jaeger et al., 2007):

- Tensão plana: caso em que uma placa tem forças aplicas nas suas arestas, e a superfície plana é livre, permitindo alívio de tensões. Nesta situação, pode ocorrer contração/expansão na direção ortogonal ao plano da placa.

- Deformação plana: caso em que a deformação é zero em um dos eixos $(\mathrm{x}, \mathrm{y}, \mathrm{z})$. Para que isso aconteça, é preciso que haja neste eixo uma tensão atuante de modo a compensar o Efeito Poisson ${ }^{3}$ provocado pelas deformações nas outras direções.

O caso da escavação subterrânea de seção transversal constante se aproxima da idealização de deformação plana. Todas as deformações só ocorrerão num plano, o da própria seção transversal. Na direção ortogonal a esse plano,

\footnotetext{
${ }^{3}$ Deformação lateral induzida pela deformação axial.
} 
assume-se que as deformações serão "estancadas" pela presença do maciço rochoso.

Matematicamente, os casos de tensão plana e deformação plana são descritos a partir de uma simplificação da matriz constitutiva D (equação 17).

$$
\begin{aligned}
& \boldsymbol{D}=\frac{E}{1-v^{2}}\left[\begin{array}{llc}
1 & v & 0 \\
v & 1 & 0 \\
0 & 0 & \frac{(1-v)}{2}
\end{array}\right] \text { (tensão plana) } \\
& \boldsymbol{D}=\frac{E}{1-v-2 v^{2}}\left[\begin{array}{ccc}
(1-v) & v & 0 \\
v & (1-v) & 0 \\
0 & 0 & \frac{(1-2 v)}{2}
\end{array}\right] \text { (deformação plana) }
\end{aligned}
$$

\subsubsection{Energia elástica de deformação}

A energia elástica é o trabalho realizado por unidade de volume durante a compressão de um sólido elástico (figura 16).

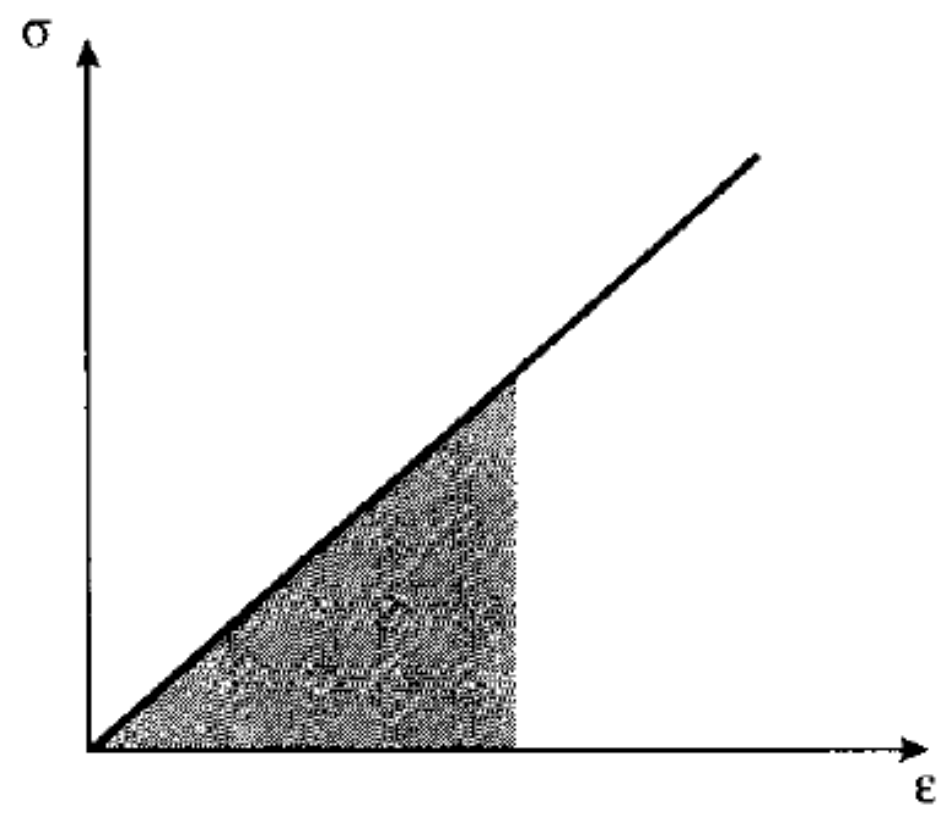

Figura 16 - Gráfico $\sigma \times \varepsilon$. A área sob o gráfico define a energia elástica do trecho deformado. 
A energia elástica é a área sob o gráfico, representada pela equação 23:

$$
W=\int_{0}^{\varepsilon_{f}} \sigma d \varepsilon
$$

Para o caso dos materiais perfeitamente elástico-lineares (onde a curva tensão x deformação é uma reta), a equação 24 pode ser simplificada para a equação 24:

$$
W=\frac{1}{2}\left(\varepsilon_{f}-\varepsilon_{0}\right) \cdot \sigma
$$

A equação 24 pode ainda ser reescrita em termos matriciais conforme a equação 25 (Davis \& Selvadurai, 1996).

$$
\boldsymbol{W}=\frac{1}{2} \operatorname{tr}(\boldsymbol{\sigma \varepsilon})
$$

Como assumimos que os materiais são sempre elástico-lineares, podemos descrever a energia elástica em função apenas da tensão e dos parâmetros elásticos $E$ e $v$, conforme se apresenta na equação 26 (Sadd, 2004):

$$
W(\sigma)=\frac{1+v}{2 E} \sigma_{i j} \sigma_{i j}-\frac{v}{2 E} \sigma_{j j} \sigma_{k k}
$$

\subsection{TENSÕES AO REDOR DE ESCAVAÇÕES SUBTERRÂNEAS}

Uma região do maciço rochoso, em profundidade, está submetida a esforços gerados pela somatória da carga litostática e das tensões tectônicas. Podemos assumir que, se este maciço for isotrópico e homogêneo, a região em estudo está sujeita a um campo de tensões homogêneo, em que todos os pontos estão sob o mesmo estado de tensões.

A realização de escavações em rocha resulta, naturalmente, em modificações no campo de tensões atuantes naquela região do espaço do maciço rochoso, 
de modo que um novo campo de tensões é definido nas proximidades imediatas da abertura (Jaeger, 1972; Hoek \& Brown, 1980a; Hoek, 2007). A explicação fundamental para este fenômeno é a ausência de tensões atuantes perpendiculares à superfície da rocha na borda da escavação (Pollard \& Fletcher, 2005).

Isto faz com que, nesta região, atuem somente tensões paralelas à superfície escavada. Este efeito vai se reduzindo gradualmente no sentido do interior do maciço. Esta redistribuição das orientações das tensões principais cria um campo de tensões heterogêneo.

As orientações das tensões principais nas proximidades da abertura no meio de um maciço rochoso tensionado podem ser representadas na forma de trajetórias das tensões principais (Hoek \& Brown, 1980a; Ramsay \& Lisle, 2000), cujas linhas representam as variações na orientação de $\sigma_{1}$ ao longo do espaço.

Hoek \& Brown (1980a) fazem uma analogia entre as linhas das trajetórias das tensões principais e o fluxo laminar de um rio, para o entendimento qualitativo da distribuição das tensões.

Um maciço rochoso isotrópico submetido a um campo de tensões homogêneo irá apresentar linhas totalmente paralelas à orientação de $\sigma_{1}$, como um rio cuja água corre sem sofrer distúrbios. No entanto, se o maciço rochoso deixa de ser perfeitamente contínuo ou isotrópico, as linhas deixarão de ser perfeitamente paralelas. No caso da realização de uma abertura subterrânea, a própria escavação funciona como obstáculo para o "fluxo" das tensões, da mesma 
maneira que um pilar em um rio, forçando as linhas de fluxo a se rearranjarem nas suas proximidades imediatas.

A figura 17 apresenta uma síntese da variação das orientações das tensões principais nas proximidades de uma abertura circular num maciço rochoso e a representação das trajetórias de tensões nesta situação.

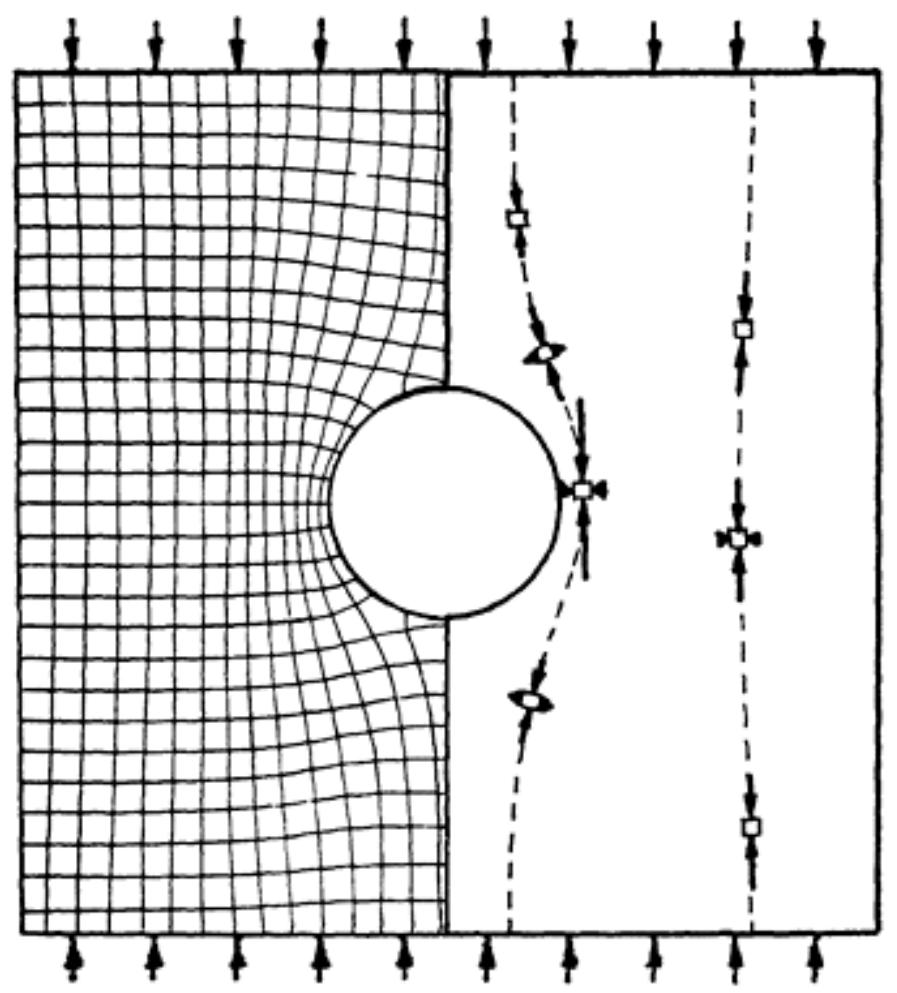

Figura 17 - Tensões ao redor de uma abertura circular, com tensão regional máxima atuando na vertical. Notar como as orientações das tensões principais locais variam suas orientações ao redor da abertura. No lado direito da figura, alguns estados de tensão são representados. A heterogeneidade do campo de tensões pode ser verificada pela diferença entre os valores e orientações destes estados de tensão. (Hoek \& Brown, 1980a). 


\subsubsection{Redistribuição de tensões e deformações: método analítico}

\subsubsection{Tensões}

Embora a analogia de Hoek \& Brown seja interessante para determinar a distribuição das tensões de maneira qualitativa, é preciso quantificar as tensões para, assim, determinar qual o grau de incremento ou redução dos esforços aplicados nos entornos da abertura.

O conjunto de equações mais antigo para a solução do cálculo bidimensional das tensões ao redor de aberturas circulares em material contínuo, homogêneo, isotrópico e linear-elástico é conhecido como equações de Kirsch, desenvolvidas por Ernst Gustav Kirsch em 1898 (Kirsch, 1898). Estas equações usam o sistema de coordenadas polares, e são usadas para o cálculo das tensões em um ponto em função da distância $r$ do centro da abertura (que é a origem do sistema de coordenadas polares neste caso) e do ângulo $\theta$ (figura 18). 


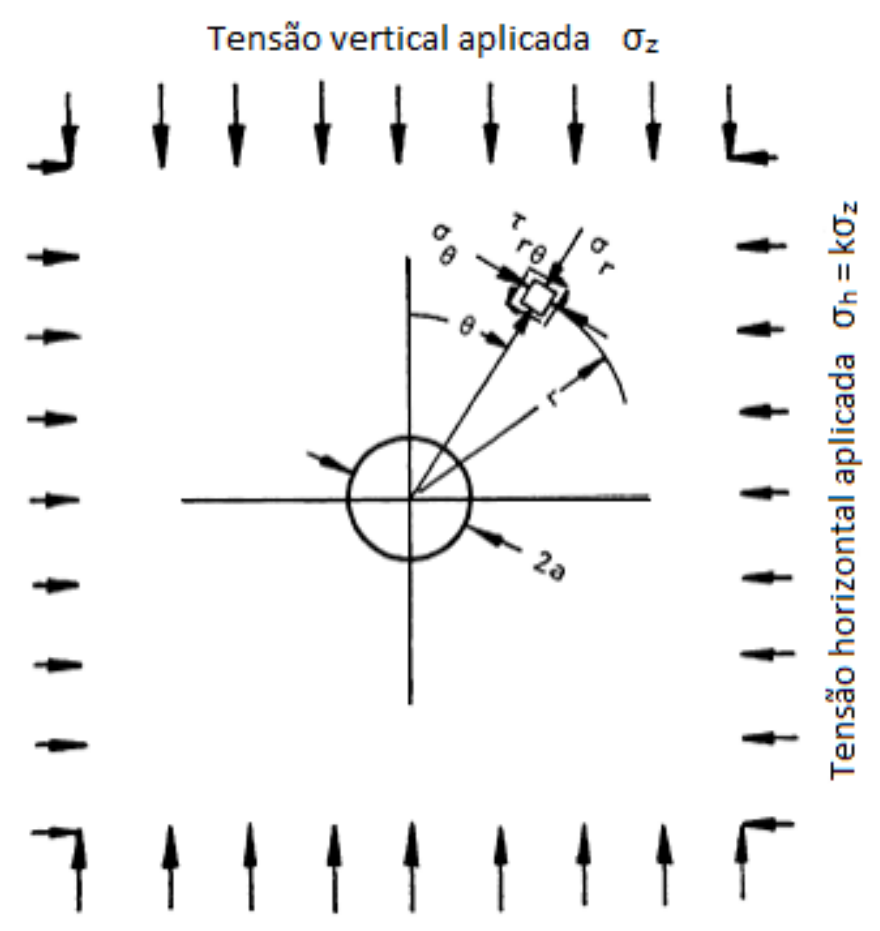

Figura 18 - Representação esquemática dos parâmetros usados na solução de Kirsch em coordenadas polares (Hoek \& Brown, 1980a).

As equações 27 a 29 determinam as tensões no ponto $(r, \theta)$ :

$$
\begin{aligned}
& \sigma_{r}=\frac{1}{2} \sigma_{z}\left((1+k)\left(1-\frac{a^{2}}{r^{2}}\right)+(1-k)\left(1-\frac{4 a^{2}}{r^{2}}+\frac{3 a^{4}}{r^{4}}\right) \cos 2 \theta\right) \\
& \sigma_{\theta}=\frac{1}{2} \sigma_{z}\left((1+k)\left(1+\frac{a^{2}}{r^{2}}\right)-(1-k)\left(1+\frac{3 a^{4}}{r^{4}}\right) \cos 2 \theta\right) \\
& \tau_{r \theta}=\frac{1}{2} \sigma_{z}\left(-(1-k)\left(1+\frac{2 a^{2}}{r^{2}}-\frac{3 a^{4}}{r^{4}}\right) \operatorname{sen} 2 \theta\right)
\end{aligned}
$$

Sendo $\sigma_{r}$ a tensão radial, $\sigma_{\theta}$ a tensão tangencial, $\tau_{r \theta}$ a tensão cisalhante, $\sigma_{z}$ a tensão vertical aplicada, $\sigma_{h}$ a tensão horizontal aplicada, $\mathrm{k}=\frac{\sigma_{\mathrm{h}}}{\sigma_{\mathrm{z}}}, a \circ$ raio da escavação, $r$ e $\theta$ as coordenadas polares. 


\subsubsection{Considerações sobre as equações apresentadas:}

Segundo as equações 27 a 29, as tensões ao redor de uma abertura circular dependem da magnitude das tensões aplicadas (definidas pelos parâmetros $\sigma_{z}$ e $k$ ) e da geometria da escavação (que é definida pelo parâmetro $a$ ).

As constantes elásticas $E$ e $v$ não estão inclusas nos cálculos, ou seja, os padrões de distribuição de tensões são independentes do tipo de material usado, contanto que ele seja elástico-linear.

Também é indiferente o raio da escavação: note-se que em nenhuma das equações descritas acima o raio do túnel, $a$, é um parâmetro independente, estando sempre associado à razão $\mathrm{a} / \mathrm{r}$. Isto significa que ao redor da escavação os valores de concentração de tensão (quantas vezes o valor de tensão aumenta ou reduz em relação ao campo de tensões original) independem do valor absoluto do raio do túnel. Os mesmos níveis de concentração de tensões serão induzidos em um túnel de $1 \mathrm{~m}$ de diâmetro e em um túnel de $10 \mathrm{~m}$ de diâmetro, escavados em um mesmo material elástico (Hoek \& Brown, 1980a).

Nos limites da escavação (na borda do túnel), como $r=a$, então $\sigma_{r}=0$ e $\tau_{r \theta}=0$. Neste caso, a equação da tensão tangencial $\left(\sigma_{\theta}\right)$, a única atuante na superfície, será:

$$
\sigma_{\theta}=\sigma_{z}((1+k)-2(1-k) \cos 2 \theta)
$$

A variação de tensões tangenciais resultantes $\left(\sigma_{\theta}\right)$ nos limites da escavação, nos pontos $\theta=0^{\circ} ; 180^{\circ}$ e $\theta=90^{\circ} ; 270^{\circ}$ para razões de tensões aplicadas $0<k<1$, é apresentada na figura 19: 


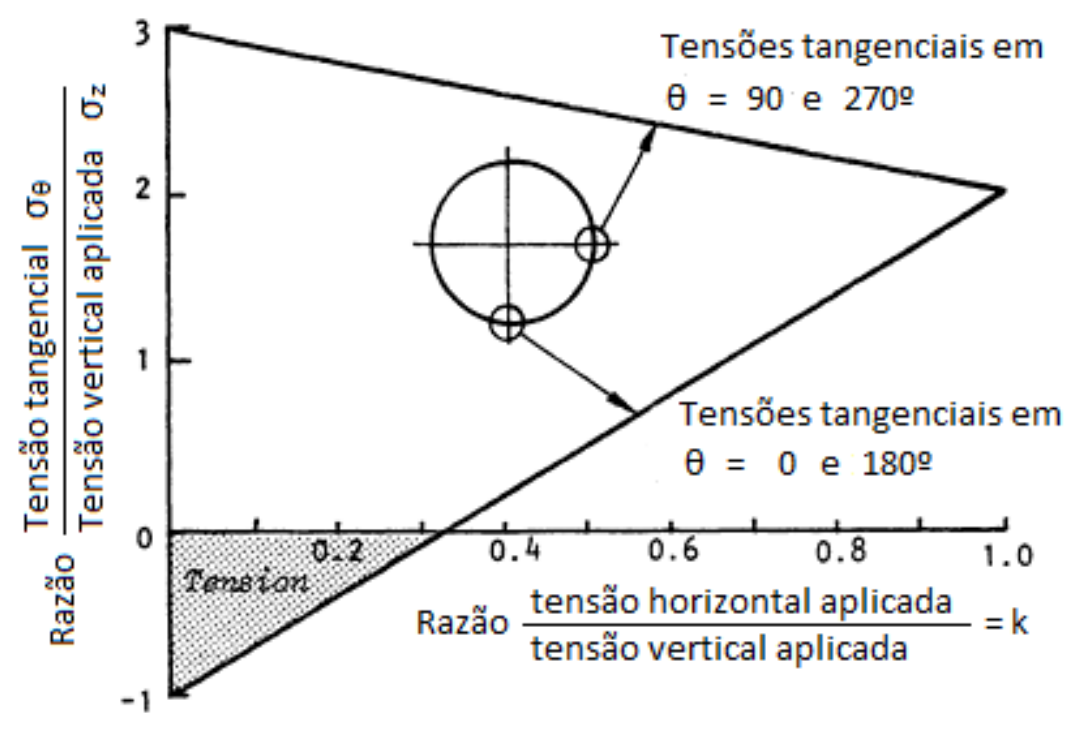

Figura 19 - Variações de tensão tangencial $\left(\sigma_{\theta}\right)$ resultante com a variação da razão $\mathrm{k}$ das tensões aplicadas.

O gráfico apresentado na figura 19 indica que (Hudson \& Harrison, 1997):

- independente do estado de tensões aplicado sobre o maciço, a execução de uma abertura subterrânea irá resultar em concentração de tensões.

- num regime uniaxial $(k=0)$, a concentração máxima de tensões é 3 (compressiva) nos pontos $\theta=90^{\circ} ; 270^{\circ}$, e a mínima é -1 (trativa) nos pontos $\theta=0^{\circ} ; 180^{\circ}$.

- em regime hidrostático $(k=1)$, a concentração de tensões é 2 ao redor de todo o limite da escavação.

- haverá tensão trativa nos limites da escavação se $k<\frac{1}{3}$.

A figura 20 indica a variação da concentração de tensões para o caso uniaxial $(k=0)$ ao longo da distância (Hoek \& Brown, 1980a). Observe-se que a influência da concentração de tensões passa a ser desprezível apenas após $r / a=3$. 


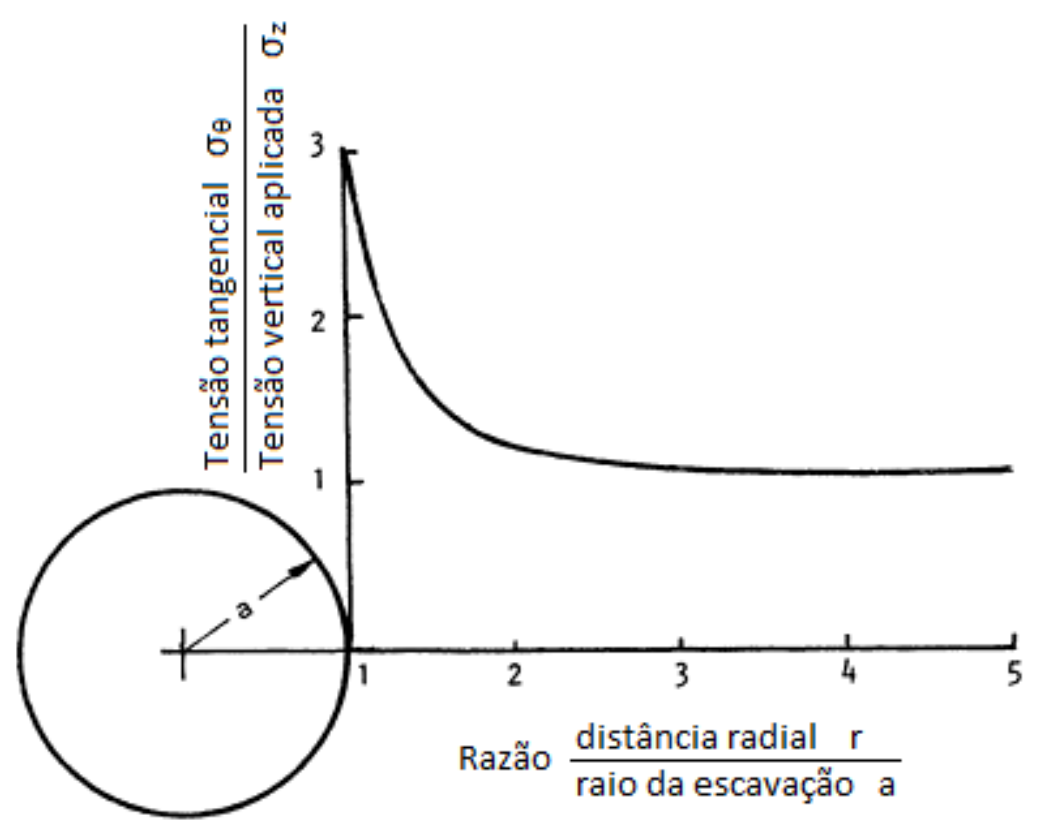

Figura 20 - Variações da concentração de tensão $\left({ }^{\sigma_{\theta}} / \sigma_{z}\right)$ com a distância em relação ao centro da escavação.

\subsubsection{Deslocamentos ao redor das escavações}

Os deslocamentos podem ser entendidos como variações nas posições dos pontos que compõem um corpo no espaço, e são associados à deformação a qual o corpo é submetido. Sendo assim, um corpo é deformado de seu estado inicial se ocorre variação na relação entre o posicionamento original e final (isto é, deslocamento) de qualquer um dos pontos que o compõem.

Ao redor de aberturas subterrâneas, é natural imaginar a ocorrência de deslocamentos, uma vez que o estado natural do maciço é modificado com a inclusão de um vazio. O maciço rochoso, tensionado, irá se acomodar, deformando-se e tendendo a ocupar o vazio criado, gerando deslocamentos nessa direção. 
De maneira similar às equações de Kirsch para tensões, podem ser também apresentadas as equações de deslocamentos induzidos por uma escavação circular, também na notação do sistema polar de coordenadas (Brady \& Brown, 1993; modificado por Unlu \& Gercek, 2003):

$$
\begin{aligned}
& u_{r}=\frac{-\sigma_{z}(1+v)}{2 E} \frac{a^{2}}{r}\left((1+k)-(1-k)\left(4(1-v)-\frac{a^{2}}{r^{2}}\right) \cos 2 \theta\right) \\
& u_{\theta}=\frac{-\sigma_{z}(1+v)}{2 E} \frac{a^{2}}{r}\left((1-k)\left(2(1-2 v)+\frac{a^{2}}{r^{2}}\right) \operatorname{sen} 2 \theta\right)
\end{aligned}
$$

Sendo $u_{r}$ o deslocamento radial, $u_{\theta} o$ deslocamento tangencial, $\sigma_{v}$ a tensão vertical aplicada, $k$ a razão $\frac{\sigma_{\mathrm{h}}}{\sigma_{\mathrm{z}}}, a$ o raio do túnel, $E$ o módulo de elasticidade, $v$ o coeficiente de Poisson, $r$ e $\theta$ as coordenadas polares.

As equações 31 e 32 apresentam consequências interessantes: de início, notase que o raio do túnel, $a$, influencia a magnitude de deslocamentos (no primeiro termo está descrita a razão $\mathrm{a}^{2} / \mathrm{r}$ ). Além disso, diferentemente das tensões, os deslocamentos são dependentes dos parâmetros elásticos: módulo de elasticidade $(E)$ e coeficiente de Poisson $(v)$.

Outra consequência notável é que em um regime hidrostático (i.e. $k=1$ ) o deslocamento tangencial $u_{\theta}$ é igual a zero.

\subsubsection{Redistribuição das tensões: método numérico}

No item 4.2.1 foram realizadas considerações sobre a redistribuição das tensões e deformações ao redor da forma geométrica mais simples para uma abertura subterrânea, que é uma cavidade cilíndrica de seção circular. As equações apresentadas são, então, as expressões mais simples possíveis. 
Embora o caso analisado no presente trabalho seja exatamente o caso mais simples, que poderia ser analisado diretamente por meio de cálculo analítico, as obras de engenharia civil e engenharia de minas lidam com escavações cujas seções apresentam geometrias mais complexas. Pretende-se obter uma metodologia que pode ser aplicada para qualquer geometria da seção transversal. Nesses casos, o cálculo da distribuição de tensões e deslocamentos ao redor da abertura, por consequência, também se torna muito mais complexo. Por este motivo, somando-se a presença de descontinuidades e heterogeneidades do maciço, métodos de soluções analíticas tornam-se inviáveis, sendo necessário o uso de métodos especiais para o tratamento dos dados nestes casos, que são os métodos de cálculo numérico.

Para solucionar este problema, diversos métodos computacionais foram desenvolvidos, e resultam em aproximações satisfatórias das condições de redistribuição de tensões e deslocamentos ao redor das aberturas subterrâneas.

Os métodos computacionais são divididos em duas categorias: métodos de discretização de superfície, e métodos de discretização de domínios. Hoek (2007) descreve ainda a possibilidade de se trabalhar com métodos híbridos, que otimizam as vantagens e reduzem as desvantagens dessas duas categorias.

\subsubsection{Discretização de Superfície}

Apenas os limites da escavação (i.e. as paredes do túnel) são discretizados, sendo divididos em elementos. O restante do maciço rochoso é considerado matematicamente como um infinito contínuo. 
A força do método é justamente esta simplificação: menos elementos são utilizados - apenas os limites da escavação -, favorecendo o rápido processamento computacional. Por outro lado, como o restante do maciço é considerado como contínuo e infinito, é bastante complicado modelar possíveis descontinuidades e heterogeneidades.

\subsubsection{Discretização de Domínios}

O interior do maciço rochoso é dividido em elementos geometricamente simples, cada um deles apresentando propriedades pré-definidas. A modelagem do maciço rochoso é obtida a partir do resultado do comportamento individual de cada elemento bem como da interação entre os diversos elementos, o que permite a caracterização de maciços rochosos bem mais complexos.

Por outro lado, a discretização de domínios é muito mais trabalhosa, no sentido de ser necessário estabelecer a malha de elementos que represente o maciço rochoso.

O presente trabalho não tem como objetivo a análise comparativa dos possíveis métodos numéricos. Será utilizada a metodologia de análise por meio de discretização de domínios por meio do método de elementos finitos, uma vez que o objetivo do estudo é a análise do comportamento do maciço como um todo, e não somente das superfícies de escavação.

\subsection{MÉTODO DOS ELEMENTOS FINITOS}

O método dos elementos finitos é um método de análise que consiste da modelagem do espaço em elementos discretos que interagem mutuamente e 
posterior confecção e resolução de um modelo matemático constituído por um conjunto de equações diferenciais (Ribeiro, 2004), aplicado nesse espaço. No caso em estudo, o espaço analisado é a região próxima a uma abertura subterrânea, e será analisada segundo modelos matemáticos de mecânica do contínuo (Brady \& Brown, 1993).

Na prática, a análise por meio do método de elementos finitos consiste em três etapas principais (Potts \& Zdravkovic, 1999; Ramsay \& Lisle, 2000; Roylance, 2001):

1- Pré-processamento: o usuário constrói um modelo do universo (ou domínio) em estudo, cuja geometria é dividida em várias regiões discretizadas, ou "elementos" de geometria simples (figura 21), interconectados em pontos denominados "nós". Alguns nós terão deslocamentos definidos, outros terão carregamentos (forças aplicadas) definidos - o que caracteriza as "condições de contorno" (figura 22). Estes modelos podem ser extremamente trabalhosos para serem preparados, e códigos comerciais possuem interfaces gráficas amigáveis para ajudar nesta etapa. 


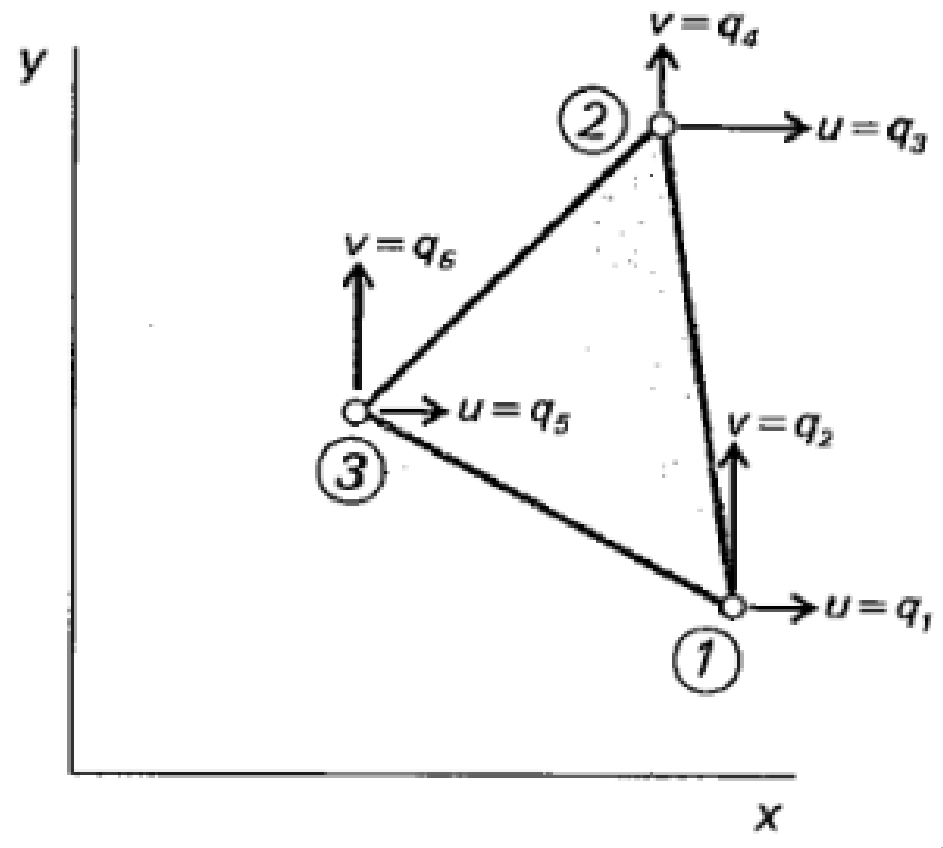

Figura 21 - Representação de um elemento triangular com três nós $(1,2,3)$, com indicação dos deslocamentos nodais $u$ e $v$, que são inseridos no vetor de deslocamentos como $u_{i}$. 


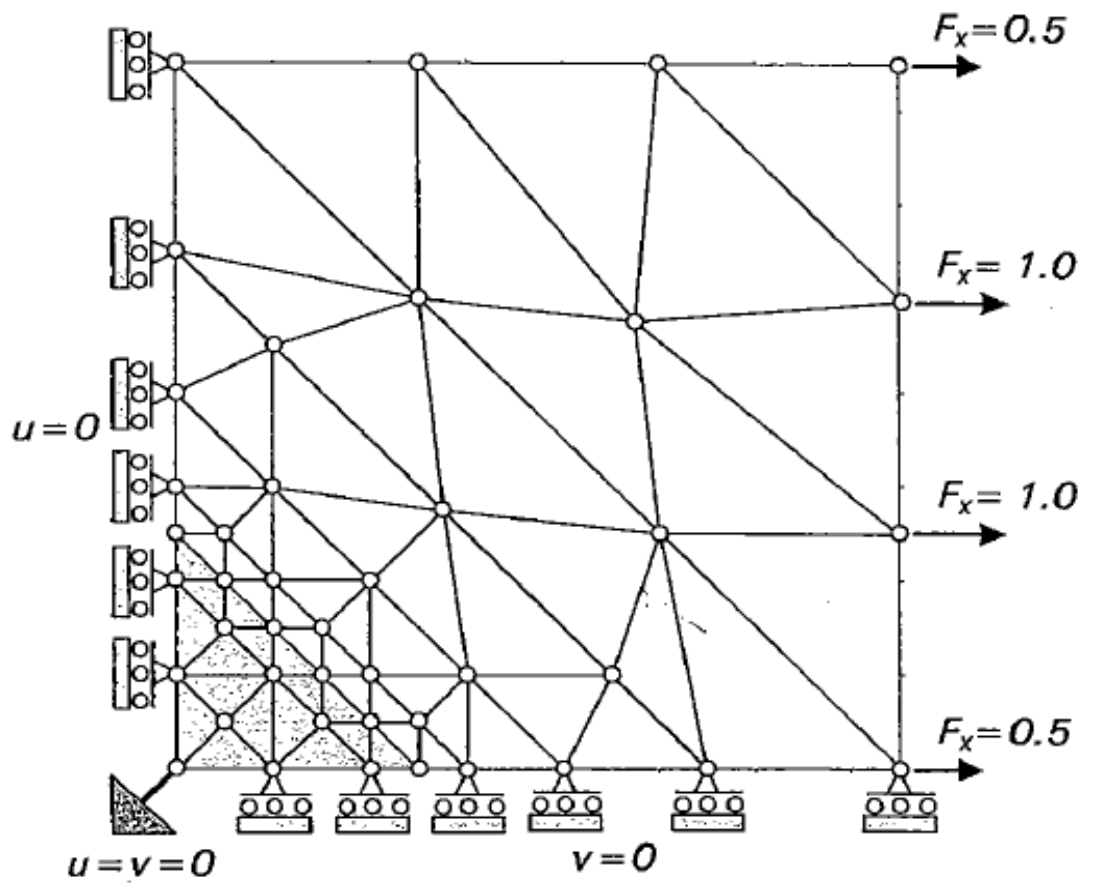

Figura 22 - Domínio discretizado, com diversos elementos justapostos, conectados pelos seus nós. Alguns nós apresentam deslocamentos ou forças pré-estabelecidos, que caracterizam as condições de contorno do domínio.

2- Análise: o conjunto montado na etapa de pré-processamento é usado para o código de elementos finitos propriamente dito, que constrói e resolve um sistema de equações algébricas não lineares. No caso de estudos de problemas relacionados a mecânica de rochas, essas equações estão associadas à teoria da elasticidade, com relações entre grandezas como forças, deslocamentos, deformações e tensões.

Nesta etapa, a sequência lógica de resolução tem início na aplicação dos cálculos para cada elemento, para em seguida unir os resultados em um conjunto global.

3- Pós-processamento: é o resultado apresentado. O resultado da análise é, na verdade, uma planilha ou matriz que listam deslocamentos e tensões em 
posições definidas no modelo. Os programas de computador que projetam interfaces mais amigáveis permitem criar isolinhas para visualização mais satisfatória dos padrões e tendências.

\subsubsection{Método de cálculo}

O cálculo da determinação de forças, tensões, etc. pelo método de elementos finitos consiste, basicamente, na aplicação da teoria da elasticidade em cada um dos elementos do domínio estudado para, em seguida, combinar os resultados elementares em resultados globais.

Na realidade, os cálculos são realizados nos nós dos elementos (isto é, pontos discretos determinados nas fronteiras dos elementos). Num primeiro momento, cada nó de cada elemento é analisado em função das propriedades do elemento. Em seguida, como os nós são compartilhados por dois ou mais elementos, os resultados da análise elementar são sobrepostos, com a obtenção de uma resultante da ação de todos os elementos comuns a cada nó sobre aquele nó.

A análise do comportamento dos elementos (Roylance, 2001) é realizada na forma matricial e opera levando em conta a rigidez de cada elemento (um equivalente para uma "constante elástica"), um por vez, e então usando este conjunto de valores de rigidez para determinar as forças que estão envolvidas no sistema a partir da sua relação com os deslocamentos dos nós que conectam os elementos (Brady \& Brown, 1993; Potts \& Zdravkovic, 1999).

As condições de contorno do problema podem indicar que determinados nós tenham deslocamentos conhecidos (em geral, são nós fixos, ou imóveis). Essencialmente, as condições de contorno, colocadas dessa forma, restringem 
a liberdade do corpo em se deformar, reduzindo a informação necessária como input em certas regiões do domínio (Ramsay \& Lisle, 2000).

O método apresenta complexidades e inclui longas relações entre equações matriciais na dedução das equações utilizadas. Não será objetivo deste trabalho apresentar estas deduções, que podem ser encontradas em Brady \& Brown (1993), Potts \& Zdravkovic (1999), Ramsay \& Lisle (2000), entre outros. A seguir, será feito um breve resumo que tem como base a literatura previamente citada.

\subsubsection{Determinação dos deslocamentos}

O primeiro passo na análise de elementos finitos é a determinação dos deslocamentos nodais induzidos por forças externas. Os deslocamentos nodais u são as incógnitas na equação 33, que é um equivalente da Lei de Hooke:

$$
K \vec{u}=\vec{f}
$$

Expandindo a equação 33 para a forma matricial, ela adquire a seguinte forma:

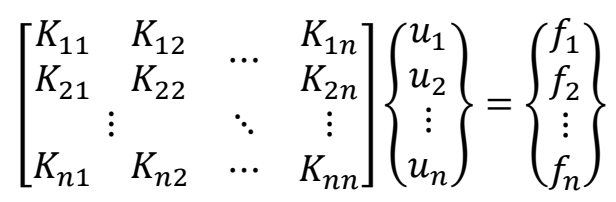

A matriz $\boldsymbol{K}$, denominada "matriz de rigidez", relaciona as forças externas aplicadas $(\vec{f})$ e deslocamentos sofridos $(\vec{u})$ em cada nó.

Nesta relação, ou as forças ou os deslocamentos devem ser conhecidos, senão criam-se mais incógnitas do que equações, e o sistema não tem solução. A forma mais comum de abordagem é tratar os deslocamentos como 
incógnitas, e utilizar forças externas aplicadas ao sistema como dado de entrada na equação.

\subsubsection{Determinação das equações elementares}

Num primeiro momento, as forças aplicadas externamente ao sistema são utilizadas na determinação de forças nodais equivalentes, resultando na equação 35:

$$
\overrightarrow{r^{e}}=K^{e} \overrightarrow{u^{e}}+\overrightarrow{f^{e}}
$$

em que $\overrightarrow{r^{e}}$ é o vetor das forças nodais equivalentes resultantes no elemento, $\overrightarrow{f^{e}}$

é o vetor de forças externas aplicadas, no elemento, $\boldsymbol{K}^{e}$ é a matriz de rigidez elementar, e $\overrightarrow{u^{e}}$ é o vetor de deslocamentos nodais elementar.

A partir da equação 35, são determinados os valores de forças e deslocamentos nos nós de um elemento, levando em consideração apenas a atuação deste elemento sobre seus nós.

\subsubsection{Determinação das equações globais}

$\mathrm{Na}$ etapa seguinte, são atribuídos a cada nó a contribuição relativa de cada elemento sobre aquele nó. Num sistema global os diversos elementos compartilham um ou mais nós, então a atuação de cada elemento deve ser somada para que se obtenha um valor resultante de forças equivalentes e deslocamento sobre cada nó.

Assume-se que deve haver equilíbrio estático em cada um dos nós analisados.

Para que isso aconteça, as forças externas globais aplicadas ao nó $\overrightarrow{f^{g}}$ devem estar balanceadas com as resultantes de forças equivalentes, $\overrightarrow{r^{g}}$. Isto é: 


$$
f_{i}^{g}=\sum r_{i}^{e}
$$

Uma vez estabelecido esse equilíbrio, é então determinada a matriz de rigidez global $\boldsymbol{K}^{g}$, criada pela sobreposição das matrizes de rigidez elementares. $\mathrm{Na}$ matriz global, as regiões que representam nós comuns aos elementos são sobrepostas, resultando em $K_{i}^{e 1}+K_{j}^{e 2}$ :

$$
\left[\begin{array}{l}
f_{x 1} \\
f_{y 1} \\
f_{x 2} \\
f_{y 2} \\
f_{x 3} \\
f_{y 3} \\
f_{x 4} \\
f_{y 4}
\end{array}\right]=\left[\begin{array}{rr:rr}
K^{\mathrm{a}} & & 0 & 0 \\
& & 0 & 0 \\
& & K^{\mathrm{a}}+K^{\mathrm{b}} & \\
\hdashline 0 & 0 & 0 & \\
0 & 0 & &
\end{array}\right]\left[\begin{array}{l}
u_{x 1} \\
u_{y 1} \\
u_{x 2} \\
u_{y 2} \\
u_{x 3} \\
u_{y 3} \\
u_{x 4} \\
u_{y 4}
\end{array}\right]+\left[\begin{array}{l}
r_{x 1} \\
r_{y 1} \\
r_{x 2} \\
r_{y 2} \\
r_{x 3} \\
r_{y 3} \\
r_{x 4} \\
r_{y 4}
\end{array}\right]
$$

Com essa equação global, são obtidos os deslocamentos resultantes em cada nó, levando em consideração a contribuição de todos os elementos que compartilham esse nó.

\subsubsection{Determinação das tensões}

Na etapa anterior foram determinados os deslocamentos nodais $\vec{u}$. A etapa seguinte vai prosseguir na determinação das deformações e tensões.

O cálculo matricial tem início na interpolação dos deslocamentos nodais para deslocamentos em um ponto qualquer do elemento triangular (figura 23).

Sejam $\overrightarrow{\mathrm{u}}$ os deslocamentos nodais e $\overrightarrow{\mathrm{q}}$ o deslocamento no ponto, de modo que: 


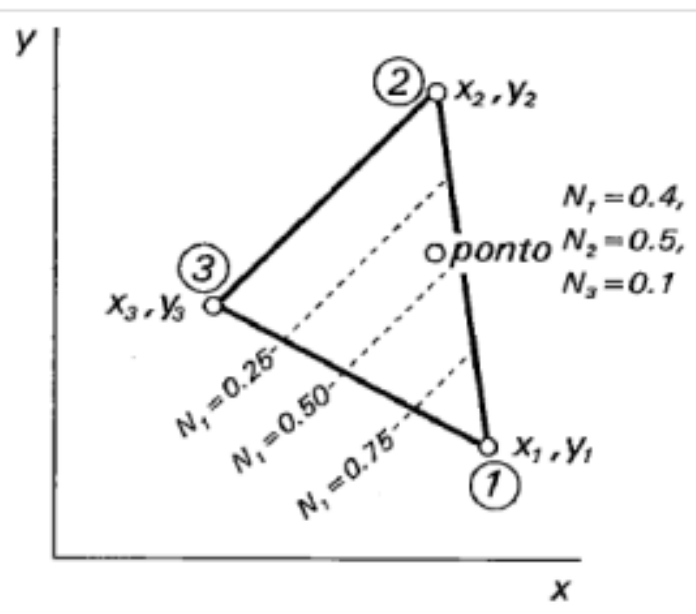

Figura 23 - Determinação de N no elemento.

O vetor $\overrightarrow{\mathrm{q}}$ pode ser decomposto em $\mathrm{q}_{\mathrm{x}}$ e $\mathrm{q}_{\mathrm{y}}$, resultando em:

$$
\begin{aligned}
& q_{x}=N_{1} u_{1}+N_{2} u_{3}+N_{3} u_{5} \\
& q_{y}=N_{1} u_{2}+N_{2} u_{4}+N_{3} u_{6}
\end{aligned}
$$

Que pode ser reescrito como:

$$
\vec{q}=\boldsymbol{N} \vec{u}
$$

Sendo $\mathrm{N}_{\mathrm{i}}$ os parâmetros de transformação para as coordenadas locais (ver Ramsay \& Lisle, 2000, p.740 e Brady \& Brown, 1993, p.183, e Potts \& Zdravkovic, 1999, p.28).

$\mathbf{N}$ é alternativamente denominada "função de forma" (shape function matrix) e tem o seguinte aspecto:

$$
\boldsymbol{N}=\left[\begin{array}{cccccc}
N_{1} & 0 & N_{2} & 0 & N_{3} & 0 \\
0 & N_{1} & 0 & N_{2} & 0 & N_{3}
\end{array}\right]=\left[\begin{array}{lll}
N_{1} & N_{2} & N_{3}
\end{array}\right] \rightarrow N_{i}=\left[\begin{array}{cc}
N_{i} & 0 \\
0 & N_{i}
\end{array}\right]
$$

Vamos agora definir a deformação em termos matriciais e baseada nos deslocamentos. Em primeiro lugar, é preciso relembrar que o conceito de deformação, conforme descrito nas equações 11 e 12, é

$\varepsilon_{x}=\frac{\partial u_{x}}{\partial x}, \varepsilon_{y}=\frac{\partial u_{y}}{\partial y}, \tau_{x y}=\frac{\partial u_{x}}{\partial y}+\frac{\partial u_{y}}{\partial x}$

Portanto, na forma matricial a deformação assume o seguinte aspecto: 


$$
[\varepsilon]=\left[\begin{array}{c}
\varepsilon_{x} \\
\varepsilon_{y} \\
\tau_{x y}
\end{array}\right]=\left[\begin{array}{c}
\frac{\partial q_{x}}{\partial x} \\
\frac{\partial q_{y}}{\partial y} \\
\frac{\partial q_{x}}{\partial y}+\frac{\partial q_{y}}{\partial x}
\end{array}\right]=\left[\begin{array}{cc}
\frac{\partial}{\partial x} & 0 \\
0 & \frac{\partial}{\partial y} \\
\frac{\partial}{\partial y} & \frac{\partial}{\partial x}
\end{array}\right]\left[\begin{array}{l}
q_{x} \\
q_{y}
\end{array}\right]
$$

Isto é,

$$
\vec{\varepsilon}=L \vec{q}
$$

Mas $\vec{q}$ foi definido acima em função de $\overrightarrow{\mathrm{u}}$ e $\mathbf{N}$, então a relação passa a ser:

$$
\vec{\varepsilon}=\boldsymbol{L} \boldsymbol{N} \vec{u}
$$

A multiplicação de $\mathbf{L}$ por $\mathbf{N}$ resulta na matriz $\mathbf{B}$, denominada strain-displacement matrix, isto é, ela transforma os deslocamentos nodais em deformação infinitesimal do elemento. A matriz B é expressa na equação 45:

$$
\boldsymbol{B}=\left[\begin{array}{cccccc}
\frac{\partial N_{1}}{\partial x} & 0 & \frac{\partial N_{1}}{\partial x} & 0 & \frac{\partial N_{1}}{\partial x} & 0 \\
0 & \frac{\partial N_{1}}{\partial x} & 0 & \frac{\partial N_{1}}{\partial x} & 0 & \frac{\partial N_{1}}{\partial x} \\
\frac{\partial N_{1}}{\partial x} & \frac{\partial N_{1}}{\partial x} & \frac{\partial N_{1}}{\partial x} & \frac{\partial N_{1}}{\partial x} & \frac{\partial N_{1}}{\partial x} & \frac{\partial N_{1}}{\partial x}
\end{array}\right]
$$

E a conversão dos deslocamentos nodais em deformação é expressa pela equação 46:

$$
\vec{\varepsilon}=\boldsymbol{B} \vec{u}
$$

Para o cálculo das tensões, usa-se a relação constitutiva básica na forma matricial (Ramsay \& Lisle, 2000):

$$
\vec{\sigma}=\boldsymbol{D} \vec{\varepsilon}
$$

A matriz D é a matriz constitutiva, e é nela que aparecem as constantes elásticas. Ela varia de acordo com o modelo bidimensional assumido (ex.: tensão plana ou deformação plana) e é aplicável para materiais lineares elásticos. 
A matriz D pode assumir as seguintes formas, conforme já apresentado no item 24, nas equações 21 e 22.

Podemos substituir o vetor de deformação $\vec{\varepsilon}$ (equação 46 ), resultando na determinação do vetor tensão em função apenas dos deslocamentos nodais:

$$
\vec{\sigma}=\boldsymbol{D} \vec{\varepsilon}=\boldsymbol{D} \boldsymbol{B} \vec{u}=\boldsymbol{D} \boldsymbol{L} \boldsymbol{N} \vec{u}
$$

\subsubsection{Apresentação de resultados}

Uma maneira convencional e bastante informativa para apresentação da distribuição das tensões, deformações e deslocamentos ao redor das aberturas subterrâneas é por meio de isolinhas de magnitudes (figura 24).

Hoek \& Brown (1980a) apresentam uma coletânea de vários padrões de trajetórias de tensões e isolinhas de magnitudes, para várias geometrias de escavação e relações entre $\sigma_{v}$ e $\sigma_{h}$. Um exemplo é apresentado na figura 25. 


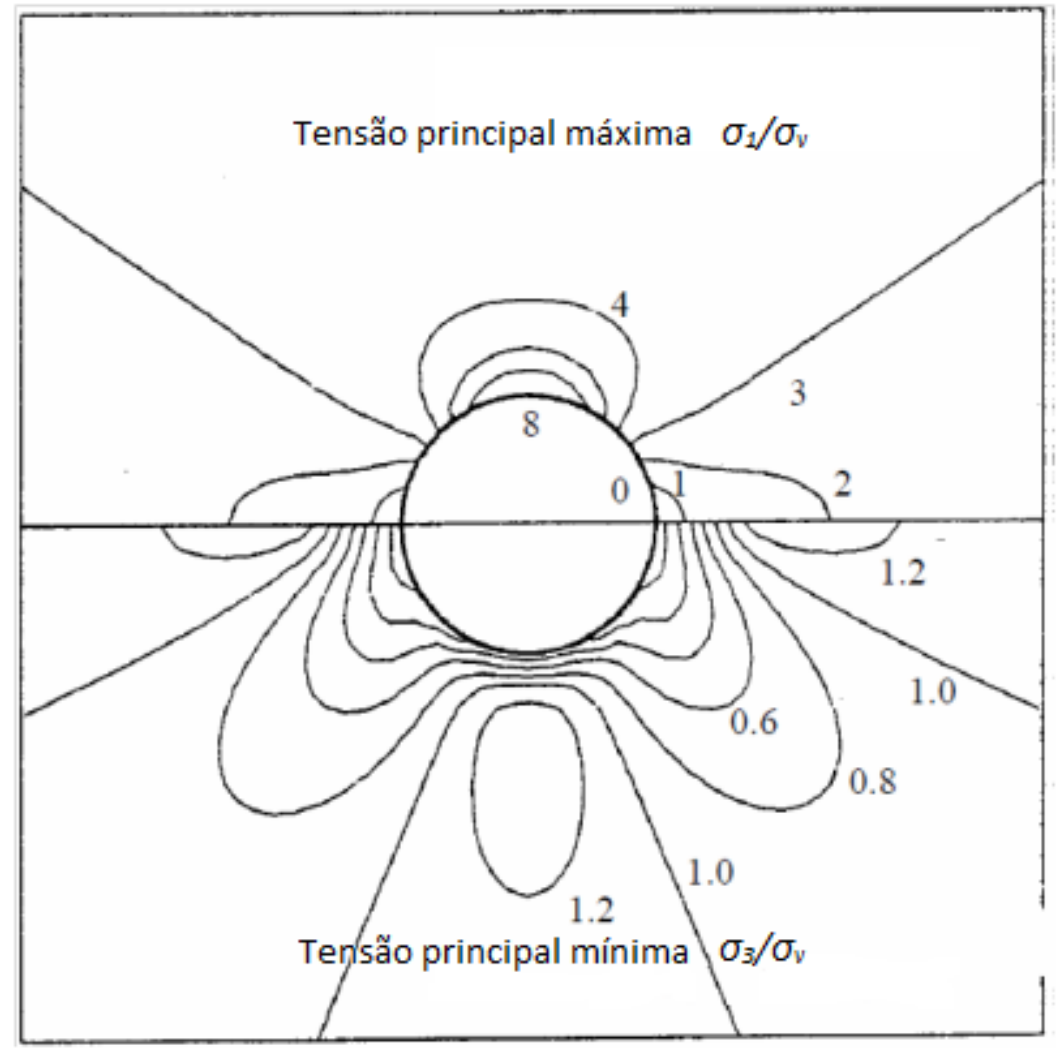

Figura 24 - Representação de isolinhas de magnitudes normalizadas das tensões principais máxima (metade superior) e mínima (metade inferior) para uma escavação circular com $\sigma_{h}=3 \sigma_{v}$. Notar a concentração de tensões nas proximidades da borda da abertura (Hoek, 2007). 




Figura 25 - Diagrama esquemático mostrando trajetórias de tensão e padrões de concentração de tensões principais para um túnel circular em que a relação $\sigma_{v} / \sigma_{h}$ é 1:0,5 (Hoek \& Brown, 1980a).

\subsection{APLICAÇÃO DO MÉTODO}

A parte analítica deste trabalho seguirá uma sequência de execução que pode ser dividida em três etapas principais: 
1- Determinação das tensões resultantes ao redor de uma abertura subterrânea circular, após a redistribuição dos esforços. Será implantado um estado de tensões homogêneo (definido por uma tensão vertical $\sigma_{v} \mathrm{e}$ uma tensão horizontal $\sigma_{h}$ ) atuando sobre o maciço rochoso que é homogêneo, isotrópico, contínuo e linear-elástico.

2- Utilização dos principais conceitos da teoria da elasticidade para relacionar as tensões obtidas com deformações associadas. Nesta etapa, serão considerados diversos valores dos parâmetros elásticos $E$ e $v$, para verificar a influência destes parâmetros no comportamento do maciço.

3- Utilização de outras relações constitutivas para determinar a energia elástica acumulada no maciço, ao redor da abertura subterrânea. Conforme a redistribuição resulta em um campo de tensões heterogêneo, assume-se que a função energia elástica também resultará em um campo heterogêneo. Por fim, será realizada a análise dos padrões da energia elástica conforme os diversos valores dos parâmetros elásticos utilizados.

\subsection{DETERMINAÇÃO DE TENSÕES AO REDOR DE UMA ABERTURA SUBTERRÂNEA}

Para conjunto de análises realizadas no presente trabalho foram admitidas as seguintes condições de contorno:

- A escavação subterrânea analisada está inserida em um maciço idealmente elástico-linear, homogêneo, contínuo e isotrópico.

- A escavação subterrânea é circular, com raio de $5 \mathrm{~m}$. 
- O maciço se estende infinitamente em todas as direções.

- O maciço rochoso está submetido, antes da escavação, a um campo de tensões homogêneo e anisotrópico, com valores de $\sigma_{v}=30 \mathrm{MPa}$ e $\sigma_{h}=10 \mathrm{MPa}$.

- A análise realizada é bidimensional, na qual se assume condição de deformação plana (plane strain).

- No limite do domínio analisado, não há deslocamentos nodais (isso foi assumido, para prevenir deformações decorrentes de recalques do terreno).

Para a determinação dos valores de tensão ao redor da escavação após a abertura, foram utilizados os dois métodos descritos nos itens anteriores: em primeiro lugar, foi confeccionada uma malha de pontos na qual foram aplicadas as equações de Kirsch, em seguida foram aplicadas as equações matriciais pelo método dos elementos finitos (FEM) nestes mesmos pontos.

A aplicação do método de elementos finitos resultou diretamente em valores de $\sigma_{1}$ e $\sigma_{2}$. A aplicação das equações de Kirsch resultou em valores de $\sigma_{r}, \sigma_{\theta}$ e $\tau_{r \theta}$, que foram convertidos em valores de tensões principais $\left(\sigma_{1}\right.$ e $\left.\sigma_{2}\right)$ a partir das relações apresentadas nas equações 49 e 50 (Hoek \& Brown, 1980a):

$$
\begin{aligned}
& \sigma_{1}=\frac{1}{2}\left(\sigma_{r}+\sigma_{\theta}\right)+\sqrt{\frac{1}{4}\left(\sigma_{r}-\sigma_{\theta}\right)^{2}+\tau_{r \theta}^{2}} \\
& \sigma_{2}=\frac{1}{2}\left(\sigma_{r}+\sigma_{\theta}\right)-\sqrt{\frac{1}{4}\left(\sigma_{r}-\sigma_{\theta}\right)^{2}+\tau_{r \theta}^{2}}
\end{aligned}
$$

Para a aplicação do método numérico por meio do método de elementos finitos, foi elaborada uma malha de elementos triangulares conforme a figura 26 e as condições gerais da escavação, listadas acima, foram utilizadas na determinação das condições de contorno do problema. 


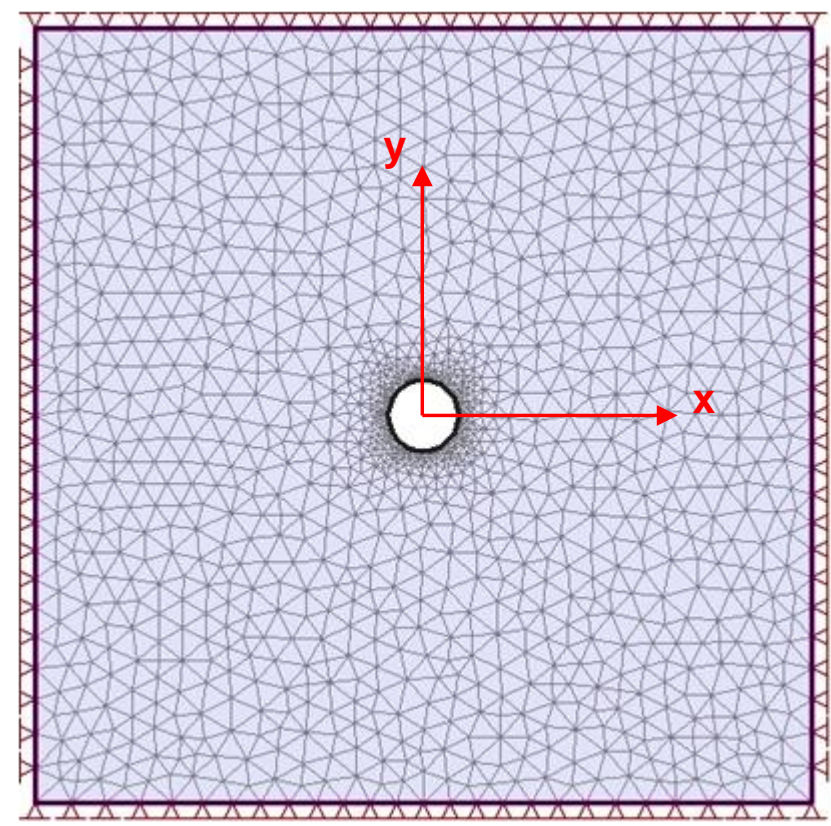

Figura 26 - Malha de elementos utilizada na análise de elementos finitos.

Foi então realizada a etapa de cálculo matricial, para a determinação da redistribuição das tensões ao redor da escavação. Os resultados obtidos foram valores das tensões principais $\left(\sigma_{1}\right.$ e $\left.\sigma_{2}\right)$ para cada um dos nós da malha de elementos.

\subsubsection{Comparação entre os resultados dos métodos}

Os resultados obtidos a partir da aplicação de cada um dos métodos foram sobrepostos nas figuras 27 e 28 . 


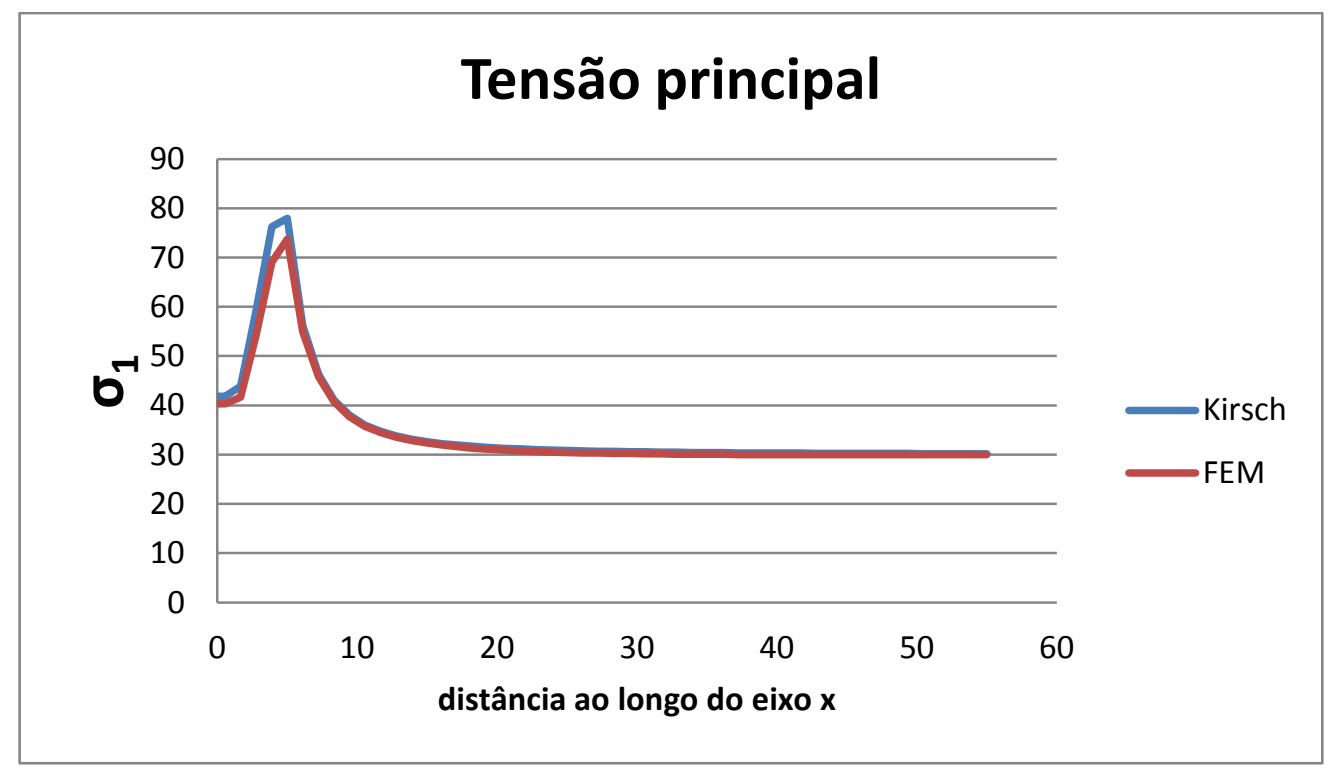

Figura 27 - Valores de $\sigma_{1}$ ao longo do eixo X segundo os métodos analítico (Kirsch) e numérico (elementos finitos).

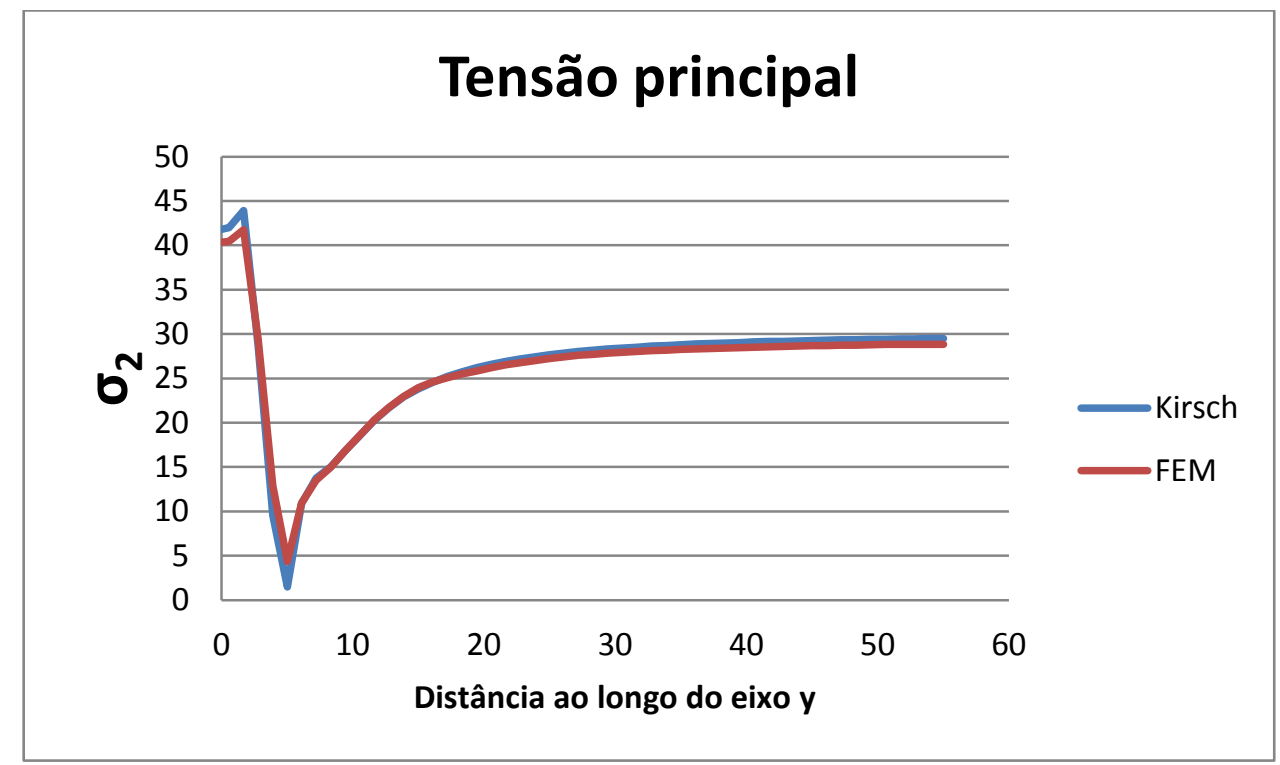

Figura 28 - Valores de $\sigma_{2}$ ao longo do eixo Y segundo os métodos analítico

(Kirsch) e numérico (elementos finitos).

Os valores de tensões principais são similares, mas valores mais extremos são notados na utlização do método analítico, nas proximidades das paredes da abertura (em que a distância $a$ é próxima do valor do raio $r$ do túnel). Para $a>r$, os valores são praticamente idênticos. 


\subsubsection{Determinação de deformações a partir dos valores de tensão}

Os valores de tensão obtidos por meio da análise numérica foram convertidos em valores de deformação segundo a relação constitutiva apresentada na equação 18.

Esta relação foi aplicada para cada um dos nós da malha de elementos finitos.

A influência dos parâmetros elásticos $E$ e $v$ foi verificada nesta etapa de cálculo: foram considerados diversos valores de cada um destes parâmetros, variando de valores mínimos, médios e máximos. Os valores numéricos utilizados foram baseados nos valores para rochas cristalinas dos trabalhos de Kumar (1976), Palmström \& Singh (2001) e Gercek (2007), conforme sintetizado na Tabela 2.

Tabela 2 - Valores dos parâmetros elásticos usados na análise numérica.

\begin{tabular}{cccc}
\hline Parâmetro & mín. & méd. & máx. \\
\hline$E(\mathrm{GPa})$ & 20 & 50 & 80 \\
$v$ & 0,1 & 0,25 & 0,4 \\
\hline
\end{tabular}

Os valores "médios" apresentados na Tabela 2 foram definidos neste trabalho como "valores-padrão" e usados como valores para os maciços rochosos denominados "modelos", ou seja, referências para comparações com os demais valores. Desta forma, o maciço rochoso "modelo" apresentado neste trabalho apresenta valores de $E=50 \mathrm{GPa}$ e $v=0,25$.

Uma questão importante é a relevância da variação dos valores dos parâmetros elásticos já na determinação das tensões atuantes ao redor da escavação. 
A teoria da equação de Kirsch mostra que a determinação das tensões independe dos parâmetros elásticos do material escavado. No entanto, o método dos elementos finitos utiliza estes parâmetros na aplicação da matriz constitutiva para transformar deslocamentos nodais em forças. Logo, os parâmetros elásticos apresentam, sim, alguma influência na determinação das tensões na aplicação do método de elementos finitos.

Na figura 29, são apresentados os valores de tensão principal $\left(\sigma_{1}\right.$ e $\left.\sigma_{2}\right)$ obtidos a partir do método de elementos finitos, ao longo do eixo X. Cada uma das linhas representa um dos valores assumidos para as constantes elásticas, conforme a tabela 2.
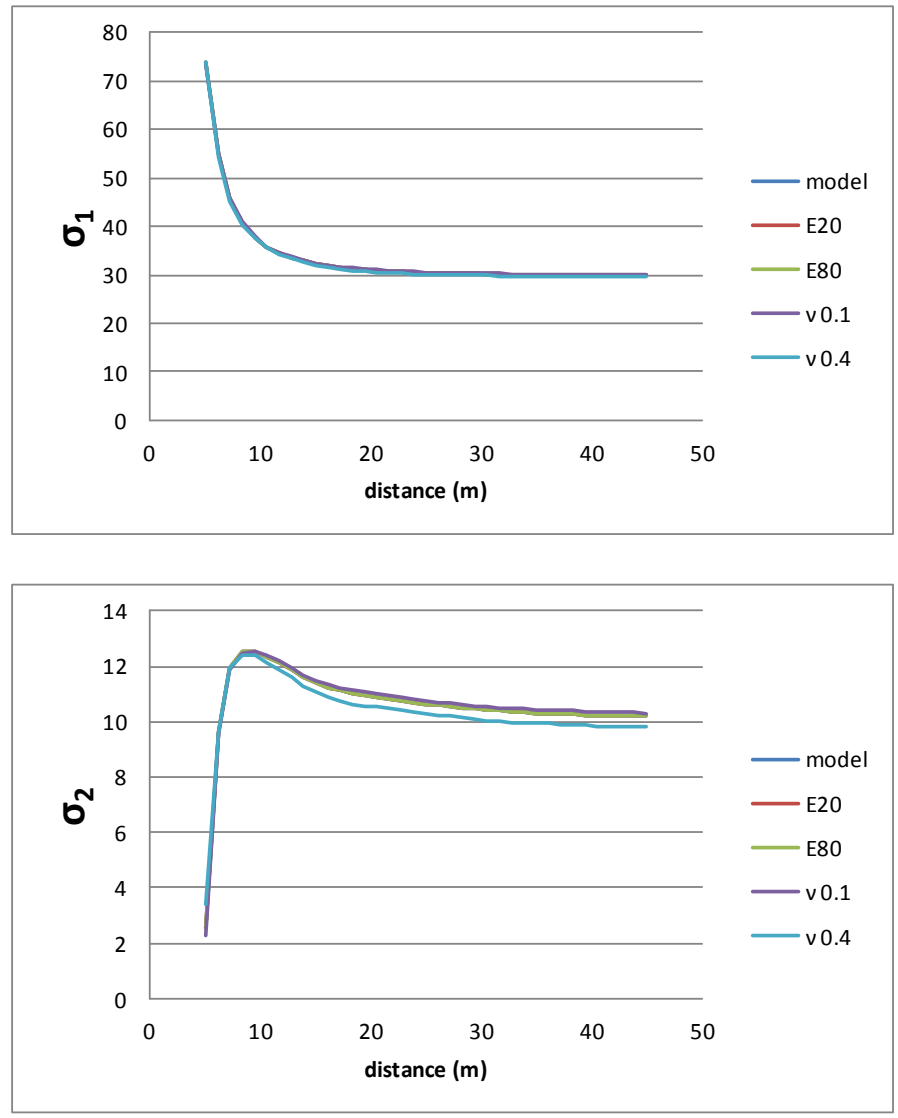

Figura 29 - Valores das tensões principais após a redistribuição de tensões $\left(\sigma_{1}\right.$ e $\sigma_{2}$ ) ao longo do eixo $\mathrm{X}$ do túnel. Variações dos valores do coeficiente de Poisson $(v)$ causam mudanças sutis nos valores de $\sigma_{2}$, mas não exercem 
influência significativa sobre os valores de $\sigma_{1}$. Variações dos valores do módulo de elasticidade $(E)$ não causam variações em nenhuma das tensões principais. De acordo com a figura 29, a variação de $v$ causa variações pequenas nos valores de $\sigma_{2}$, mas não resulta em variações significativas nos valores de $\sigma_{1}$. 0 parâmetro $E$ não apresenta influência em nenhuma das duas tensões principais. Portanto, as variações causadas pela influência dos parâmetros

elásticos na determinação dos valores das tensões principais após a redistribuição de tensões são muito pequenas e podem ser desconsideradas.

\subsubsection{Determinação da energia elástica}

Conforme a redistribuição das tensões resulta em um campo de tensões heterogêneo, assume-se que a função energia elástica (W) também resultará em um campo heterogêneo.

Para a determinação de W foi utilizada a equação 25.

Para os valores de tensão, foram utilizados os valores obtidos diretamente pelo método dos elementos finitos. Para os valores de deformação, foram utilizados os vários resultados obtidos para os diversos valores de $E$ e $v$ da tabela 2 .

Com isso, foi obtido um conjunto de valores de W, cujos valores são função da variação dos parâmetros elásticos $E$ e $\nu$. 


\section{RESULTADOS}

\subsection{ENERGIA ELÁSTICA COMO FUNÇÃO DOS PARÂMETROS}

\section{ELÁSTICOS}

Os resultados obtidos na determinação dos valores de $\mathrm{W}$ a partir dos vários valores de $\varepsilon$, que por sua vez foram obtidos dos vários valores de $E$ e $v$, são apresentados na forma de isolinhas de energia ao redor da escavação (Figura 30). 

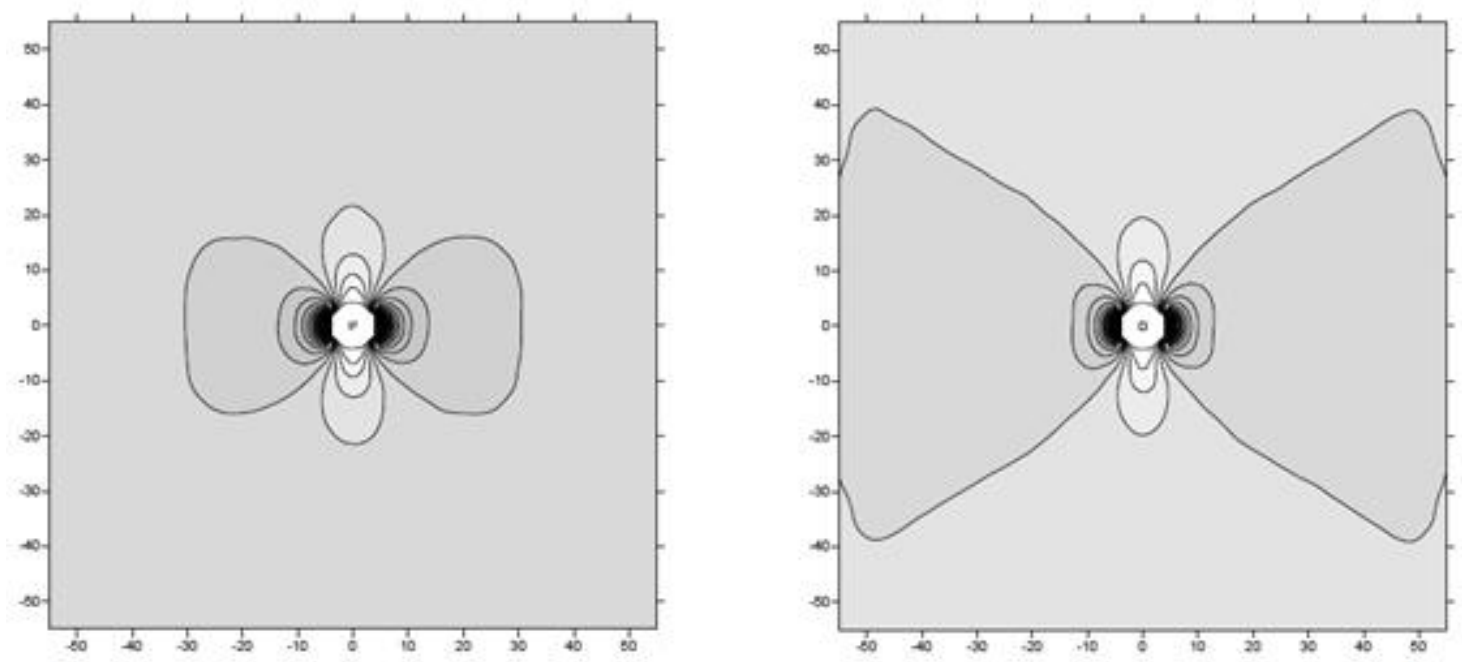

a.

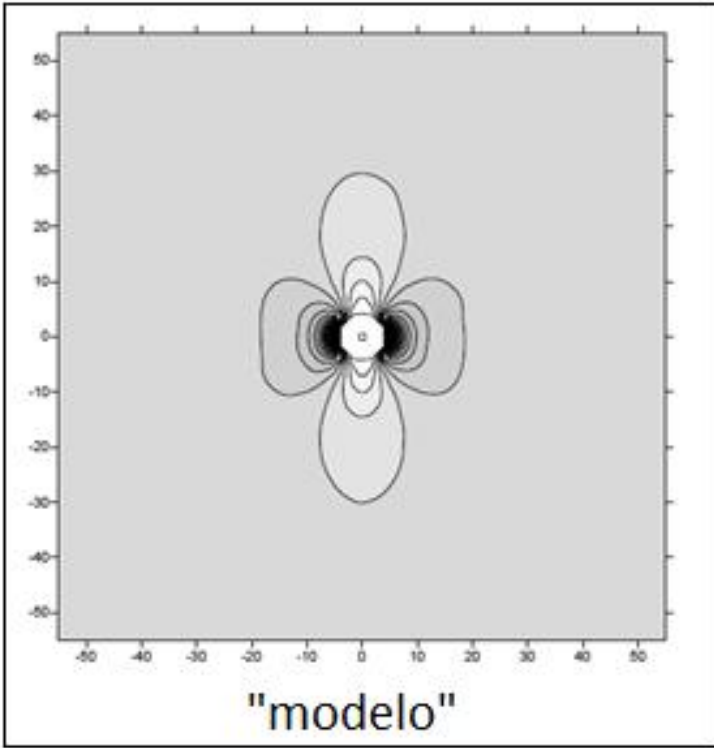

b.
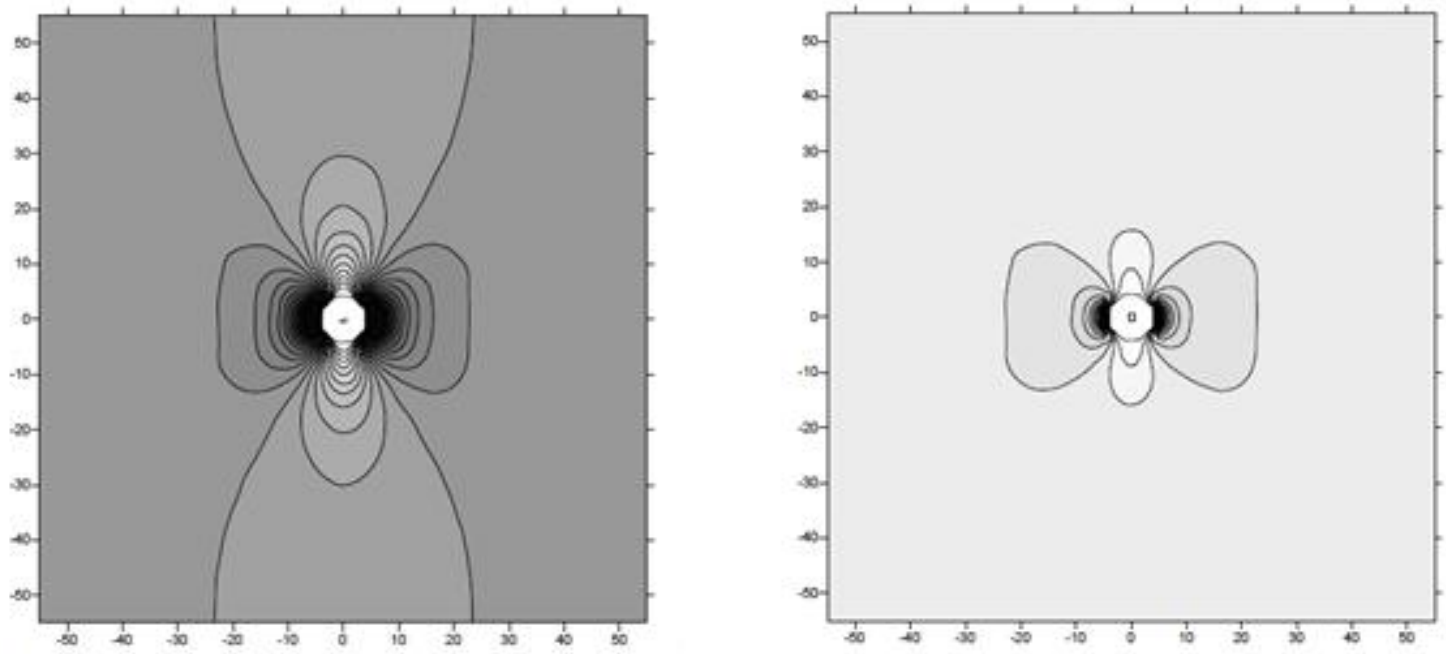

C.

d.

Figura 30 - Resultados das análises pelo método de elementos finitos. Tons mais escuros indicam maiores valores de W. O resultado para valores "modelo" 
$\mathrm{E}=50 \mathrm{GPa}, v=0,25$ está apresentado no centro. As imagens superiores ( $a$ e b) representam variação nos valores de $v$ (respectivamente 0,1 e 0,4 ), fixado $E=50 \mathrm{GPa}$. As imagens inferiores (c e d) representam variação nos valores de $E$ (respectivamente 20GPa e 80GPa), fixado $v=0,25$.

A análise comparativa entre os diversos resultados é mostrada na figura 31, na qual os valores obtidos para $\mathrm{W}$ foram superpostos em um único gráfico, que relaciona o valor de $\mathrm{W}$ e a distância ao longo do eixo X do túnel.

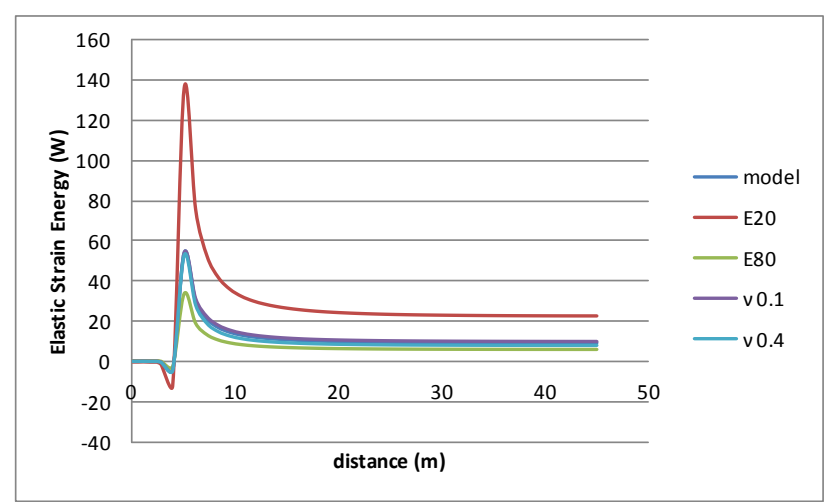

Figura 31 - Gráfico da variação dos valores de W com a distância, ao longo do eixo X do túnel. As diferentes linhas mostram resultados para os diferentes valores considerados para os parâmetros elásticos. 


\section{DISCUSSÃO}

\subsection{ENERGIA EM FUNÇÃO DOS PARÂMETROS ELÁSTICOS}

De acordo com os resultados ilustrados nas figuras 30 e 31, a variação nos valores do módulo de elasticidade $(E)$ induz modificações significativas nos valores e W. Quanto menor o valor de $E$, maior o valor de W para qualquer ponto no espaço (figura 32).

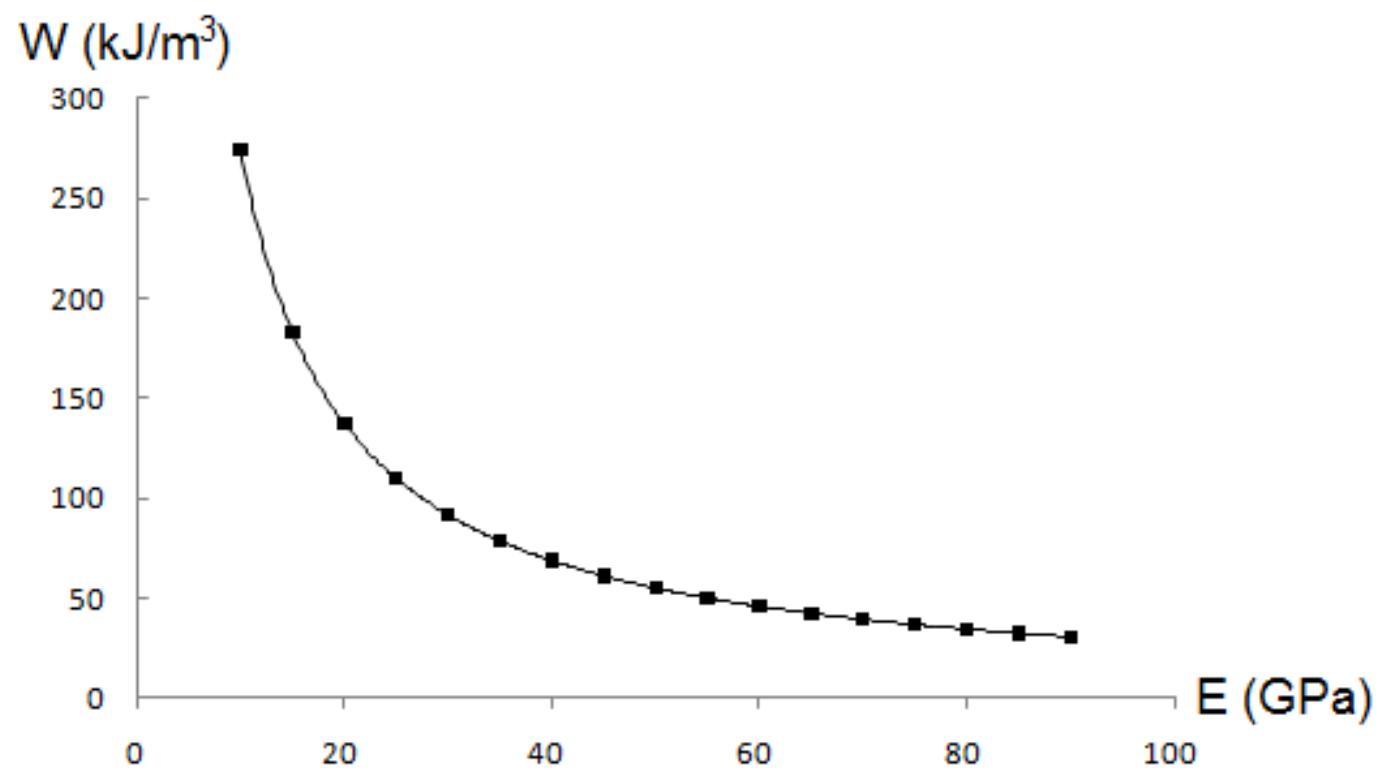

Figura 32 - Comportamento da energia elástica $W$ em relação a valores de $E$, para o ponto [0,5]. Fixado o valor de $v$, a mesma tendência é observada para a aplicação das equações em qualquer ponto do espaço.

Por outro lado, os valores de W não são afetados de maneira considerável por variações do coeficiente de Poisson $(v)$. As curvas dos resultados para o maciço "modelo" são muito parecidas com as curvas nas quais $v$ variou $\pm 0,15$. No entanto, existe um padrão muito interessante a ser observado: os menores valores de $v$ não induzem necessariamente maiores concentrações de $\mathrm{W}$, como seria de se esperar. Variações mais significativas no padrão da relação 
$W(v)$ são observadas nas proximidades imediatas dos limites da escavação. A figuras 34 e 35 mostram a relação $W(v)$ no eixo $X$, entre os pontos [5,0;0] e $[6,0 ; 0]$.

No ponto [5,0;0], o máximo valor de $\mathrm{W}$ ocorre para $v=0,25$, e a relação tem forma parabólica, com a concavidade para baixo. No entanto, à medida que se afasta do limite da escavação, o máximo valor de W passa a ocorrer cada vez para valores menores de $v$, e a relação passa a ter forma cada vez mais parecida com uma reta. 


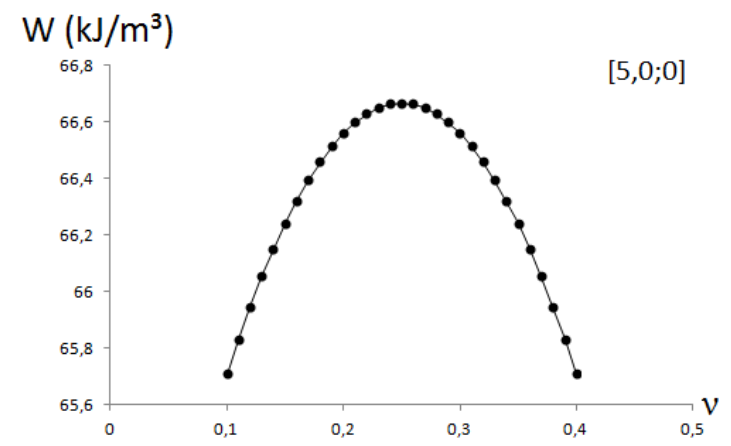

$\mathrm{W}\left(\mathrm{kJ} / \mathrm{m}^{3}\right)$
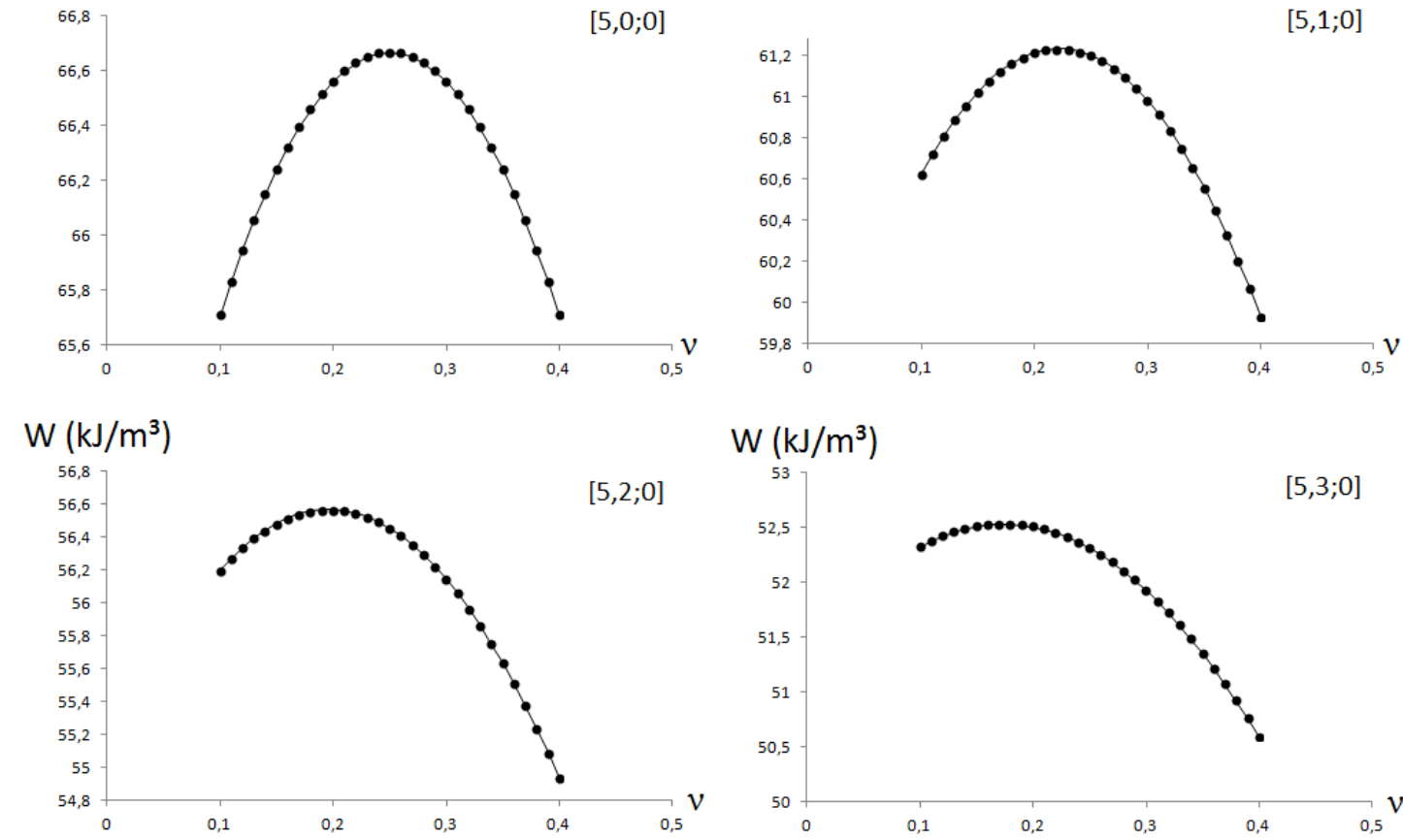

$\mathrm{W}\left(\mathrm{kJ} / \mathrm{m}^{3}\right)$
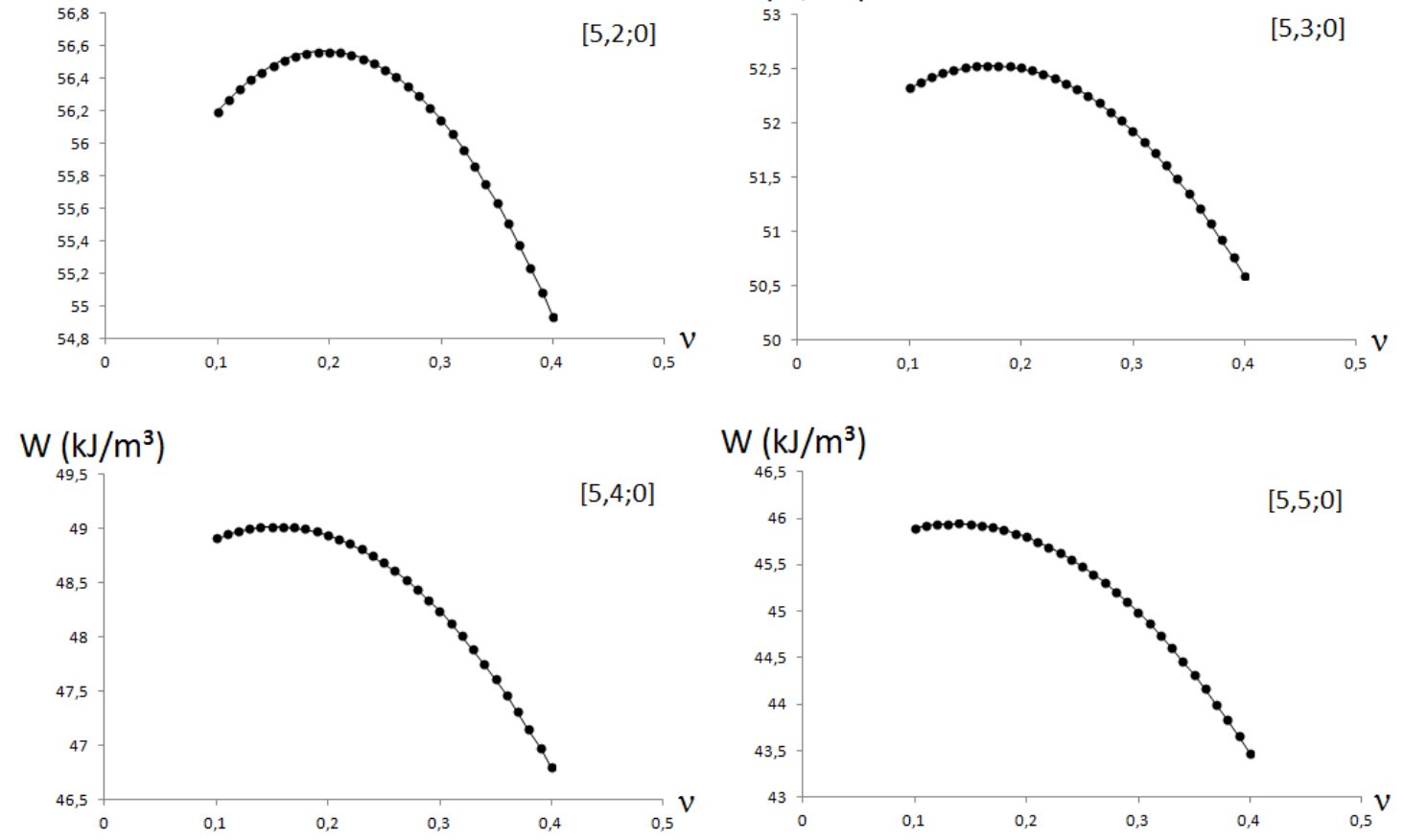

Figura 33 - Relação $W(v)$ para os pontos situados ao longo do eixo $\mathrm{X}$ entre $[5,0 ; 0]$ e $[5,5 ; 0]$. 

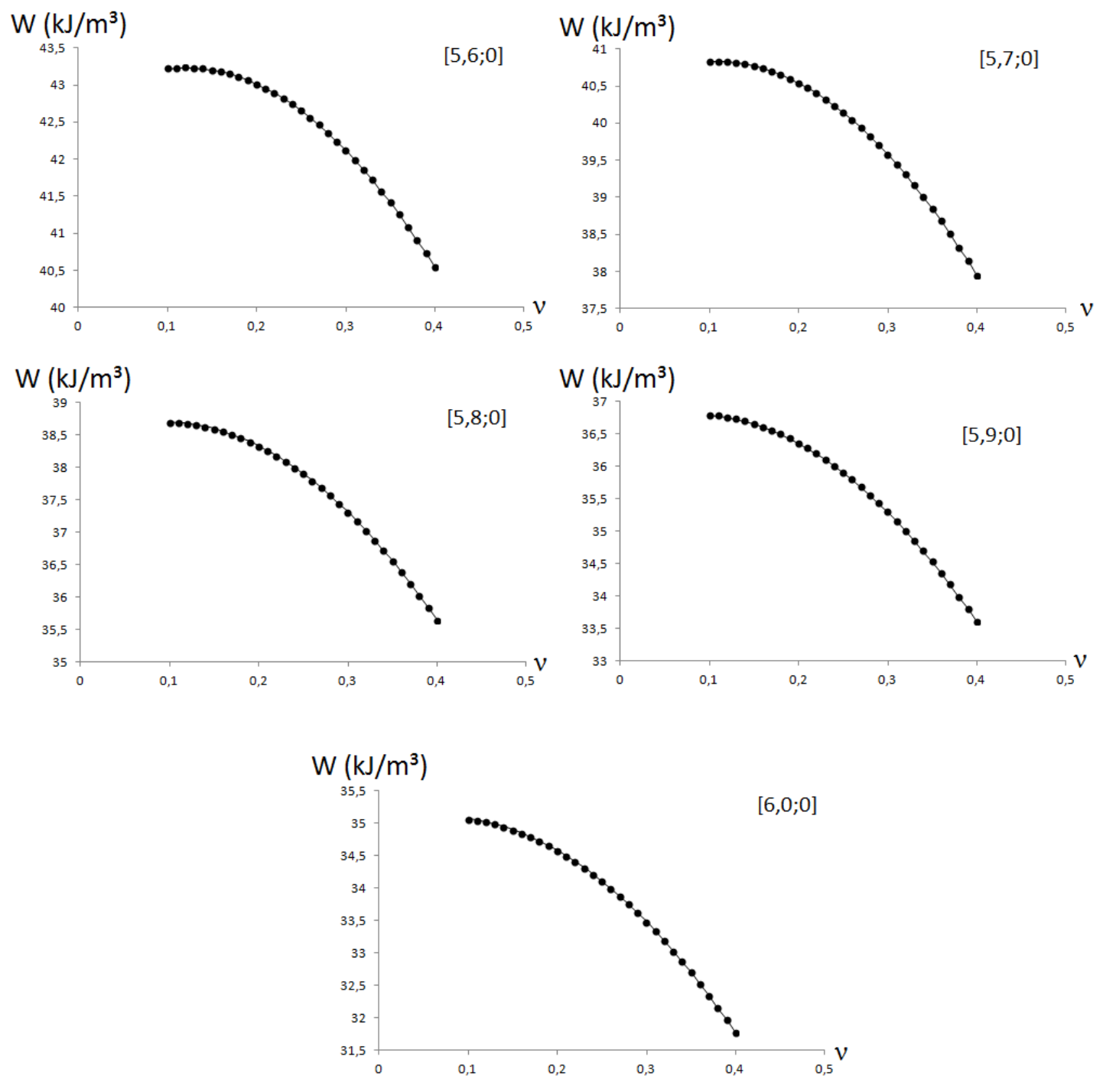

Figura 34 - Relação $W(v)$ para os pontos situados ao longo do eixo $\mathbf{X}$ entre $[5,6 ; 0]$ e $[6,0 ; 0]$.

Os resultados gráficos obtidos pelo método de elementos finitos e posterior complemento algébrico (figuras 30 e 31) estão de acordo com os resultados esperados pela aplicação das equações 25 e 26.

A influência do coeficiente de Poisson é reduzida, uma vez que este parâmetro apresenta baixos valores absolutos (cujos limites teóricos variam de 0 a 0,5) e está presente nas equações sob a forma de $(1-v)$ ou $(v)$ - o que pode explicar a forma do gráfico $W(v)$ apresentado na figura 34 -, enquanto o módulo de 
Young apresenta elevados valores absolutos (que variam de 10-100GPa em rochas cristalinas) e ocorre nas equações na forma de $2 E$.

Lembrando da definição do módulo de Young, maciços rochosos com baixos valores de $E$ são mais susceptíveis à deformação, isto é, esses maciços sofrem maiores deslocamentos e deformações sob o efeito de um determinado estado de tensões.

Consequentemente, maiores deslocamentos sob um mesmo estado de tensões resultam em mais trabalho, isto é, maiores quantidades de energia elástica são acumuladas (figura 35).

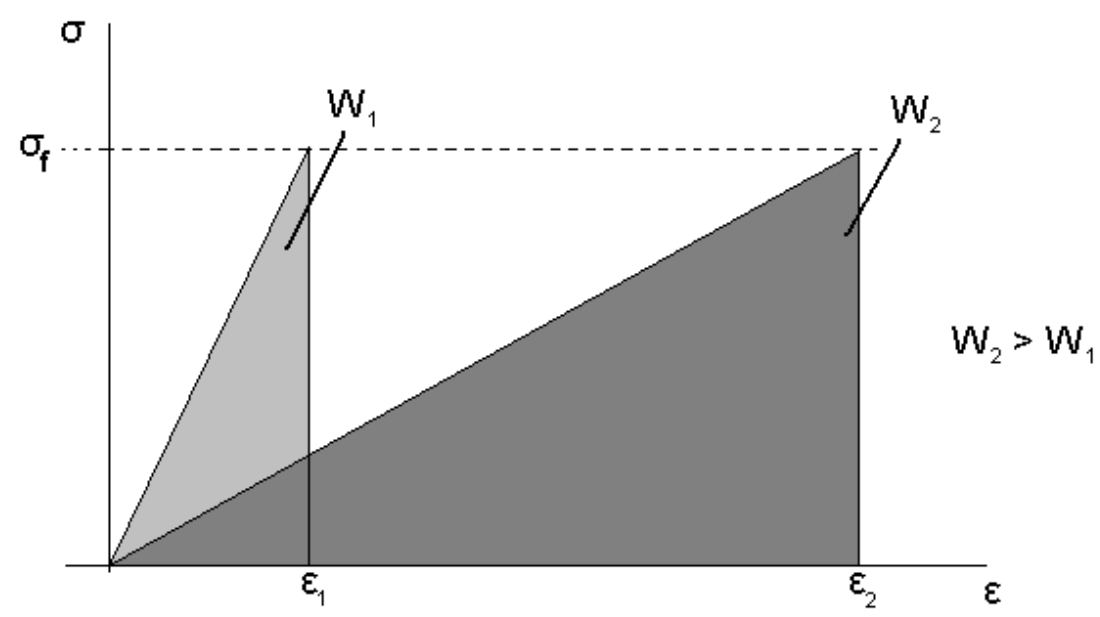

Figura 35 - Para um determinado estados de tensões $\left(\sigma_{f}\right)$, materiais mais duros

(1) deformam menos que materiais mais macios (2), resultando em $\varepsilon_{2}>\varepsilon_{1}$.

Sendo assim, $W_{2}>W_{1}$.

Isto leva à conclusão que, para um determinado estado de tensões, rochas mais deformáveis, que apresentam menores valores de $E$, têm a capacidade de acumular maiores quantidades de energia elástica, em relação a rochas menos deformáveis. 
No entanto, se as equações e os resultados apresentados graficamente nas figuras 30 e 31 indicam que o módulo de Young é o principal parâmetro elástico na determinação da energia elástica acumulada, então qual seria o efeito real e a importância do coeficiente de Poisson?

Conforme Davis \& Reynolds (1996) reportam em experimentos de compressão uniaxial em laboratório, se não ocorre expansão lateral acompanhando compressão axial a amostra de rocha está sujeita a maior acumulação de energia elástica, assim resultando em maior liberação de energia uma vez que ela se rompe.

No caso do processo de escavação de uma abertura subterrânea num maciço rochoso, a falta de confinamento na superfície de escavação pode resultar em uma situação muito semelhante a um teste de compressão uniaxial se não houver a presença de suporte nas paredes do túnel (referências, q eu sei que tem). Nesta situação, a superfície da escavação está sujeita à ação apenas de tensões tangenciais $\left(\sigma_{\theta}\right)$, resultando em deslocamentos no sentido da abertura como consequência do "efeito Poisson.

Segundo o "efeito Poisson", a compressão axial da rocha intacta resulta em expansão lateral, como é demonstrado na equação 15 , que é grosso modo a definição do coeficiente de Poisson:

$$
v=\frac{\varepsilon_{\text {lat }}}{\varepsilon_{a x}}
$$

em que $\varepsilon_{\text {lat }}$ é a deformação lateral, e $\varepsilon_{a x}$ é a deformação axial (Timoshenko \& Goodier, 1970; Davis \& Reynolds, 1996).

A deformação lateral induzida pela deformação axial também resulta em trabalho realizado pelo material. Valores muito elevados de $v$, resultam em 
deformações que são mais próximas de deformações volumetricamente constantes. O limite superior teórico de 0,5 seria o caso extremo de uma deformação volumetricamente constante. Neste caso, o trabalho realizado pela compressão uniaxial seria compensado integralmente pelo trabalho realizado por expansão lateral.

O papel do coeficiente de Poisson, então, seria criar um desequilíbrio nesta relação. Com a redução do valor de $v$, ocorre um incremento na relação entre $\varepsilon_{a x} / \varepsilon_{\text {lat }}$. Deste modo, quanto menor o valor de $v$, mais desbalanceada fica a relação entre energia axial/lateral, resultando em maiores valores de energia elástica total armazenada durante a compressão.

Apesar de todas essas considerações, os resultados apresentados foram baseados em idealizações em relação ao maciço rochoso avaliado: ele foi tratado como idealmente elástico linear, homogêneo e contínuo. Embora esse tipo de simplificação seja válido para determinar o comportamento geral do maciço, o fenômeno de acúmulo e liberação de energia em maciços rochosos reais, deve levar em conta outros parâmetros.

Além disso, o acúmulo de energia elástica em função do coeficiente de Poisson apresenta uma tendência estranha, adequada em relação às equações algébricas, mas cujo sentido físico ainda não foi totalmente compreendido. É possível que uma nova equação se faça necessária para descrever este fenômeno? 


\subsection{CONSEQUÊNCIAS DA CONCENTRAÇÃO DE TENSÕES}

\subsubsection{Em termos de instabilidades nos entornos das escavações}

Até o momento, tratamos de idealizações em que os maciços rochosos são considerados perfeitamente elástico-lineares. Neste modelo, as deformações induzidas nos maciços são diretamente proporcionais às tensões aplicadas sobre eles. No entanto, esta idealização apresenta limites. Ensaios de laboratório mostram que as rochas apresentam um limite de elasticidade (Davis \& Reynolds, 1996). Ao ser excedida determinada tensão, o maciço passa a se comportar plasticamente, com ocorrência de ruptura - a deformação irreversível do modelo plástico.

O estudo das relações entre as tensões aplicadas ao maciço rochoso e suas propriedades de resistência foi realizado por diversos autores ao longo do tempo. Como resultado, foram desenvolvidas equações denominadas critérios de ruptura (Hoek et al., 1993; Hoek, 2007), que fazem parte do estudo de mecânica de fraturas.

Os critérios mais conhecidos e utilizados são os critérios de Mohr-Coulomb, Griffith e Hoek-Brown. Não é objetivo deste trabalho discorrer sobre os detalhes dos critérios de ruptura. Para um estudo mais aprofundado sobre este tema, recomenda-se a leitura de Cook (1965), Hoek et al. (1993), Davis \& Reynolds (1996). Um breve resumo encontra-se no Apêndice 2.

O rearranjo das tensões provocado pela presença da escavação subterrânea pode elevar os valores das tensões principais máximas $\sigma_{1}$ e reduzir as tensões principais mínimas $\sigma_{3}$ de tal maneira que criam-se localmente estados de tensão muito anisotrópicos, que podem superar os limites da envoltória de 
ruptura para o material. Isto é, o puro rearranjo de tensões pode causar concentrações suficientes para provocar a ruptura no maciço rochoso.

\subsubsection{Em termos de energia}

Como foi observado na equação 45, a energia de deformação pode ser descrita somente em função da tensão $\sigma$ e dos parâmetros elásticos $E$ e $v$. Segundo a forma da equação 45, os valores de energia são diretamente proporcionais a termos quadráticos de tensão. Isto significa que existe uma relação direta entre concentração de tensões e concentração de energia elástica.

Os processos de deformação plástica são responsáveis pela dissipação da energia elástica acumulada nos maciços rochosos (Cook et al., 1966; Broch \& Sørheim, 1984; Wang \& Park, 2001). Os fenômenos previstos pelos critérios de ruptura são processos de deformação plástica. Portanto, parte da energia elástica acumulada durante a compressão do maciço rochoso é dissipada durante o fraturamento do material.

Se após o mecanismo de ruptura nos entornos da abertura ainda houver uma grande quantidade de energia elástica acumulada, ela tende a se transformar em energia cinética, com a ejeção de blocos rochosos a partir das paredes da escavação, resultando em rupturas violentas no maciço - rock bursts e fenômenos similares (Cook et al., 1966; Müller, 1991). 


\subsection{MACIÇO ROCHOSO: RESISTÊNCIA E REDUÇÃO DE PARÂMETROS}

\subsubsection{Resistência de rocha intacta e de maciço rochoso}

Uma análise que é baseada puramente na teoria da elasticidade, como é o caso da análise realizada neste trabalho, não leva em consideração a resistência do maciço rochoso.

Para grande parte dos trabalhos prévios, as rochas cristalinas mais duras têm maior propensão a sofrerem fraturamentos violentos devido à sua melhor capacidade de acumular energia (Broch \& Sørheim, 1984; Lee et al., 2004; Diederichs, 2007).

Segundo a figura 33 , sob um determinado estado de tensões as rochas mais deformáveis têm a capacidade de acumular maiores quantidades de energia elástica, em relação a rochas menos deformáveis.

No entanto, as rochas menos deformáveis são mais resistentes e têm a capacidade de suportar maior quantidade de tensão que rochas mais deformáveis, ou menos resistentes. Isto é, as rochas mais resistentes necessitam de estados de tensão mais extremos para romperem. As rochas menos resistentes não têm a capacidade de suportarem estados de tensão tão elevados, e rompem em condições muito mais brandas.

Se a rocha rompe sob um estado de tensões que é menos intenso, então menores quantidades de energia são armazenadas entre o estado inicial e a ruptura. Logo, menores quantidades de energia são liberadas no momento de ruptura da rocha. Esta energia excessiva é transformada em energia cinética, resultando em ejeção violenta do material rompido. Quanto maior a quantidade de energia excessiva, maior a violência do processo (figura 36). 


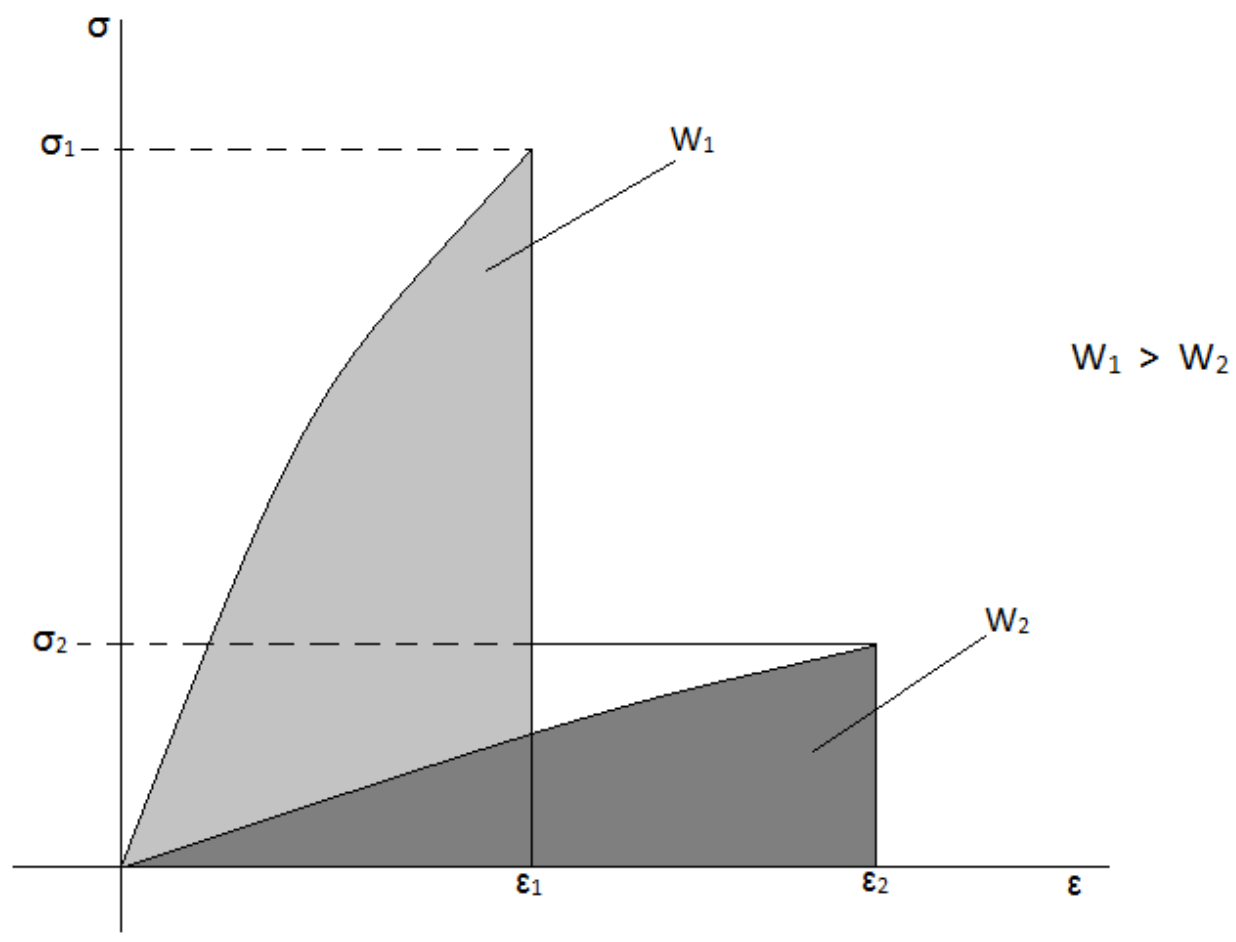

Figura 36 - Materiais mais resistentes (1) conseguem suportar maiores tensões antes da ruptura $\left(\sigma_{1}\right)$. Assim, embora a deformação seja maior para materiais menos resistentes (2), a tensão de ruptura é menor $\left(\sigma_{2}\right)$ e, assim, a energia elástica $W_{1}$ é maior que a energia elástica $W_{2}$.

\subsubsection{Parâmetros elásticos de maciços rochosos}

Uma outra observação em relação à situação ideal de um maciço contínuo e perfeitamente elástico é que os maciços rochosos reais apresentam inúmeras descontinuidades,

A presença destas descontinuidades, não apenas em macroescala (como fraturas, sistemas de juntas, falhas, etc.), mas também em microescala (microfraturas), é responsável por reduções nos valores absolutos do módulo de Young, conforme mostram Palmström \& Singh (2001) e Hoek \& Diederichs (2006). 
$\mathrm{Na}$ análise dos parâmetros elásticos para maciços rochosos - um estudo mais rigoroso e aprofundado em relação à rocha intacta,$- E_{i}$ é o módulo de elasticidade para rocha intacta, e $E_{r m}$ é o módulo de elasticidade para o maciço rochoso. $E_{i}$ é o equivalente ao parâmetro $E$, que foi utilizado ao longo deste trabalho, pois o maciço foi assumido como idealmente elástico e contínuo.

O valor de $E_{r m}$ é derivado do valor de $E_{i}$, que é modificado em função do nível de fraturamento do maciço, representado por parâmetros de descrição de qualidade de maciços rochosos como Rock Mass Rating (RMR; Bieniawski, 1989) ou Geological Strength Index (GSI; Hoek, 2007), e por um índice de perturbação do maciço $D$, que é induzido pela escavação (Hoek \& Diederichs, 2006). A figura 37 mostra curvas de $E_{r m} / E_{i}$ como função de GSI e $D$.

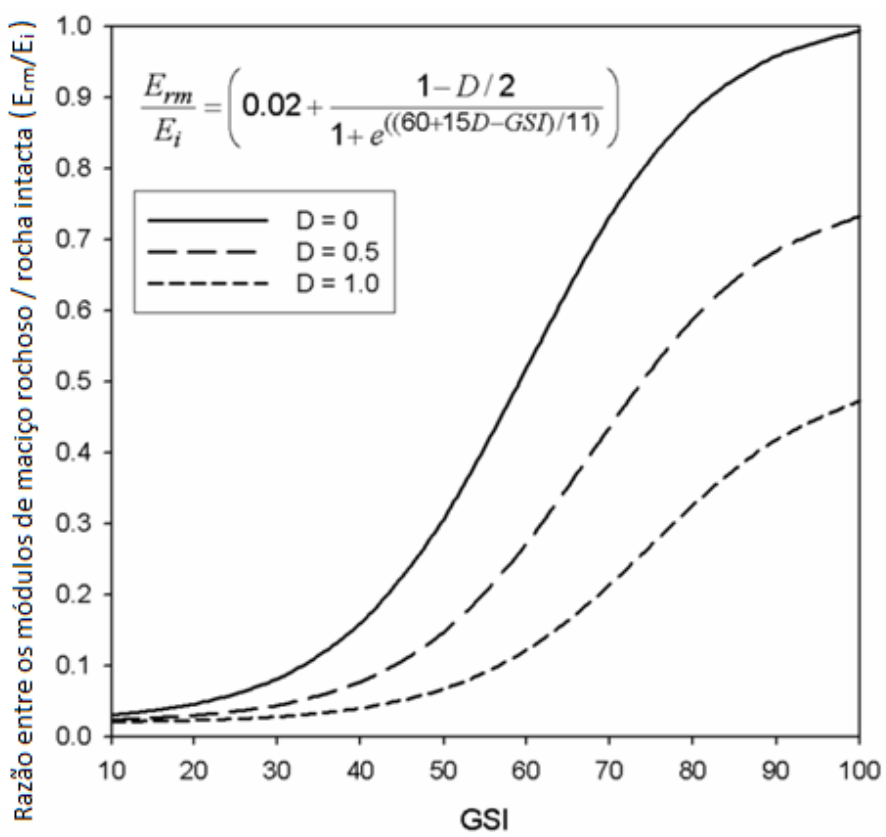

Figura 37 - Equação de Hoek-Diederichs para estimativas empíricas do modulo elástico para maciços rochosos $\left(E_{r m}\right)$, em função do Geological Strength Index (GSI) e do módulo de elasticidade da rocha intacta $\left(E_{i}\right)$. (Hoek \& Diederichs, 2006). 
A redução no valor absoluto do módulo de elasticidade a partir da presença de descontinuidades não afeta consideravelmente os resultados obtidos com a utilização de valores para rocha intacta.

Isso pode ser assumido, pois os intervalos considerados para $E_{r m}$ ao invés de E teriam as mesmas diferenças entre valores máximos e mínimos, e os resultados gráficos seriam os mesmos.

\subsubsection{Teoria de fraturas e danos no maciço}

Conforme explicitado no item 3.2, os maciços fraturados, descontínuos, apresentam comportamento distinto em relação a maciços idealmente contínuos. Portanto, mecânica das fraturas e avaliação dos danos induzidos ao maciço rochoso, que não foram temas abordados neste trabalho, têm grande importância no processo de rock burst.

O efeito de dissipação de energia em processos plásticos de deformação como geração de microfraturas e sua coalescência e propagação quando certa porcentagem da resistência da rocha é excedida (Scholz, 1968; Wang \& Park, 2001), e a razão de liberação de energia, ERR (Cook et al. 1966), são conceitos importantes na determinação do excesso de energia disponível após os processos de ruptura e se a energia excessiva será suficiente para causar fenômenos de ruptura violenta. 


\section{CONCLUSÃO}

Os parâmetros elásticos são essenciais nas relações constitutivas e têm influência direta no acúmulo de energia elástica (W).

Para um determinado estado de tensões, a variação do módulo de Young $(E)$ induz maiores variações nos valores de $\mathrm{W}$ que a variação nos valores do coeficiente de Poisson $(v)$. Esta é a consequência direta da aplicação das relações constitutivas baseadas na teoria da elasticidade.

O significado físico dos resultados indicam que, para um mesmo estado de tensões, rochas mais "macias" (mais deformáveis) têm a capacidade de armazenar maiores quantidades de energia elástica do que rochas mais "duras" (menos deformáveis).

No entanto, rochas mais resistentes suportam maior quantidade de tensão do que rochas menos resistentes. Logo, é possível atingir valores de tensão muito maiores em uma rocha mais "dura" antes dela romper, se comparado com rochas mais "moles". Como resultado, são acumulados maiores valores de energia elástica nas rochas mais resistentes. Esta conclusão é corroborada pela literatura.

Parte da energia acumulada é dissipada no processo de deformação plástica (desenvolvimento e propagação de microfraturas), e a energia excessiva é transformada em energia cinética, resultando na ejeção de blocos de rocha na direção do túnel, a partir das paredes de escavação.

A teoria da elasticidade, por si só, não é suficiente para explicar os mecanismos complexos que ocorrem em um maciço rochoso durante os processos de fraturamento e ruptura. Em especial, a importância do coeficiente 
de Poisson $(v)$, como possível principal responsável pelo acúmulo de energia (Davis \& Reynolds, 1996), não pôde ser observada a partir das equações utilizadas. Uma tendência "anômala" foi observada: valores de $v$ medianos (próximo a 0,25 ) induzem maiores valores de $W$ no limite da escavação (no ponto $[5,0 ; 0])$. Conforme se afasta deste limite no sentido do interior do maciço, valores cada vez menores de $v$ passam a induzir os maiores valores de $\mathrm{W}$.

Para uma compreensão mais completa do problema de rock burst, teorias complementares devem ser incorporadas, para análises mais rigorosas e precisas (teorias de fraturamento, análise de danos, influência dos métodos de escavação, etc.).

Ainda assim, o presente trabalho mostra que os parâmetros elásticos, especialmente o módulo de elasticidade $(E)$, induzem variações nos padrões de acúmulo de energia elástica $(W)$ no maciço rochoso.

Isto significa, em termos práticos, que projetos de escavações subterrâneas precisam ser efetuados de maneira que sejam utilizados os valores mais realistas possíveis dos parâmetros elásticos, e que o uso de valores padronizados ao invés de valores extraídos in situ pode acarretar em problemas inesperados e, eventualmente, geração de rock burst onde as condições sejam favoráveis. 


\section{APÊNDICES}




\section{APÊNDICE I TEORIA DA ELASTICIDADE}

A teoria da elasticidade tem diversas aplicações no estudo quantitativo das propriedades dos sólidos e na previsão de seu comportamento. Tensões relacionam a aplicação de forças na superfície do sólido. Num ponto do espaço pode ser definido o estado de tensão, e ao longo do espaço cartesiano os estados de tensão definem campos de tensão, homogêneos ou heterogêneos. Deformações relacionam deslocamentos sofridos pelas partes deste sólido. Podem ser homogêneas ou heterogêneas. A relação entre tensão e deformação pode ser descrita a partir de equações constitutivas, que envolvem parâmetros como módulo de elasticidade, coeficiente de Poisson, entre outros.

A teoria da elasticidade é composta por um conjunto de modelos matemáticos que tratam das relações entre as distribuições de tensões, deformações e deslocamentos em sólidos elásticos sob a influência de forças externas (Sadd, 2004).

Como ponto de partida para a apresentação da teoria da elasticidade, será necessário definir, aqui, as diferentes respostas que os sólidos apresentam frente aos esforços aplicados sobre eles (figura A.1):

Elásticos: os sólidos elásticos apresentam deformação proporcional ao esforço aplicado sobre eles, e esta deformação é totalmente reversível após a remoção dos esforços.

Plásticos: os sólidos plásticos não apresentam deformação até um valor-limite de tensão ser atingido, e a partir deste momento ocorre deformação, que é irreversível. 
Viscosos: em geral, materiais viscosos são líquidos ou materiais que apresentam propriedades similares a líquidos. A taxa de deformação varia com o tempo quando aplicada uma tensão constante.
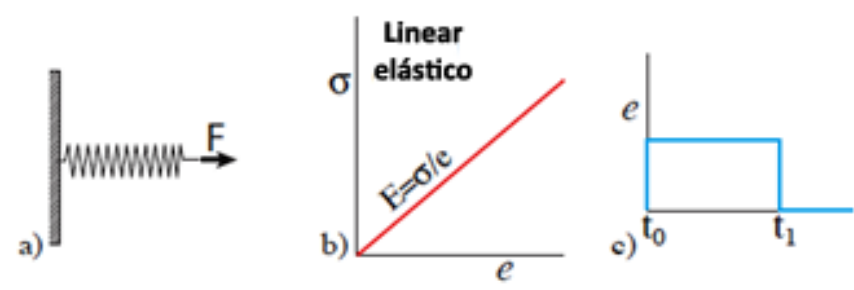

- Relação linear entre tensão e deformação - Resposta imediata à aplicaçäo de tensäo - Deformaçäo totalmente reversível (nāo permanente)
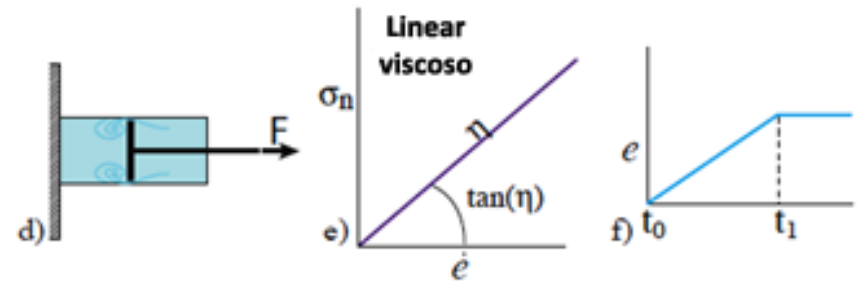

- Relação linear entre tensäo e deformaçäo - Tensão é dependente da taxa de deformação - Resposta atrasada em relaçäo à tensäo (quanto maior tempo, maior a deformaçäo) - Deformaçäo permanente
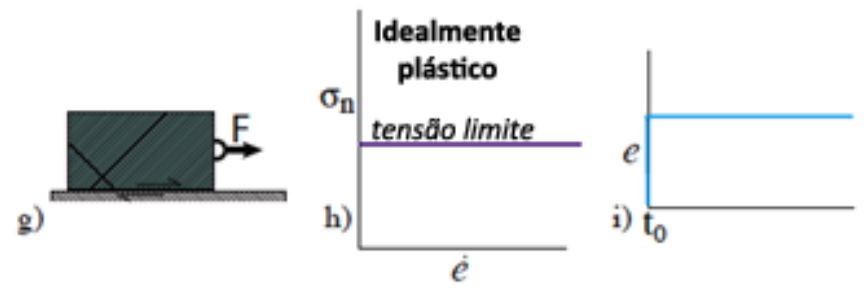

- Deformaçäo ocorre sob uma tensão constante, uma vez atingida a tensão limite - Tensäo constante, independente da deformaçä́o

- Deformaçäo permanente

Figura A.1 - Comportamento dos materiais segundo deformação elástica, viscosa e plástica, ilustrado por curvas tensão x deformação (b, e, h) e história de deformação $(c, f, i)$.

Na prática, os materiais sólidos não seguem perfeitamente nenhum dos três modelos citados acima. Em ensaios de compressão, o comportamento real dos materiais é aproximadamente elástico, até o momento em que o limite de resistência do material é excedido, quando ocorrem deformações plásticas em processos de ruptura do sólido. No entanto, aproximações para o modelo elástico têm sido usadas devido à sua maior simplicidade matemática, e os resultados obtidos em experimentos são bastante satisfatórios. Por este 
motivo, neste trabalho os maciços rochosos serão tratados como meios contínuos perfeitamente elásticos.

O conceito das relações elásticas entre forças e deformações foi proposto por Robert Hooke em 1678, mas uma base matemática mais sólida para a descrição dos fenômenos observados só foi desenvolvida no século XIX. Ao longo da história do estudo do comportamento mecânico dos sólidos encontram-se nomes como Navier, Cauchy, Young, Bernoulli, Lord Kelvin, Poisson, Lamé, Green, Saint-Venant, Betti, Airy, Kirchhoff, Lord Rayleigh, Love, Timoshenko, Kolosoff, Muskhelishvilli, entre outros.

O foco do presente trabalho não é a conceituação profunda do estudo de mecânica do contínuo e teoria da elasticidade. O estudo de tensões e deformações possui uma bibliografia muito vasta, cada uma com seu enfoque, e cada um dos tópicos abordados possui complexidade suficiente para um livro. Neste trabalho será feito um resumo dos conceitos principais, fundamentado em trabalhos de autores consagrados.

A mecânica dos sólidos para aplicações na mecânica dos materiais - estudo de barras metálicas, concreto, etc. - apresenta uma abordagem matemática muito complexa e refinada (cf. Timoshenko \& Goodier, 1970; Jaeger \& Cook, 1979; Gurtin, 1981). A aplicação do estudo de tensões para geologia pura costuma ser muito mais descritiva e conceitual (cf. Fossen, 2010; Davis \& Reynolds, 1996). Alguns autores tentaram produzir trabalhos que caracterizassem um meio-termo entre estas duas abordagens, bastante descritivas e com suficiente aprofundamento matemático (cf. Means, 1976; Ramsay \& Lisle, 2000). 
O presente trabalho buscará um equivalente deste último tipo de abordagem. Primeiro serão apresentados os conceitos descritivos fundamentais, para em seguida serem desenvolvidos os conceitos matemáticos que solidificam a base teórica. Para isto, a literatura supracitada será usada como base.

\section{A1.1 TENSÕES}

\section{A1.1.1 Base conceitual}

O conceito de "tensão" é similar ao conceito de "pressão", pois ambas lidam com forças de superfície atuando sobre uma unidade de área. A relação é simples, definida pela equação A.1:

$$
\vec{\sigma}=\frac{\vec{F}}{A}
$$

Em que $\vec{\sigma}$ é o vetor tensão, resultado da razão da atuação do vetor força $\vec{F}$ sobre uma área $A$.

Os sólidos reais dificilmente estão sujeitos à atuação de uma única componente de força. As forças atuantes sobre um determinado ponto no espaço são combinadas e atuam sobre o sólido em várias direções. Podemos admitir que as forças atuam em planos imaginários nos pontos do espaço, o que nos permite realizar associações que resultam na relação força/área, que caracteriza tensão.

Davis \& Reynolds (1996, p.109), Ramsay \& Lisle (2000, p. 702) definem "estados de tensão" como a coleção de tensões atuando nos planos das infinitas orientações que passam por um único ponto discreto de um corpo em um determinado instante de tempo. 
Uma analogia simples apresentada por Davis \& Reynolds é a que relaciona forças e tensões com flechas e alvos: uma única flecha atingindo um alvo representa uma força com determinada magnitude atuando sobre um plano com determinada área; o comprimento da flecha é proporcional à magnitude da força, e a orientação relativa da flecha em relação ao alvo representa a direção de atuação da força em relação ao plano.

Pensemos agora em um conjunto infinitamente numeroso de flechas atingindo um alvo esférico em todas as direções possíveis. Esta é a analogia com estado de tensões (Figura A.2). Um detalhe importante é que a dimensão e orientação das flechas neste alvo esférico são bastante ordenadas, isto é, o arranjo de forças que compõem este sistema é, para os casos reais, muito regular.

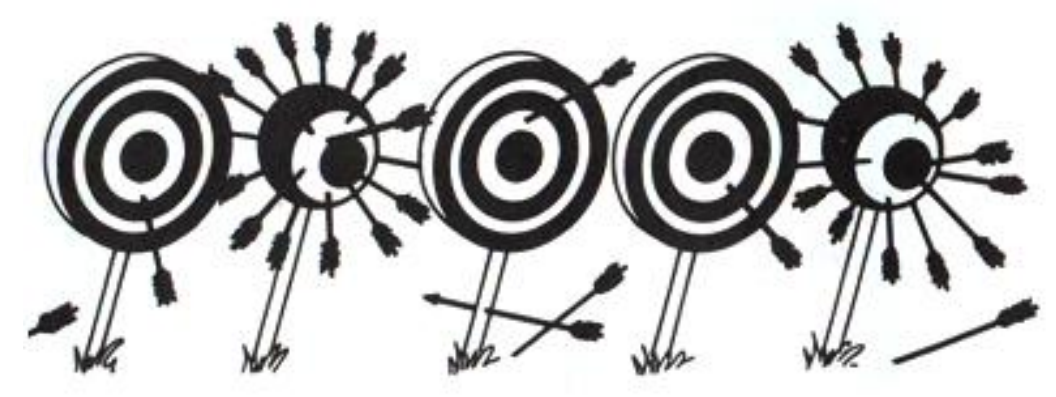

Figura A.2 - uma flecha atingindo um alvo é o equivalente a um vetor de força atuando sobre um plano. Um alvo esférico com infinitas flechas ao seu redor é o equivalente a um estado de tensões (Davis \& Reynolds, 1996).

Em um estado de tensões qualquer, existe um par de tensões que assume valor máximo, um par de tensões que assume valor intermediário e um par de tensões que assumo valor mínimo. Em cada um destes pares, a orientação do vetor $\vec{\sigma}$ será oposta, para que haja equilíbrio no sistema (isto é, não exista uma força resultante que provoque aceleração). Estes pares especiais são 
chamados tensões principais, e são indexados respectivamente $\sigma_{1}$ (tensão principal máxima), $\sigma_{2}$ (tensão principal intermediária) e $\sigma_{3}$ (tensão principal mínima).

Naturalmente, existem outros valores de tensão além destes três pares principais. O conjunto de todas as tensões que atuam sobre um ponto no espaço é descrito geometricamente na forma de um elipsoide, cujos eixos principais estão associados aos vetores das tensões principais (figura A.3). Um plano arbitrário que cruze este elipsoide terá atuando sobre ele as tensões principais $\sigma_{1}, \sigma_{2}$ e $\sigma_{3}$. A partir das tensões principais, é possível estabelecer as tensões principal e cisalhante atuando sobre este plano (Davis \& Reynolds, 1996).

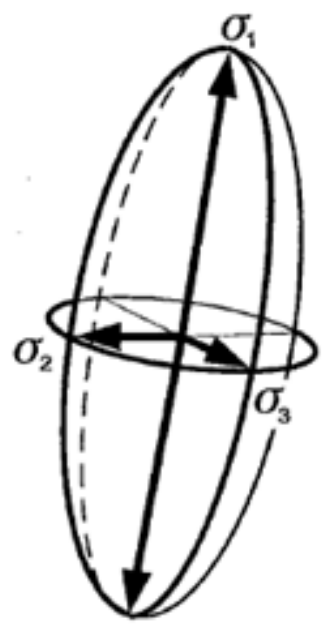

Figura A.3 - Elipsoide de tensões (Ramsay \& Lisle, 2000).

O conjunto de estados de tensão em vários pontos do espaço é denominado campo de tensões. O campo de tensões pode ser homogêneo, se os estados de tensões forem iguais ao longo de todo o espaço analisado, ou pode ser heterogêneo, se os estados de tensões forem variáveis no espaço. 
A figura A.4 mostra um espaço cartesiano bidimensional $(x, y)$ no qual são avaliados os estados de tensão a partir das tensões principais $\sigma_{1}$ e $\sigma_{2}$.

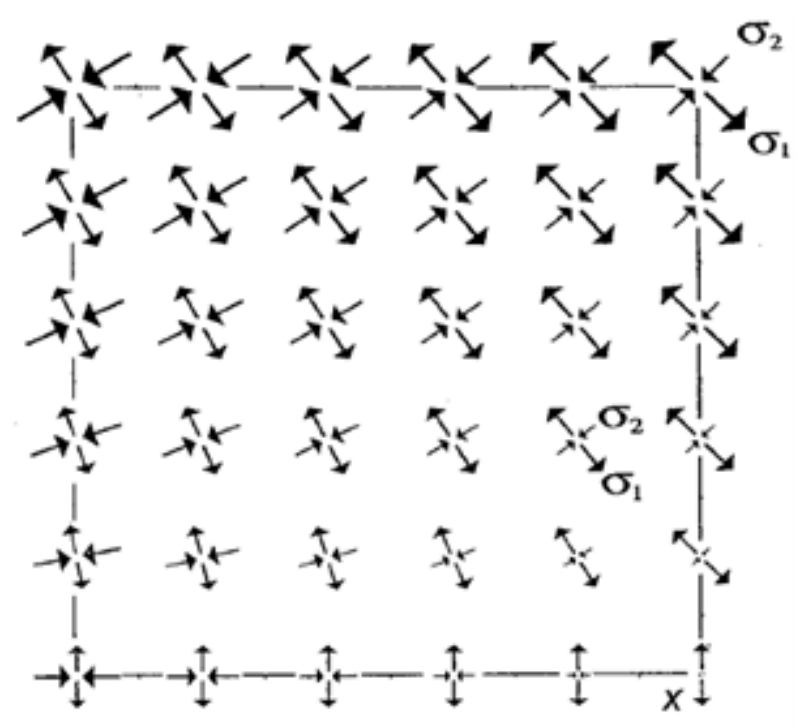

Figura A.4 - Espaço cartesiano com diversos estados de tensão, diferentes entre si, caracterizando um campo de tensões heterogêneo (Ramsay \& Lisle, 2000).

O campo de tensões apresentado na figura A.4 é heterogêneo, pois os estados de tensão são variáveis com a posição $(\mathrm{x}, \mathrm{y})$. Em um campo de tensões homogêneo, as componentes de tensão são constantes ao longo de todo o espaço $(x, y)$.

\section{A1.1.2 Base matemática}

O ponto arbitrário no espaço, com o qual vínhamos trabalhando, passa agora a ser um sólido cúbico no qual atuam forças diversas em várias direções faremos isso para que o ponto tenha faces, com determinada área, e as forças aplicadas sobre elas possam ser então redefinidas como tensões. Para simplificar os cálculos, o cubo tem suas faces orientadas paralelamente aos eixos $x, y$ e z (Figura A.5). 


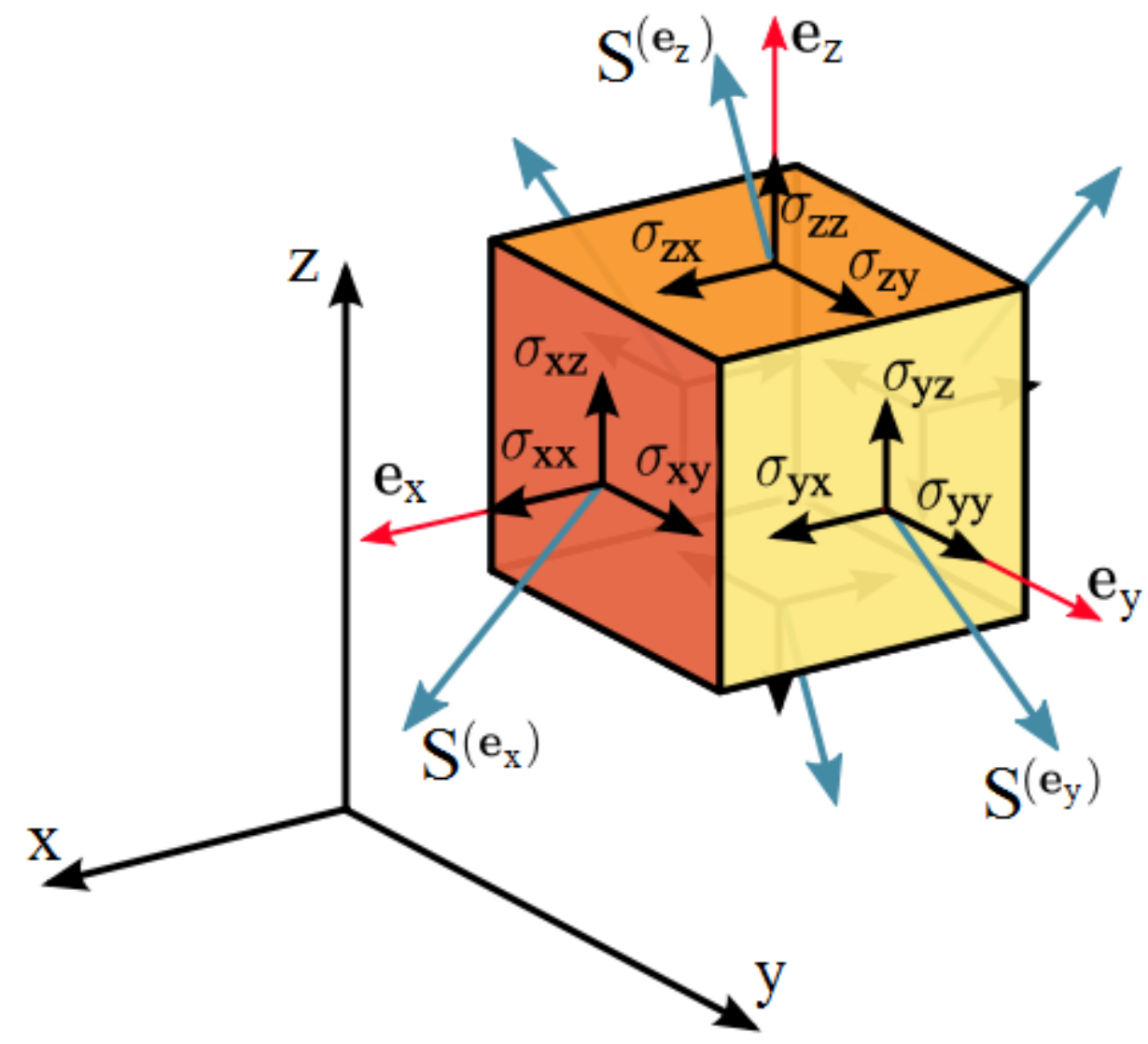

Figura A.5 - descrição vetorial das tensões atuantes nas faces de um cubo orientado segundo os eixos cartesianos $(\mathrm{x}, \mathrm{y}, \mathrm{z})$.

A figura A.5 mostra que:

- cada uma das 6 faces do cubo é um plano, com determinada área, e as forças atuantes na superfície de cada face produzirão uma tensão resultante $\overrightarrow{S_{n}}$ atuante sobre ela.

- cada tensão resultante pode ser decomposta em seus componentes normal (ortogonal ao plano) e cisalhantes (paralelos ao plano). As tensões cisalhantes serão orientadas de acordo com os eixos cartesianos.

- Como o cubo de referência está alinhado de acordo com os eixos cartesianos, podemos usar este sistema de referência e adotar uma notação na forma 
indicial, em que $\sigma_{\mathrm{ij}}$ é a tensão atuante no plano i e orientado na direção j. Para tensões normais, $\mathrm{i}=\mathrm{j}$ e para tensões cisalhantes $\mathrm{i} \neq \mathrm{j}$.

A tensão atuante sobre um plano arbitrário $\mathrm{P}$ envolve a relação entre as magnitudes das tensões, descritas pelo estado de tensões, e a orientação relativa do estado de tensões com respeito ao plano.. Em análises tridimensionais, a relação pode ser calculada por meio de matrizes. $\mathrm{P}$ pode ser representado pelo versor $\vec{P}$, um vetor unitário perpendicular ao plano que descreve sua orientação, em relação aos eixos $x, y$ e z:

$$
\vec{P}=\left[\begin{array}{l}
P_{x} \\
P_{y} \\
P_{z}
\end{array}\right]
$$

A fórmula de Cauchy resolve o cálculo da tensão resultante $\vec{S}$ atuante sobre um plano $\vec{P}$ usando os elementos $P_{x}, P_{y}$ e $P_{z}$ e as componentes de tensão $\sigma_{i j}$ atuantes nas faces do cubo da figura 4. Algebricamente, $\vec{S}$ é calculada em cada uma das direções $\mathrm{x}, \mathrm{y}$ e $\mathrm{z}$, de onde é extraído o vetor da tensão resultante:

$$
\begin{aligned}
& \vec{S}=\left[\begin{array}{l}
S_{x} \\
S_{y} \\
S_{z}
\end{array}\right] \\
& S_{x}=\sigma_{x x} P_{x}+\sigma_{x y} P_{y}+\sigma_{x z} P_{z} \\
& S_{y}=\sigma_{y x} P_{x}+\sigma_{y y} P_{y}+\sigma_{y z} P_{z} \\
& S_{z}=\sigma_{z x} P_{x}+\sigma_{z y} P_{y}+\sigma_{z z} P_{z}
\end{aligned}
$$

Ou, matricialmente: 


$$
\left[\begin{array}{l}
S_{x} \\
S_{y} \\
S_{z}
\end{array}\right]=\left[\begin{array}{lll}
\sigma_{x x} & \sigma_{x y} & \sigma_{x z} \\
\sigma_{y x} & \sigma_{y y} & \sigma_{y z} \\
\sigma_{z x} & \sigma_{z y} & \sigma_{z z}
\end{array}\right] \cdot\left[\begin{array}{c}
P_{x} \\
P_{y} \\
P_{z}
\end{array}\right]
$$

A notação matricial pode ser simplificada, resultando na relação $\vec{S}=\boldsymbol{\sigma} \vec{P}$.

A matriz $\boldsymbol{\sigma}$ é denominada matriz de tensões, é a descrição matemática do elipsoide de tensões e descreve o estado de tensões no ponto $P(x, y, z)$. Seus elementos são as componentes de tensão apresentadas na decomposição das tensões mostradas na figura 4.

A matriz de tensões pode ter representada alternativamente com os índices da diagonal principal simplificados $\left(\sigma_{x x}=\sigma_{x}, \sigma_{y y}=\sigma_{y}, \sigma_{z z}=\sigma_{z}\right)$. Os elementos situados fora da diagonal principal representam a tensão cisalhante e podem ser representados pela letra grega $\tau$, com os respectivos índices $\left(\tau_{x y}, \tau_{x z}\right.$, etc.).

Como estamos considerando o sistema em equilíbrio estático, assumimos que as forças atuantes se anulam e não ocorre aceleração linear nem angular, de modo que o corpo não sofra translação nem rotação (Pollard \& Fletcher, 2005; Ramsay \& Lisle, 2000). Deste modo, a matriz de tensões pode ser simplificada, em que os elementos $\sigma_{\mathrm{ij}}$ são iguais a $\sigma_{\mathrm{ji}}$, o que torna a matriz simétrica.

$$
\boldsymbol{\sigma}=\left[\begin{array}{ccc}
\sigma_{x} & \tau_{x y} & \tau_{x z} \\
& \sigma_{y} & \tau_{y z} \\
& & \sigma_{z}
\end{array}\right]
$$

Como visto acima, o conjunto de estados de tensão no espaço define o campo de tensões. Se os estados de tensão forem iguais em todos os pontos do espaço, então o campo de tensões é homogêneo, e pode ser definido por uma matriz de tensões com elementos constantes (equação A.9). Se, por outro lado, os estados de tensão forem variáveis no espaço e, assim, se tornarem funções 100 
de $x$, y e z, então o campo de tensões é heterogêneo, e pode ser definido por uma matriz de tensões com elementos variáveis (equação A.10).

$$
\begin{gathered}
\boldsymbol{\sigma}=\left[\begin{array}{lll}
a & b & c \\
& d & e \\
& & f
\end{array}\right] \\
\boldsymbol{\sigma}=\left[\begin{array}{ccc}
a y^{2} & b x^{2} & c \\
& d x & -2 b x z \\
& & e
\end{array}\right]
\end{gathered}
$$

\section{A1.2 DEFORMAÇÕES}

O conceito de deformação pode ser entendido como a variação na configuração dos pontos de um corpo no espaço. Sendo assim, um corpo é deformado de seu estado inicial se ocorre variação na relação entre a configuração original e final de qualquer um dos pontos que o compõem.

\section{A1.2.1 Base conceitual}

Embora as deformações sejam as respostas dos corpos aos esforços aos quais são submetidos, o estudo inicial das deformações irá tratar de sua análise pura, isto é, vamos tratar da reconstrução dos movimentos aplicados na formação e deformação das rochas sem levar em conta as forças responsáveis por estes movimentos. Em capítulos seguintes vamos elaborar as relações complexas existentes entre os esforços e as deformações decorrentes de sua aplicação.

A resposta de um corpo submetido a deformações pode ser de dois tipos: rígida e não rígida (Davis \& Reynolds, 1996). Na deformação rígida o corpo mantém o posicionamento relativo de todos os pontos que o compõem (caso de translação e rotação); na deformação não rígida ocorre variação na relação 
entre os pontos (caso de dilatação e distorção). A figura A.6 resume as possíveis resposta de um corpo às deformações:

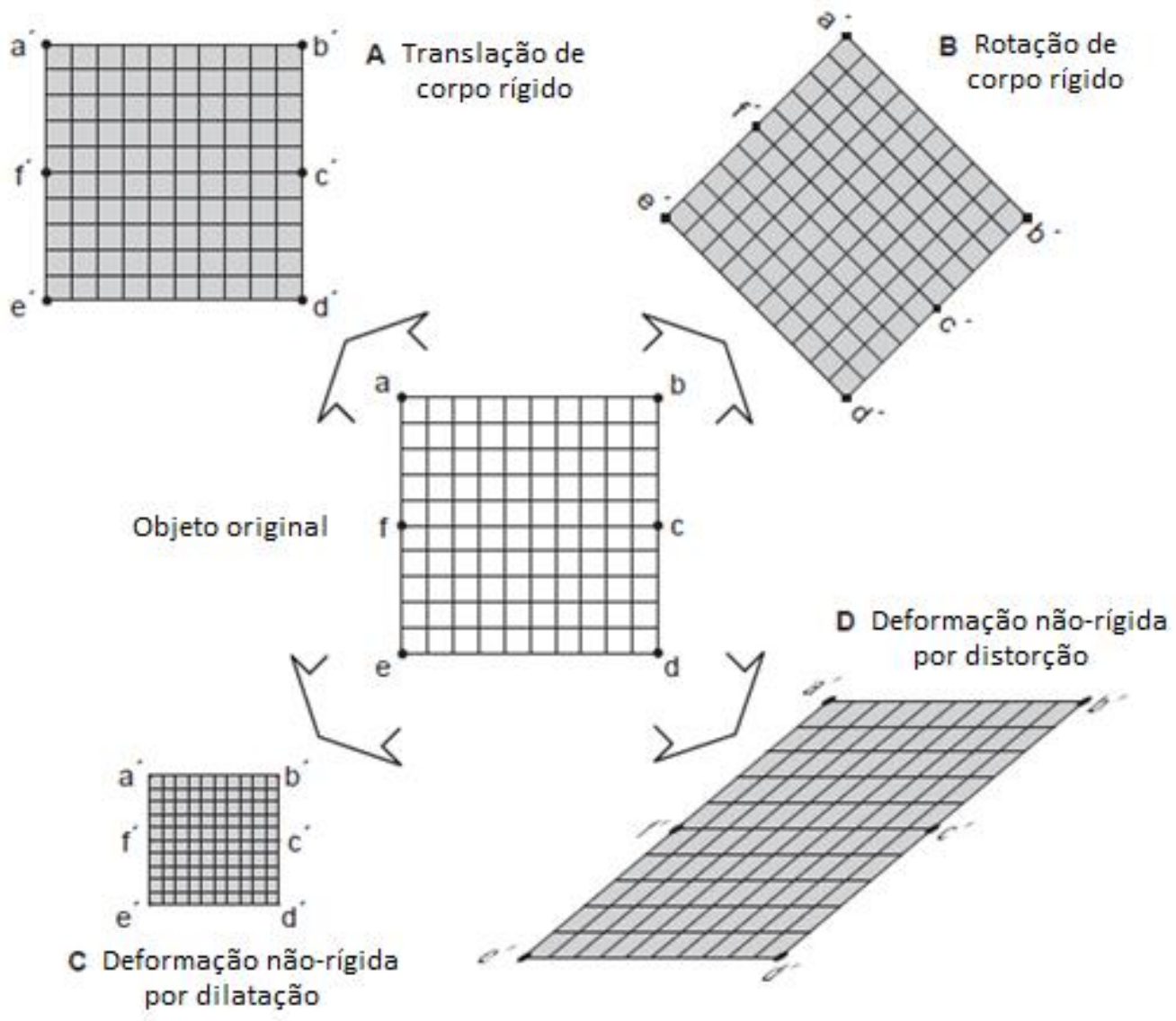

Figura A.6 - possíveis tipos de deformação (Davis \& Reynolds ,1996).

A deformação não rígida é o que se entende por strain ${ }^{4}$. Em qualquer um dos casos descritos acima, a deformação é homogênea, isto é (Davis \& Reynolds, 1996; Hudson \& Harrison, 1997): (a) linhas retas permanecem retas, e linhas paralelas permanecem paralelas; (b) círculos deformam para elipses;.(c) elipses deformam para outras elipses. De maneira geral, entende-se que a deformação não-rígida deve ser uniforme na deformação homogênea.

\footnotetext{
${ }^{4}$ Não existe um termo específico em português para diferenciar esse tipo de deformação. No presente estudo, a deformação será tratada de maneira geral, e deformação rígida e não rígida fazem parte de uma mesma matriz de deformação (F, ver abaixo).
} 
A deformação heterogênea é muito complexa. De acordo com Ramsay (1967): "É quase impossível aplicar a teoria matemática a sistemas estruturais heterogêneos, irregularmente deformados".

Deste modo, assumimos uma simplificação, restringindo as análises de deformação para o universo da deformação homogênea. Embora seja uma simplificação, as deformações heterogêneas podem ser divididas em subdomínios de deformação homogênea, resultando em uma análise final bastante satisfatória (Davis \& Reynolds, 1996).

\section{A1.2.2 Base matemática}

Vamos assumir que um ponto de um corpo no espaço tem sua posição determinada por coordenadas cartesianas $P=P(X, Y, Z)$, no estado inicial, ou indeformado. Com a deformação, este ponto é movido, e sua configuração passa a ser $p=p(x, y, z)$, no estado final ${ }^{5}$ ou deformado.

Conceitos usados para tratar da relação entre os estados inicial (indeformado) e final (deformado) do ponto, ou conjunto de pontos no espaço são o deslocamento e a deformação.

O deslocamento é um vetor que liga as coordenadas do ponto nos dois estados, sendo assim, sua descrição é:

$$
\vec{u}=\left[\begin{array}{l}
u_{x} \\
u_{y} \\
u_{z}
\end{array}\right]=\left[\begin{array}{l}
p_{x}-P_{X} \\
p_{y}-P_{Y} \\
p_{z}-P_{Z}
\end{array}\right]
$$

\footnotetext{
${ }^{5}$ Denominaremos "estado final" porque consideramos apenas duas etapas, deformado e indeformado. No entanto, o movimento de um corpo pressupõe a possibilidade de vários estágios de deformação, e qualquer estado além do inicial pode ser considerado deformado.
} 
As magnitudes dos deslocamentos não são necessariamente constantes em todos os pontos que compõem o corpo. Para representar a variação dos deslocamentos ao longo dos eixos cartesianos, utiliza-se o gradiente de deslocamentos, com derivadas parciais em relação às direções $x, y$ e z:

$$
\boldsymbol{\nabla} \overrightarrow{\mathbf{u}}=\left[\begin{array}{lll}
\frac{\partial u_{x}}{\partial x} & \frac{\partial u_{x}}{\partial y} & \frac{\partial u_{x}}{\partial z} \\
\frac{\partial u_{y}}{\partial x} & \frac{\partial u_{y}}{\partial y} & \frac{\partial u_{y}}{\partial z} \\
\frac{\partial u_{z}}{\partial x} & \frac{\partial u_{z}}{\partial y} & \frac{\partial u_{z}}{\partial z}
\end{array}\right]
$$

A deformação é a expressão matemática que relaciona as coordenadas nos dois estados, por meio de equações de transformação de coordenadas. Estas equações podem ser descritas para o estado indeformado, a partir das coordenadas no estado deformado, ou vice versa. A expressão geral para a descrição do estado deformado a partir do estado indeformado é:

$x=f(X)$,

que define a coordenada do estado deformado em função da coordenada original. O mais comum é que a notação siga o padrão de indicar as coordenadas minúsculas para o estado deformado, e coordenadas maiúsculas para o estado indeformado.

Há outros meios de se expressar a deformação, e estudos mais aprofundados sobre o tema foi realizado por Means (1976) e Gurtin (1981).

Da mesma forma que os deslocamentos, as magnitudes das deformações não são necessariamente constantes em todos os pontos que compõem o corpo. Para representar a variação das deformações ao longo dos eixos cartesianos, utiliza-se o gradiente de deformação: 


$$
\mathbf{F}=\left[\begin{array}{lll}
\frac{\partial x}{\partial X} & \frac{\partial x}{\partial Y} & \frac{\partial x}{\partial Z} \\
\frac{\partial y}{\partial X} & \frac{\partial y}{\partial Y} & \frac{\partial y}{\partial Z} \\
\frac{\partial z}{\partial X} & \frac{\partial z}{\partial Y} & \frac{\partial z}{\partial Z}
\end{array}\right]
$$

\section{A1.2.2.1 Deformação finita e deformação infinitesimal}

A deformação apresenta várias abordagens, incluindo os estudos de deformação finita e deformação infinitesimal, que abordam respectivamente deformações de grandes magnitudes e deformações de pequenas magnitudes. O estudo de deformação finita pode ser encontrado em vasta literatura (cf. Ramsay \& Huber, 1984; Davis \& Reynolds, 1996; Means, 1976). No entanto, para este trabalho consideram-se as deformações de pequena magnitude, portanto iremos utilizar os conceitos da deformação infinitesimal (Means, 1976; Gurtin, 1981).

A diferença fundamental entre a análise de deformação finita e infinitesimal é que na infinitesimal os coeficientes derivativos $\frac{\partial u_{i}}{\partial j}$ são pequenos, e suas potências e produtos podem ser desconsiderados dos cálculos principais (Jaeger, 1971). Além disso, os gradientes de deslocamento, em se considerando os estados deformado e indeformado, resultam em valores tão próximos que podem ser considerados como iguais, isto é, independe se a referência usada é a coordenada inicial ou final dos pontos do corpo (Means, 1976).

$\mathrm{Na}$ análise infinitesimal, a relação entre as matrizes $\boldsymbol{\nabla \mathbf { u }}$ e $\mathbf{F}$ é:

$$
\nabla \overrightarrow{\mathbf{u}}=\boldsymbol{F}-\boldsymbol{I}
$$

Em que I é a matriz identidade. 
A matriz de deformações infinitesimais $(\boldsymbol{\varepsilon})$ é definida a partir do gradiente de deslocamentos como:

$\boldsymbol{\varepsilon}=\frac{1}{2}\left(\boldsymbol{\nabla} \overrightarrow{\boldsymbol{u}}+\nabla \overrightarrow{\boldsymbol{u}}^{t}\right)$

Esta relação resulta em:

$\boldsymbol{\varepsilon}=\left[\begin{array}{ccc}\frac{\partial u_{x}}{\partial x} & \frac{1}{2}\left(\frac{\partial u_{x}}{\partial y}+\frac{\partial u_{y}}{\partial x}\right) & \frac{1}{2}\left(\frac{\partial u_{x}}{\partial z}+\frac{\partial u_{z}}{\partial x}\right) \\ \frac{1}{2}\left(\frac{\partial u_{y}}{\partial x}+\frac{\partial u_{x}}{\partial y}\right) & \frac{\partial u_{y}}{\partial y} & \frac{1}{2}\left(\frac{\partial u_{y}}{\partial z}+\frac{\partial u_{z}}{\partial y}\right) \\ \frac{1}{2}\left(\frac{\partial u_{z}}{\partial x}+\frac{\partial u_{x}}{\partial z}\right) & \frac{1}{2}\left(\frac{\partial u_{z}}{\partial y}+\frac{\partial u_{y}}{\partial z}\right) & \frac{\partial u_{z}}{\partial z}\end{array}\right]$

\section{A1.2.2.2 Componentes de deformação:}

De maneira semelhante às tensões, as deformações atuantes em um corpo podem ser decompostas em duas componentes, uma normal e outra cisalhante. No caso das deformações, a componente normal representa o estiramento sofrido pelo corpo em determinado eixo, e a componente cisalhante representa o desvio da perpendicularidade entre duas retas ortogonais.

Segundo a definição de Jaeger (1971), a notação fundamental para descrever estas deformações é:

$\varepsilon_{i}=\frac{\partial u_{i}}{\partial j}$

com $i=j$, caracterizando o estiramento, e:

$\gamma_{i j}=\gamma_{j i}=\left(\frac{\partial u_{i}}{\partial j}+\frac{\partial u_{j}}{\partial i}\right)$

com $i \neq j$, descreve a deformação cisalhante. 
Desta maneira, a matriz $\varepsilon$ apresentada na equação $A .15$ pode ser reescrita da seguinte maneira:

$$
\boldsymbol{\varepsilon}=\left[\begin{array}{ccc}
\varepsilon_{x} & \frac{1}{2} \gamma_{x y} & \frac{1}{2} \gamma_{x z} \\
\frac{1}{2} \gamma_{x y} & \varepsilon_{y} & \frac{1}{2} \gamma_{y z} \\
\frac{1}{2} \gamma_{x z} & \frac{1}{2} \gamma_{y z} & \varepsilon_{z}
\end{array}\right]
$$

A matriz $\varepsilon$ é um tensor, análogo ao tensor das tensões, e descreve o estado de deformação de um ponto no espaço, no estado deformado. Esta matriz relaciona o vetor posição de um ponto $\vec{x}$ com o vetor deslocamento $\vec{u}$ conforme a equação A.19:

$\vec{u}=\varepsilon \vec{x}$

\section{A1.2.2.3 Compatibilidade}

As deformações foram analisadas até este momento no sentido de pontos, linhas e corpos com geometrias muito simples (quadrados, retângulos). No entanto, os corpos estudados na mecânica de rochas e geologia estrutural possuem dimensões e geometrias bem mais complexas, o que cria a necessidade de analisar a deformação em maciços rochosos como um todo e não apenas em linhas ou pontos isolados.

Um maciço rochoso, que é um corpo com geometria mais complexa, pode ser dividido em vários elementos menores, de geometria simples. Cada um destes elementos menores sofrerá deformação, e o conjunto destes elementos, que são adjacentes entre si, deve sofrer deformação de modo que não sejam criadas sobreposições ou buracos entre os elementos individuais (princípio básico de mecânica dos meios contínuos). Ou seja, para que o maciço rochoso 
permaneça contínuo, as deformações em diferentes posições dentro do maciço deverão ser compatíveis entre si.

Este é o conceito de compatibilidade de deformações, apresentado de maneira bastante didática em Ramsay \& Lisle (2000, p.721), da qual a figura A.7 foi extraída e resume o conceito descrito acima.

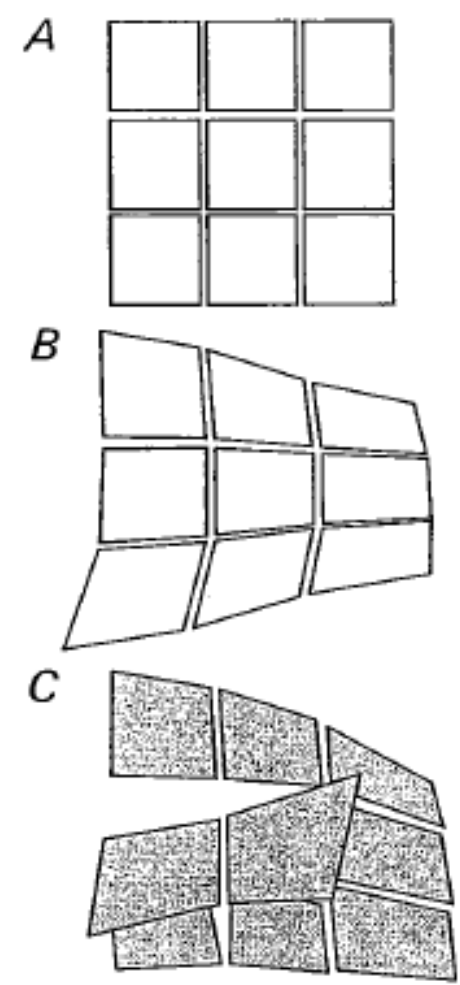

Figura A.7 - conceito de compatibilidade de deformações. Em A, um corpo indeformado é dividido em elementos quadrados. Em B, um padrão de deformações compatível, com manutenção da integridade/continuidade do corpo. Em C, um padrão de deformações incompatível, com criação de vazios e sobreposições (Ramsay \& Lisle, 2000).

Matematicamente, o conceito de compatibilidade de deformações é aplicado sobre as equações simples de deformação, já estudadas. Ramsay \& Lisle (2000) apresentam a compatibilidade de deformação como gradientes das 
equações A.16 e A.17 em termos de x, y e z. Após realizar diferenciações nestas equações, o resultado final da compatibilidade de deformação é um conjunto de 6 equações:

$\frac{\partial^{2} \varepsilon_{y}}{\partial z^{2}}+\frac{\partial^{2} \varepsilon_{z}}{\partial y^{2}}=2 \frac{\partial^{2} \gamma_{y z}}{\partial y \partial z}$

$\frac{\partial^{2} \varepsilon_{z}}{\partial x^{2}}+\frac{\partial^{2} \varepsilon_{x}}{\partial z}=2 \frac{\partial^{2} \gamma_{z x}}{\partial z \partial x}$

$\frac{\partial^{2} \varepsilon_{x}}{\partial y^{2}}+\frac{\partial^{2} \varepsilon_{y}}{\partial x^{2}}=2 \frac{\partial^{2} \gamma_{x y}}{\partial x \partial y}$

$\frac{\partial^{2} \varepsilon_{x}}{\partial y \partial z}=\frac{\partial}{\partial x}\left(-\frac{\partial \gamma_{y z}}{\partial x}+\frac{\partial \gamma_{z x}}{\partial y}+\frac{\partial \gamma_{x y}}{\partial z}\right)$

$\frac{\partial^{2} \varepsilon_{y}}{\partial z \partial x}=\frac{\partial}{\partial y}\left(-\frac{\partial \gamma_{y z}}{\partial x}+\frac{\partial \gamma_{z x}}{\partial y}+\frac{\partial \gamma_{x y}}{\partial z}\right)$

$\frac{\partial^{2} \varepsilon_{z}}{\partial x \partial y}=\frac{\partial}{\partial x}\left(-\frac{\partial \gamma_{y z}}{\partial x}+\frac{\partial \gamma_{z x}}{\partial y}+\frac{\partial \gamma_{x y}}{\partial z}\right)$

\section{A1.3 RELAÇÕES CONSTITUTIVAS}

Fossen (2010) apresenta o conceito de tensões como: "tensões são um dos conceitos mais abstratos em geologia estrutural, pois nunca são observadas de maneira direta, embora seu resultado possa ser observado se resultarem em deformações de qualquer tipo [...], no entanto o mais profundo conhecimento sobre o estado de tensões não permite compreender as deformações resultantes a menos que se conheçam outras informações como propriedades mecânicas da rocha, temperatura, pressão e condições de contorno.".

Isso significa que tensões e deformações se relacionam, mas há outros parâmetros envolvidos na teoria da elasticidade que também devem ser estudados para descrever esta relação de maneira completa. 
A teoria da elasticidade aproxima os sólidos estudados para materiais homogêneos, isotrópicos, e linear-elásticos. Isto significa que a relação entre tensão e deformação é diretamente proporcional, de acordo com a Lei de Hooke (equações A.26 e A.27):

Num corpo idealmente elástico, a deformação é proporcional à tensão aplicada e a relação $\varepsilon=f(\sigma)$ descreve uma reta (figura A.8).

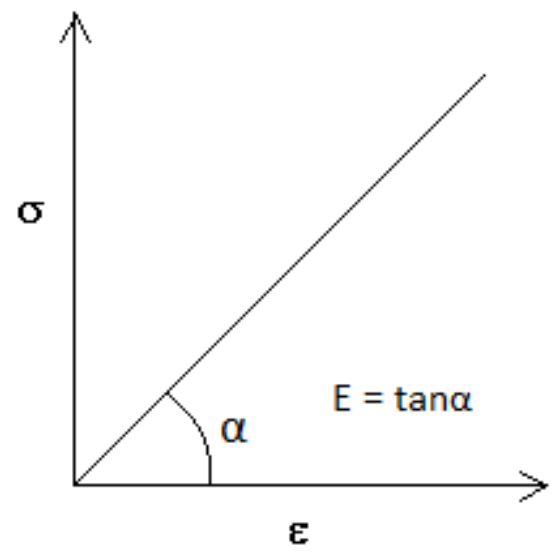

Figura A.8 - Relação entre tensão $(\sigma)$ e deformação $(\varepsilon)$, para materiais lineares-elásticos.

$\sigma=E \varepsilon$

$\varepsilon=\frac{\sigma}{E}$

onde $\sigma$ é a tensão aplicada, $E$ é o módulo de elasticidade (ou Módulo de Young) e $\varepsilon$ é a deformação sofrida pelo material.

Outro parâmetro característico dos sólidos é o coeficiente de Poisson, representado pela letra grega $v(\mathrm{nu})$. Este coeficiente relaciona a deformação lateral de um corpo quando este se deforma longitudinalmente.

$v=\frac{\varepsilon_{\text {lat }}}{\varepsilon_{\text {long }}}$ 
Como visto em itens anteriores, a tensão e deformação podem ser caracterizadas por seus componentes cartesianos $\left(\sigma_{x x}, \tau_{x y}, \varepsilon_{x x}, \gamma_{x y}\right.$, etc). A relação completa é dada pelo conjunto de equações conhecido como lei geral de Hooke para sólidos elasticos isotrópicos (Timoshenko \& Goodier, 1970; Ramsay \& Lisle, 2000; Pollard \& Fletcher, 2005; Sadd, 2004):

$$
\begin{aligned}
& \varepsilon_{x}=\frac{1}{E}\left[\sigma_{x}-v\left(\sigma_{y}+\sigma_{z}\right)\right] \\
& \varepsilon_{y}=\frac{1}{E}\left[\sigma_{y}-v\left(\sigma_{z}+\sigma_{x}\right)\right] \\
& \varepsilon_{z}=\frac{1}{E}\left[\sigma_{z}-v\left(\sigma_{x}+\sigma_{y}\right)\right] \\
& \gamma_{x y}=\frac{2(1+v)}{E} \tau_{x y} \\
& \gamma_{y z}=\frac{2(1+v)}{E} \tau_{y z} \\
& \gamma_{x z}=\frac{2(1+v)}{E} \tau_{x z}
\end{aligned}
$$

Este conjunto de equações pode ser escrito de maneira compacta em uma relação matricial da forma

$$
\varepsilon_{i j}=D_{i j k l} \sigma_{k l}
$$

Em que D é a matriz constitutiva. Os elementos da matriz, $\mathrm{D}_{\mathrm{ijk} k}$, são constantes de proporcionalidade entre $\varepsilon$ e $\sigma$, denominados rigidez (Means, 1976), e são descritos em termos dos parâmetros elásticos $E$ e $v$ do material, que relacionam tensão e deformação. A relação matricial expandida então se apresenta da seguinte forma: 


$$
\left[\begin{array}{c}
\varepsilon_{x} \\
\varepsilon_{y} \\
\varepsilon_{z} \\
\gamma_{x y} \\
\gamma_{y z} \\
\gamma_{x z}
\end{array}\right]=\left[\begin{array}{cccccc}
\frac{1}{E} & -\frac{v}{E} & -\frac{v}{E} & 0 & 0 & 0 \\
-\frac{v}{E} & \frac{1}{E} & -\frac{v}{E} & 0 & 0 & 0 \\
-\frac{v}{E} & -\frac{v}{E} & \frac{1}{E} & 0 & 0 & 0 \\
0 & 0 & 0 & \frac{2(1+v)}{E} & 0 & 0 \\
0 & 0 & 0 & 0 & \frac{2(1+v)}{E} & 0 \\
0 & 0 & 0 & 0 & 0 & \frac{2(1+v)}{E}
\end{array}\right]\left[\begin{array}{c}
\sigma_{x} \\
\sigma_{y} \\
\sigma_{z} \\
\tau_{x y} \\
\tau_{y z} \\
\tau_{x z}
\end{array}\right]
$$

Gurtin (1981) e Sadd (2005) apresentam ainda a lei geral de Hooke em forma matricial utilizando outros parâmetros elásticos, o módulo de Lamé $(\lambda)$ e módulo de cisalhamento $(\mu)$.

Estes dois parâmetros são definidos por relações entre $E$ e $v$.

$$
\begin{aligned}
& \lambda=\frac{E v}{(1+v)(1-2 v)} \\
& \mu=\frac{E}{2(1+v)}
\end{aligned}
$$

Segundo Gurtin (1981), a tensão é descrita a partir da deformação de acordo com a equação A.39:

$$
\boldsymbol{\sigma}=2 \mu \boldsymbol{\varepsilon}+\lambda(\operatorname{tr} \boldsymbol{\varepsilon}) \boldsymbol{I}
$$

Esta equação pode ser adaptada, para que seja descrita a deformação a partir da tensão, como se apresenta na equação A.40.

$$
\boldsymbol{\varepsilon}=\frac{1}{2 \mu}\left(\boldsymbol{\sigma}-\frac{\lambda}{3 \mu+3 \lambda}(\operatorname{tr} \boldsymbol{\sigma}) \boldsymbol{I}\right)
$$




\section{APÊNDICE II RESISTÊNCIA DAS ROCHAS E CRITÉRIOS DE RUPTURA}

No momento em que uma rocha perde sua integridade e sua capacidade de atender às solicitações impostas a elas, diz-se que ela rompeu. $O$ fenômeno de ruptura em rocha e em maciços rochosos está diretamente associado à presença e atuação dos esforços (tensões) sobre o material. Se, sobre um material rochoso, atuarem mais esforços do que ele conseguir resistir, então este material irá perder sua integridade.

O comportamento da rocha frente aos esforços pode ser estudado em laboratório: amostras de rocha são submetidas a ensaios com tensão controlada (estados de tensão conhecidos, definidos pelas tensões principais $\sigma_{1}$ e $\sigma_{2}$ ). É comum se associar este estado às tensões correspondentes ao pico da curva tensão-deformação (resistência de pico). Cabe lembrar que após o pico da curva tensão-deformação, a rocha não perde completamente sua capacidade de resistência, podendo atingir um estado de tensões denominado residual (resistência residual).

O estudo equivalente para maciços rochosos (incluindo também as descontinuidades presentes como fraturas ou falhas) pode ser realizado com a utilização de modelos de classificação de maciços rochosos.

As análises dos estados de tensão necessários para que a rocha ou maciço rochoso se rompa são conhecidos como critérios de ruptura (Jaeger, 1971; Hoek et al., 1993; Davis \& Reynolds, 1996; Wyllie \& Mah, 2004; Hoek, 2007; Fossen, 2010). 
Desde o século XVIII, vêm sido desenvolvidos critérios de ruptura para a determinação da resistência de rochas. Os itens seguintes descrevem os diferentes métodos mais utilizados e aceitos até o momento.

\section{A2.1 CRITÉRIO DE MOHR-COULOMB}

A determinação de resistência para rochas sob compressão foi definida por Coulomb (1773) e aperfeiçoada por Mohr (1900), resultando no critério de ruptura de Mohr-Coulomb.

Este critério utiliza parâmetros simples para rochas: várias amostras de um tipo de rocha são ensaiadas em laboratório, e são medidos vários possíveis estados de tensão (definidos por $\sigma_{1}$ e $\sigma_{2}$ ) nos quais a rocha se rompa por cisalhamento. Cada um destes estados de tensão define um círculo (círculo de Mohr). O desenho de uma linha tangente a todos os círculos determina a envoltória de ruptura, uma reta cuja equação é descrita pela equação A.41 e representada na figura $A .9$ :

$\tau=c+\sigma_{n} \operatorname{tg} \phi$

onde: $\tau$ é a resistência ao cisalhamento; $c$ é a coesão na superfície de ruptura; $\sigma_{\mathrm{n}}$ é a tensão normal ao plano de ruptura; $\phi$ é o ângulo de atrito. 


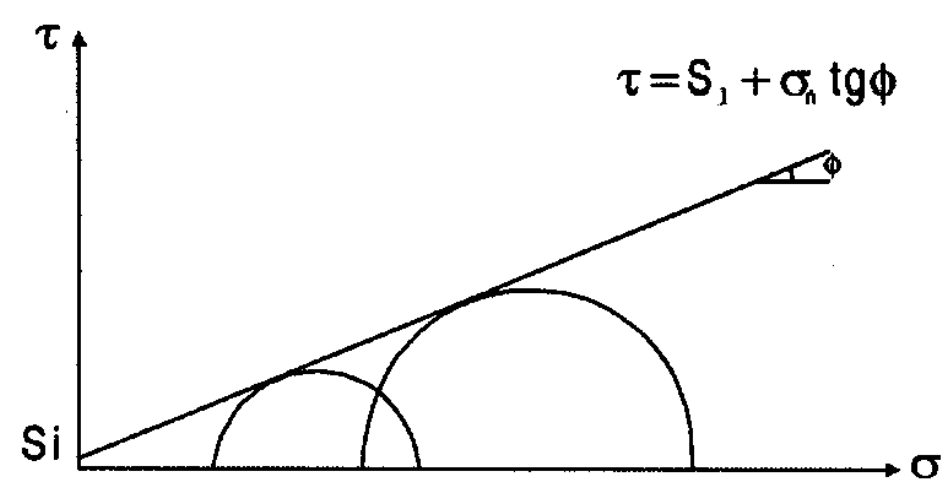

(a)

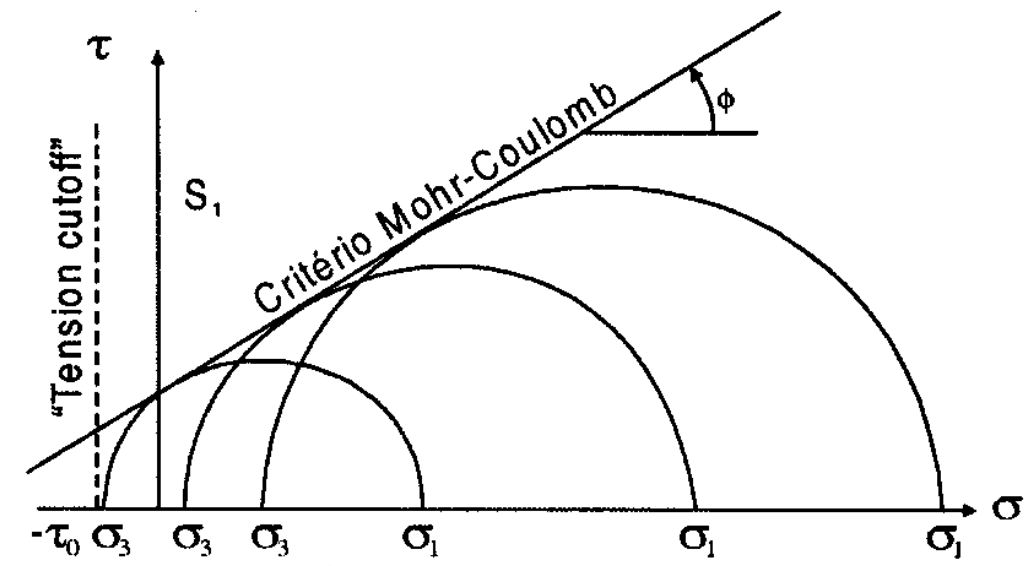

(b)

Figura A.9 - representação gráfica do critério de ruptura de Mohr-Coulomb.

O critério de Mohr-Coulomb é normalmente válido para solos, alguns tipos de rocha intacta e descontinuidades lisas e planas ou aquelas preenchidas por solos de granulometria fina. No entanto, para maciços rochosos e para uma grande variedade de tipos de rocha, nota-se claramente uma não linearidade para o gráfico Erro! Indicador não definido. $\sigma$ versus $\tau$ Erro! Indicador não definido.

\section{A2.2 CRITÉRIO DE GRIFFITH}

Ainda no âmbito do estudo das rochas intactas, Griffith (1921) observou a nãolinearidade para valores baixos ou negativos de $\sigma_{2}$. Foi definido, então, um cirtério de ruptura baseado na hipótese que a fratura é causada por 
concentração das tensões nas pontas de microfraturas existentes no material. Foi considerada a resistência à tração dos materiais ensaiados (equação A.42).

$\tau^{2}+4 T \sigma_{n}-4 T^{2}=0$

Em que $\mathrm{T}$ é a resistência à tração.

Esta equação desenha o seguinte gráfico (figura A.10):

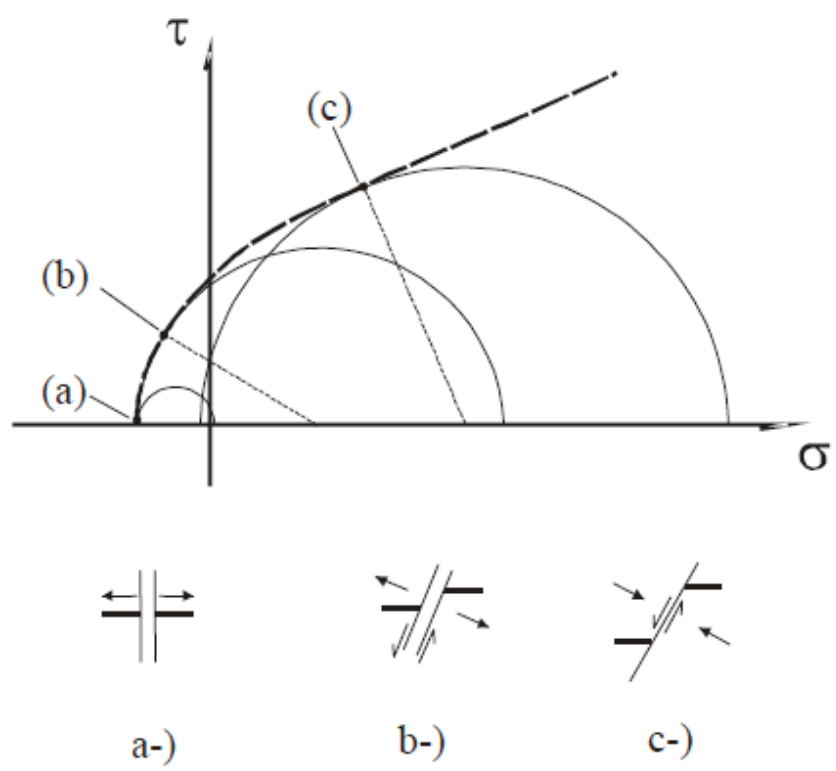

Figura A.10 - representação gráfica do critério de ruptura de Griffith.

O critério de ruptura de Griffith, originalmente desenvolvido em 1921, passou por diversas revisões e complementos. No entanto, este critério parecia ser bem aplicável para rochas intactas, mas ainda não era capaz de descrever a resistência de um maciço rochoso que contém descontinuidades.

\section{A2.3 CRITÉRIO DE HOEK-BROWN}

Este critério foi desenvolvido para gerar informações necessárias para projetos de escavações subterrâneas. Era preciso que fosse desenvolvido um critério que considerasse não apenas a rocha intacta, mas o maciço rochoso como um 
todo. O desenvolvimento da mecânica de rochas, a partir da década de 1960, levou diversos autores a buscarem soluções para o problema do comportamento de rocha intacta e maciços rochosos (Cook, 1965a; Cook, 1965b, Cook et al., 1966; Scholz, 1968a; Scholz, 1968b; Hoek, 1968; Hoek \& Brown, 1980a, Bieniawski, 1973, Barton et al., 1974, entre outros),

O critério de Hoek \& Brown (1980b) surgiu como uma adaptação do critério de Griffith para escavações subterrâneas. Os autores realizaram centenas de ensaios e chegaram numa relação empírica, assumindo que o maciço rochoso é confinado e a ruptura é controlada por movimentações em blocos de rocha individuais, separados por superfícies de fraturas criando um conjunto "caótico" sem direções preferenciais, resultando em um maciço isotrópico. A formulação original tem a seguinte forma:

$\sigma_{1}=\sigma_{3}+\sqrt{m \sigma_{3} \sigma_{c}+s \sigma_{c}^{2}}$

$\sigma_{c}$ é a resistência à compressão da rocha intacta

$m$ e $s$ são parâmetros de resistência de Hoek \& Brown.

Após uma série de revisões do critério de Hoek-Brown (cf. Hoek \& Marinos, 2007), foi estabelecida a versão mais atual, ainda empírica (Hoek et al., 2002), mas que já passava a levar em consideração métodos consideravelmente consistentes para caracterização de maciços rochosos, que deram origem aos critérios RMR (Bieniawski, 1989) e GSI (Hoek, 1994).

A aplicação do critério de Hoek-Brown (2002) consiste de duas etapas fundamentais: em primeiro lugar estima-se a resistência da rocha intacta, conforme a equação A.44. 
$\sigma_{1}^{\prime}=\sigma_{3}^{\prime}+\sigma_{c i}\left(m_{i} \frac{\sigma_{3}^{\prime}}{\sigma_{c i}}+1\right)^{0,5}$

em que $\sigma_{1}^{\prime}$ e $\sigma_{3}^{\prime}$ são os valores de tensão máxima e mínima, respectivamente; $\sigma_{c i}$ é o valor de resistência à compressão da rocha intacta, e $m_{i}$ é a constante de Hoek-Brown para rochas intactas, e varia de acordo com o material.

Em seguida são considerados os parâmetros característicos do maciço rochoso (GSI, a, s, D) determinando-se assim a resistência do maciço rochoso como um todo (Hoek, 2007), conforme a equação A.45 (Generalised HoekBrown Criterion).

$\sigma_{1}^{\prime}=\sigma_{3}^{\prime}+\sigma_{c}\left(m_{b} \frac{\sigma_{3}^{\prime}}{\sigma_{c}}+s\right)^{a}$

Em que:

$$
\begin{aligned}
& \frac{m_{b}}{m_{i}}=\exp \left(\frac{G S I-100}{28-14 D}\right) \\
& s=\exp \left(\frac{G S I-100}{9-3 D}\right) \\
& a=\frac{1}{2}+\frac{1}{6}\left(e^{-G S I / 15}-e^{-20 / 3}\right)
\end{aligned}
$$

Graficamente, a envoltória de ruputra descrita pelo critério de Hoek-Brown pode ser observada na figura A.11. 


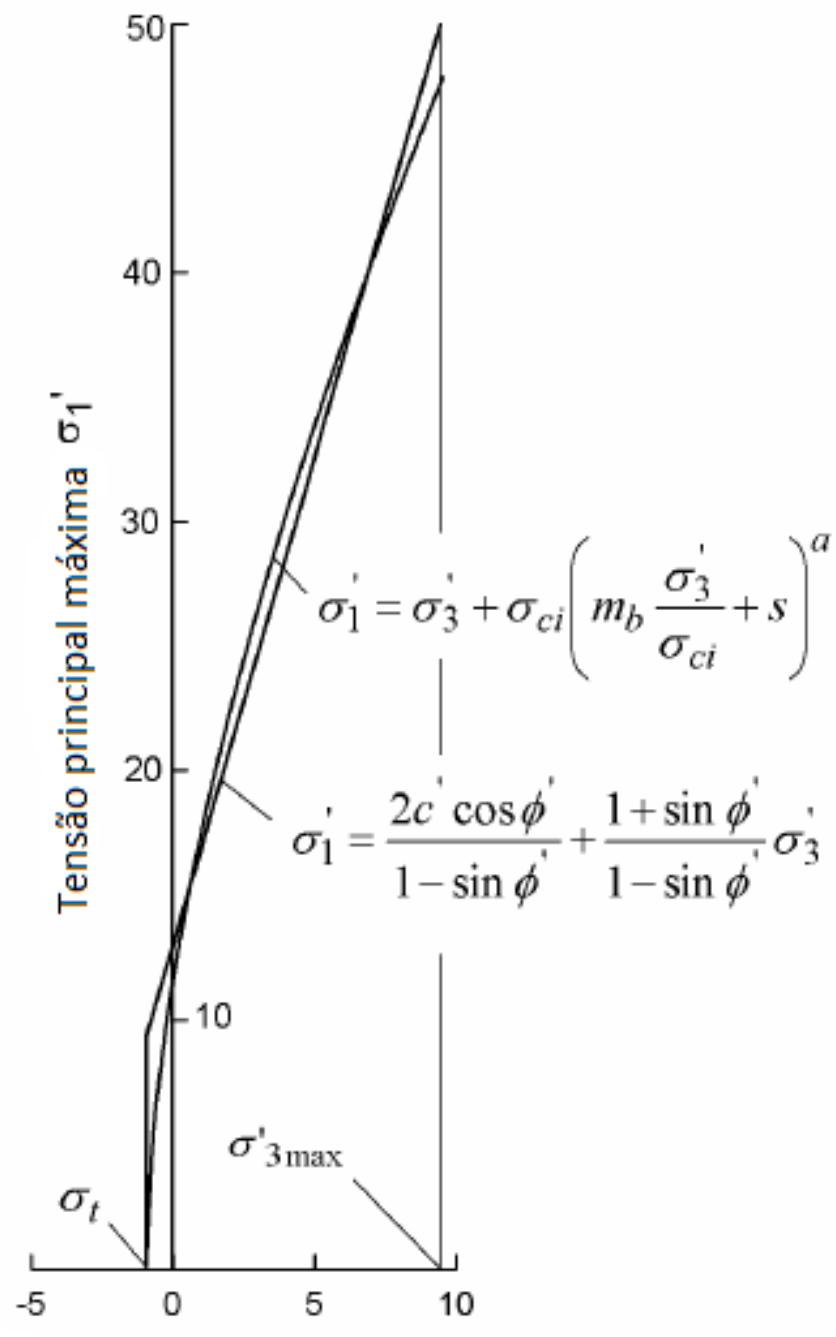

Tensão principal mínima $\sigma_{3}^{\prime}$

Figura A.11 - representação gráfica do critério e ruptura de Hoek-Brown.

E, uma vez que o critério de Mohr-Coulomb também é válido e aplicável para muitos casos, os autores também fazer a correlação entre os parâmetros dos diferentes critérios, colocando os valores de coesão e ângulo de atrito (MohrCoulomb) em função dos valores dos parâmetros de Hoek-Brown (Hoek et al., 2002; Hoek, 2007): 


$$
\begin{aligned}
& \phi^{\prime}=\sin ^{-1}\left[\frac{6 a m_{b}\left(s+m_{b} \sigma_{3 n}^{\prime}\right)^{a-1}}{2(1+a)(2+a)+6 a m_{b}\left(s+m_{b} \sigma_{3 n}^{\prime}\right)^{a-1}}\right] \\
& c^{\prime}=\frac{\sigma_{c i}\left|(1+2 a) s+(1-a) m_{b} \sigma_{3 n}^{\prime}\right|\left(s+m_{b} \sigma_{3 n}^{\prime}\right)^{a-1}}{(1+a)(2+a) \sqrt{1+\left(6 a m_{b}\left(s+m_{b} \sigma_{3 n}^{\prime}\right)^{a-1}\right) /((1+a)(2+a))}}
\end{aligned}
$$

$$
\text { onde } \sigma_{3 n}=\sigma_{3 \max }^{\prime} / \sigma_{c i}
$$




\section{BIBLIOGRAFIA}

Bardet, J.P. 1989. Finite element analysis of rockburst as surface instability. Computers and Geotechnics, 8(3): 177-193.

Barton, N.R., Lien, R., Lunde, J. 1974. Engineering classification of rock masses for the design of tunnel support. Rock Mechanics, 6(4):189-239.

Bieniawski, Z.T. 1973. Engineering classification of jointed rock masses. Transcripts of the South African Institute of Civil Engineers, 15:335-344.

Bieniawski, Z.T. 1989. Engineering rock mass classifications. New York: Wiley. $272 p$.

Brady, B.H.G., Brown, E.T. 1993. Rock Mechanics for Underground Mining, $2^{\text {nd }}$ ed. Chapman \& Hall, London. 571p.

Bräuner, G. 1994. Rockbursts in coal mines and their prevention. Balkema, Rotterdam. 144p.

Broch, E., Sørnheim, S. 1984. Experiences form the planning, construction and supporting of a road tunnel subjected to heavy rockbursting. Rock Mechanics and Rock Engineering. 17:15-35.

Cook, N.G.W. 1965a. The failure of rock. International Journal of Rock Mechanics and Mining Sciences. 2:389-403.

Cook, N.G.W. 1965b. A note on rockbursts considered as a problem of stability. Journal of the South African Institute of Mining and Metallurgy. 65:437-446.

Cook, N.G.W., Hoek, E., Pretorius, J.P.G., Ortlepp, W.D., Salamon, M.D.G. 1966. Rock mechanics applied to the study of rockbursts. Journal of the South African Institute of Mining and Metallurgy. 66:436-528. 
Davis, G.H., Reynolds, S.J. 1996. Structural Geology of Rocks and Regions. $2^{\text {nd }}$ ed. John Wiley \& Sons, New York. 800p.

Davis, R.O., Selvadurai, A.P.S. 1996. Elasticity and Geomechanics. Cambridge University Press, Cambridge, UK. 201p.

Diederichs, M.S. 2007. The 2003 Canadian Geotechnical Colloquium: Mechanistic interpretation and practical application of damage and spalling prediction criteria for deep tunneling. Canadian Geotechnical Journal. 44:10821116.

Diederichs, M.S. 2014. When does brittle failure become violent? Spalling and rockburst characterization for deep tunneling projects. In.: World Tunnel Congress, 2014, Foz do Iguaçu, Brazil. 10p.

Fossen, H. 2010. Structural Geology. University Press, Cambridge. 480p.

Gercek, H. 2007. Poisson's ratio values for rocks. Int. J. Rock Mech. Min. Sci. 44:1-13.

Griffith, A.A. 1921. The phenomena of rupture and flow in solids. Philosophical Transactions of the Royal Society of London. A, 221:183-198.

Grimstad, E. 1986. Rockburst problems in road tunnels. In: Norwegian Road Tunneling, Publ. nำ4, Norgewian Soil and Rock Engineering Assoc., p.57-72. Trondheim: Tapir Publishers.

Gurtin, M.E. 1981. An introduction to continuum mechanics. Academic Press, New York. 265p. 
Hoek, E. 1968. Brittle failure of rock. In Rock Mechanics in Engineering Practice. (eds K.G. Stagg and O.C. Zienkiewicz), cap. 4, pp. 99-124. London: Wiley.

Hoek, E., Brown, E.T. 1980a. Underground Excavation in Rock. London: Inst. Min. Metall. 536p.

Hoek, E., Brown, E.T. 1980b. Empirical strength criterion for rock masses. Journal of Geotechnical and Geoenvironmental Engineering, 106(GT9):10131035.

Hoek, E., Kaiser, P.K., Bawden, W.F. 1993. Support of Underground Excavations in Hard Rock. Balkema, Rotterdam. 235p.

Hoek E. 1994. Strength of rock and rock masses. ISRM News Journal, 2(2):416.

Hoek, E., Carranza-Torres, C. Corkum, B. 2002. Hoek-Brown criterion - 2002 edition. Proc. NARMS-TAC Conference, Toronto, 2002, 1:267-273.

Hoek, E. 2007. Practical Rock Engineering. North Vancouver. Rocscience. 237p.

Hoek, E., Marinos, P. 2007. A brief history of the development of the HoekBrown failure criterion. Soils and Rocks, 2:(PÁGINAS)

Hudson, J.A., Harrison, J.P. 1997. Engineering Rock Mechanics. An Introduction to the Principles. Pergamon. London. 444p.

Jaeger, J.C. 1971. Elasticity, Fracture and Flow with Engineering and Geological Applications. Chapman \& Hall, London. 280p. 
Jaeger, J.C. 1972. Rock Mechanics and Engineering. Cambridge University Press. 472p.

Jaeger, J.C., Cook, N.G.W. 1979. Fundamentals of Rock Mechanics. $3^{\text {rd }}$ ed. Chapman \& Hall, London. 620p.

Jaeger, J.C., Cook, N.G.W., Zimmerman, R.W. 2007. Linear Elasticity. In.: Fundamentals of Rock Mechanics. $4^{\text {th }}$ ed. Blackwell Publishing, Malden, MA. pp. 106-144.

Khanlari, G.R., Ghaderi-Meybodi, R. 2011. Analysis of rock burst in critical section of second part of Tehran Water Supply Tunnel. In.: Vogt, Schuppener, Straub \& Bräu (eds): 3rd International Symposium on Geotechnical Safety and Risk, München, Bundesanstalt für Wasserbau. pp. 661-667.

Kirsch, E.G. 1898. Die Theorie der Elastizität und die Bedürfnisse der Festigkeitslehre. Zeitschrift des Vereines deutscher Ingenieure. 42:797-807.

Kranz, R.L. 1983. Microcracks in rocks: a review. Tectonophysics. 100:449-480.

Kumar, J. 1976. The effect of Poisson's ratio on rock properties. In.: The 51st Annual Fall Technical Conference and Exhibition of the Society of Petroleum Engineers of AIME. AIME: New Orleans. SPE 6094.

Kwásniewski M., Szutkowski I., Wang J.-A. 1994. Study of ability of coal from seam 510 for storing elastic energy in the aspect of assessment of hazard in Porabka-Klimontow Colliery. Sci. Rept. Silesian Technical University.

Lee, S.M., Park, B.S., Lee, S.W. 2004. Analysis of rockbursts that have occurred in a waterway tunnel in Korea. International Journal of Rock Mechanics and Mining Sciences. 41(3)-CD-ROM. 
Li, W., ZhongLiang, L.,Qian, G. 2012. A numerical study of rock burst development and strain energy release. International Journal of Mining Science and Technology. 22:675-680.

Linkov, A.M. 1996. Rockbursts and instability of rock masses. International Journal of Rock Mechanics and Mining Sciences \& Geomechanics Abstracts. 33:727-732.

Litwiniszyn, J. 1985. A model for the initiation of coal-gas outbursts. International Journal of Rock Mechanics and Mining Sciences \& Geomechanics Abstracts. 22(1):39-46.

Liu, L., Wang, X., Zhang, Y., Jia, Z., Duan, Q. 2011. Tempo-spatial characteristics and influential factors of rockburst: a case study of transportation and drainage tunnels in Jinping II hydropower station. Journal of Rock Mechanics and Geotechical Engineering. 3(2):179-185.

Lloyd, G.E., Knipe, R.J. 1992. Deformation mechanisms accommodating faulting of quartzite under upper crustal conditions. Journal of Structural Geology. 14(2):127-143.

Means, W.D. 1976. Stress and Strain. Basic concepts of continuum mechanics for geologists. Springer-Verlag, New York, Berlin. 339p.

Mitaim, S., Detournay, E. 2004. Damage around a cylindrical opening in a brittle rock mass International Journal of Rock Mechanics and Mining Sciences. 41:1447-1457.

Monroe, James S., and Reed Wicander. 1996 The Changing Earth: Exploring Geology and Evolution, 2nd ed. Belmont: West Publishing Company, p. 96. 
Müller, W. 1991. Numerical simulation of rock bursts. Mining Science and Technology. 12:27-42.

Ortlepp, W.D., Stacey, T.R. 1994. Rockburst mechanisms in tunnels and shafts. Tunneling and Underground Space Technology. 9(1):59-65.

Palmström, A. 1995. Characterizing rock burst and squeezing by the rock mass index. In.: International Conference on Design and Construction of Underground Structures. New Delhi. 10p.

Pollard, D.D., Fletcher, R.C. 2005. Fundamentals of Structural Geology. Cambridge Univ. Press. Cambridge. 502p.

Potvin, Y., Hudyma, M.R., Jewell, R.J. 2000. Rockburst and seismic activity in underground Australian mines - an introduction to a new research project. In.: GeoENG 2000. Lancaster, Pennsylvania, USAq, CD, pp. Proceedings on CD.

Ramsay, J.G. 1967. Folding and fracturing of rock. McGraw-Hill, New York. $568 p$.

Ramsay, J.G., Huber, M.I. 1984. The techniques of modern structural geology, volume 1: Strain Analysis. Academic Press, London. 307p.

Ramsay, J.G., Lisle, R.J. 2000. The techniques of modern structural geology, volume 3: Applications of continuum mechanics in structural geology. Academic Press, $1061 \mathrm{p}$.

Ribeiro, L.F.B. 2004. Introdução ao Método dos Elementos Finitos. Programa de Engenharia Civil, COPPE/UFRJ. Notas de aula. 93p.

Russeness, B.F. 1974. Analyses of rockburst in tunnels in valley sides. MSc Thesis, Norwegian Institute of Technology, Trondheim. 247p. 
Sadd, M.H. 2004. Elasticity - Theory, Applications, and Numerics. Elsevier, Oxford, UK. 480p.

Scholz, C.H. 1968a. Microfracturing and the inelastic deformation on compression. J. Geoph. Res. 73(4):1417-1432.

Scholz, C.H. 1968b. Experimental study of the fracturing process on brittle rock. J. Geoph. Res. 73(4):1447-1454.

Timoshenko, S.P., Goodier, J.N. 1970. Theory of Elasticity. $3^{\text {rd }}$ ed. New York, McGraw-Hill. 547p.

Unlu, T., Gercek, H. 2003. Effect of Poisson's ratio on the normalized radial displacements occurring around the face of a circular tunnel. Tunneling and Underground Space Technology. 18:547-553.

Wang, J.A., Park, H.D. 2001. Comprehensive prediction of rockburst based on analysis of strain energy in rocks. Tunneling and Underground Space Technology. 16:49-57.

Whyatt, J.K., Williams, T.J., Blake, W. 1993. Concentration of rock burst activity and in situ stress at the Lucky Friday Mine. In.: Rockbursts and Seismicity in Mines (R.P. Young, ed.). Balkema, Rotterdam, pp. 135-139.

Whyatt, J.K., Blake, W., Williams, T.J., White, B.G. 2002. 60 years of rockbursting in the Coeur D'Alene district of northern Idaho, USA: Lessons learned and remaining issues. In.: Proc. of the $109^{\text {th }}$ Annual Exhibit and Meeting. Society for Mining, Metallurgy and Exploration, Feb25-27, 2002. Phoenix, AZ. Preprint 02-164, pp.1-10.

Wyllie, D.C., Mah, C.W. 2004. Rock Slope Engineering - Civil and Mining, $4^{\text {th }}$ ed. London, Spon Press, 456p. 
Xie, H., Pariseau, W.G. 1993. Fractal character and mechanisms of rock bursts. International Journal of Rock Mechanics and Mining Sciences \& Geomechanics Abstracts. 30(4): 343-351.

Xie, H.; Li, L.; Peng, R. and Ju, Y. 2009. Energy analysis and criteria for structural failure of rocks. Journal of Rock Mechanics and Geotechnical Engineering. 1(1), 11-20.

Zhang, C., Feng, X., Zhou, H., Quu, S., Wu, W. 2012. Case histories of four extremely intense rockbursts in deep tunnels. Rock Mechanics and Rock Engineering. 45:275-288.

Zhu, W.C., Li, Z.H., Tang, C.A. 2010. Numerical simulation on rockburst of underground opening triggered by dynamic disturbance. Tunneling and Underground Space Technology. 25:587-599. 